\title{
The Thermal Structure of the Venus Atmosphere: Intercomparison of Venus Express and Ground Based Observations of Vertical Temperature and Density Profiles
}

\begin{abstract}
Sanjay S. Limaye ${ }^{1}$, Sebastien Lebonnois ${ }^{7}$, Arnaud Mahieux ${ }^{4,25}$, Martin Pätzold ${ }^{10}$, Steven Bougher ${ }^{2}$, Sean Bruinsma ${ }^{3}$, Sarah Chamberlain ${ }^{4}$, R. Todd Clancy ${ }^{5}$, Jean-Claude Gérard ${ }^{6}$, Gabriella Gilli ${ }^{7}$, Davide Grassi ${ }^{8}$, Rainer Haus ${ }^{9}$, Maren Herrmann ${ }^{10}$, Takeshi Imamura ${ }^{11}$, Erika Kohler ${ }^{12}$, Pia Krause ${ }^{10}$, Alessandra Migliorini ${ }^{8}$, Franck Montmessin ${ }^{13}$, Christophe Pere ${ }^{14,16}$, Moa Persson $^{15}$, Arianna Piccialli ${ }^{13,16}$, Miriam Renge ${ }^{17,18}$, Alexander Rodin ${ }^{19}$, Brad Sandor ${ }^{5}$, Manuela Sornig ${ }^{10,20}$, Håkan Svedhem ${ }^{21}$, Silvia Tellmann ${ }^{10}$, Paolo Tanga ${ }^{14}$, Ann C. Vandaele ${ }^{4}$, Thomas Widemann ${ }^{22,23}$, Colin F. Wilson ${ }^{15}$, Ingo Müller-Wodarg ${ }^{24}$ and Ludmila Zasova ${ }^{19}$
\end{abstract}

Contribution of the ISSI International Team on Venus Atmospheric Structure (2013)

1 November 2016

Revised 12 April 2017

1. Space Science and Engineering Center, University of Wisconsin, Madison, Wisconsin, USA

2. University of Michigan, Ann Arbor, Michigan, USA

3. CNES, Toulouse, France

4. IASB-BIRA, Brussels, Belgium

5. Space Science Institute, Boulder, Colorado, USA

6. LPAP, Université de Liège, Liège, Belgium

7. LMD, Paris, France

8. INAF, Rome, Italy

9. University of Münster, Münster, Germany

10. RIU-Planetenforschung an der Universität zu Köln, Cologne, Germany

11. ISAS/JAXA, Sagamihara, Japan

12. University of Arkansas, Fayetteville, Arkansas, USA 
13. LATMOS, Paris, France

14. Laboratoire Lagrange, Université Côte d'Azur, Observatoire de la Côte d'Azur, CNRS, Nice, France

15. Oxford University, Oxford, United Kingdom

16. Observatoire de Paris/CNRS/LESIA, Meudon, France

17. Max-Planck-Institut für Sonnensystemforschung, Göttingen, Germany

18. European Space Astronomy Centre, ESAC, ESA, 28691 Villanueva de la Cañada, Spain

19. Space Research Institute, Moscow, Russia

20. I. Physikalisches Institut, Universität zu Köln, Köln, Germany

21. ESTEC, European Space Agency, Noordwijk, The Netherlands

22. LESIA, UMR CNRS 8109, Paris Observatory, France

23. DYPAC, EA 2449, Université de Versailles-Saint-Quentin-en-Yvelines, Guyancourt (France)

24. Imperial College, London, United Kingdom

25. Fonds National de la Recherche Scientifique, Brussels, Belgium 


\section{Abstract}

The Venus International Reference Atmosphere (VIRA) model contains tabulated values of temperature and number densities obtained by the experiments on the Venera entry probes, Pioneer Venus Orbiter and multi-probe missions in the 1980s. The instruments on the recent Venus Express orbiter mission generated a significant amount of new observational data on the vertical and horizontal structure of the Venus atmosphere from $40 \mathrm{~km}$ to about $180 \mathrm{~km}$ altitude from April 2006 to November 2014. Many ground based experiments have provided data on the upper atmosphere (90-130 km) temperature structure since the publication of VIRA in 1985. The "Thermal Structure of the Venus Atmosphere" Team was supported by the International Space Studies Institute (ISSI), Bern, Switzerland, from 2013 to 2015 in order to combine and compare the ground-based observations and the VEx observations of the thermal structure as a first step towards generating an updated VIRA model. Results of this comparison are presented in five latitude bins and three local time bins by assuming hemispheric symmetry. The intercomparison of the ground-based and VEx results provides for the first time a consistent picture of the temperature and density structure in the $40 \mathrm{~km}-180 \mathrm{~km}$ altitude range. The Venus Express observations have considerably increased our knowledge of the Venus atmospheric thermal structure above $\sim 40 \mathrm{~km}$ and provided new information above $100 \mathrm{~km}$. There are, however, still observational gaps in latitude and local time above certain regions. Considerable variability in the temperatures and densities is seen above $100 \mathrm{~km}$ but certain features appear to be systematically present, such as a succession of warm and cool layers. Preliminary modeling studies support the existence of such layers in agreement with a global scale circulation. The intercomparison focuses on average profiles but some VEx experiments provide sufficient global coverage to identify solar thermal tidal components.

The differences between the VEx temperature profiles and the VIRA below $0.1 \mathrm{mbar} / 95 \mathrm{~km}$ are small. There is, however, a clear discrepancy at high latitudes in the 10-30 mbar (70-80 km) range. The VEx observations will also allow the improvement of the empirical models (VTS3 by Hedin et al., 1983 and VIRA by Keating et al., 1985) above $0.03 \mathrm{mbar} / 100 \mathrm{~km}$, in particular the 100-150 km region where a sufficient observational coverage was previously missing. The next steps in order to define the updated VIRA temperature structure up to $150 \mathrm{~km}$ altitude are (1) define the grid on which this database may be provided, (2) fill what is possible with the results of the data intercomparison, and (3) fill the observational gaps. An interpolation between the datasets may be performed by using available General Circulation Models as guidelines.

An improved spatial coverage of observations is still necessary at all altitudes, in latitude-longitude and at all local solar times for a complete description of the atmospheric thermal structure, in 
particular on the dayside above $100 \mathrm{~km}$. New in-situ observations in the atmosphere below $40 \mathrm{~km}$ are missing, an altitude region that cannot be accessed by occultation experiments. All these questions need to be addressed by future missions. 


\section{Introduction}

A systematic global coverage of the temperatures in the Venus atmosphere was obtained by the VORTEX experiment (also called Orbiter Infrared Radiometer, Taylor et al. 1980; Schofield and Taylor, 1983) on board Pioneer Venus Orbiter (PVO) using a six channel filter radiometer. Density and temperature profiles retrieved from PVO radio occultations provided latitudinal variations of the structure in the 40-75 km altitude range. Deep atmospheric temperature profiles were obtained from the Venera probes (6 to 14) and by the four Pioneer Venus probes (named Large, Day, Night, and North) in 1982. These were the basic observations that led to the development of the thermal structure model compiled for the Venus International Reference Atmosphere (VIRA) published through the efforts of Pioneer Venus and Venera scientists (Kliore et al., 1985; Seiff et al., 1985). In the interim, limited compilations were prepared by Seiff (1983) and Moroz (1981). An empirical model of the Venus thermosphere (VTS3) was also developed based on the available data by Hedin et al. (1983). Many results, including ground based results that were developed just prior to the development of the VIRA model could not be included in the model. The VIRA profiles from the low atmosphere were compiled from Venera measurements and Pioneer Venus probes profiles. The latter were extrapolated adiabatically by the hydrostatic law from $12 \mathrm{~km}$ to the surface assuming a composition of $96.5 \% \mathrm{CO}_{2}$ and $3.5 \% \mathrm{~N}_{2}$ (the Pioneer Venus probes suffered from an electrical failure when the probes were at $12 \mathrm{~km}$ above the surface).

The VIRA thermal structure model was found to be very useful by the Venus scientific community for further investigations of the planetary atmosphere. Many new observations of the thermal structure of Venus have been obtained since its publication: from Venera-15 Fourier spectrometry (1983), from Venera 15, Venera 16 and Magellan radio occultations in 1992, by the Venus Express orbiter since April 2006-till late 2014 from five independent experiments and by numerous ground based observations. A temperature profile of the low atmosphere was measured in situ with high vertical resolution by the VeGa-2 Lander in 1984. These new observations provided spatial and temporal overlap, extended the knowledge of the temperature structure downwards to the surface, revealed temporal and spatial variations. It is now possible to compare these results in order to understand the differences and reconcile them by looking at the experimental approaches, their inherent limitations and potential errors. Such intercomparison is a pre-requisite step for developing a new VIRA thermal structure model.

Zasova and Moroz (1992) and Moroz and Zasova (1997) reviewed the datasets that were collected between the publication of VIRA in 1985 and the publication of the respective papers. It was suggested to update the thermal structure model in view of the new datasets, particularly from the VeGa 2 lander, the two VeGa balloons and the detailed thermal structure of the mesosphere from the Venera- 
15 Fourier spectrometer. Potential other sources for the improvement of VIRA were also addressed, using later radio occultation results from Pioneer Venus, Magellan, Galileo NIMS experiments and ground-based observations.

This study presents the results of an intercomparison of data from the Venus neutral atmosphere obtained after the publication of VIRA by an international team sponsored by the International Space Science Institute (ISSI), Bern, Switzerland from July 2013 to February 2015. Thermal structure observations that were obtained after the publication of VIRA in 1985 (Table 1) and prior to the arrival of Venus Express (VEX) in April 2006 include the following:

- Extended mission radio occultation profiles from Pioneer Venus Orbiter (Kliore, 1985)

- Radio occultation profiles from Venera-15, 16 (Yakovlev et al., 1991)

- VeGa 1 and VeGa 2 balloon data (Sagdeev et al., 1986)

- VeGa 2 Lander data (Linkin et al., 1987; Zasova et al., 2006)

- Retrievals of thermal profiles from Venera 15 Fourier spectrometer data (Schaefer et al., 1990, Zasova et al., 2006, 2007, Haus et al.,2013)

- Galileo NIMS fly-by observations (Roos-Serote et al., 1995)

- Magellan Orbiter radio occultation profiles (Jenkins and Hinson 1994)

Earth-based thermal structure observations obtained since Venus Express commenced operations include:

- Thermospheric ground based temperature structure profiles (Clancy et al., 2008; 2012a, Rengel et al., 2008a,2008b, Sonnabend et al. 2008; 2010)

- 2012 Venus transit observations, deriving the temperature from the sunlight refraction in the mesosphere (Tanga et al., 2012; Pere et al., 2016)

The list of ground based measurements included in this study is certainly not exhaustive, but representative. The principal idea was to include those data sets which are accessible in digital form as much as possible to facilitate the detailed comparison.

Five experiments operated from the Venus Express orbiter that yield atmospheric profiles of neutral number density and temperature versus altitude or pressure and in-situ atmospheric mass density from drag or aerobraking experiments:

- Solar Occultation in the Infra-Red (SOIR): The solar occultation method retrieves vertical profiles of carbon dioxide abundance and atmospheric temperature from $\mathrm{CO}_{2}$ number density as well as molecular rotational temperatures from $\mathrm{CO}_{2}$ spectral structure (Bertaux et al., 2007) at the morning and evening terminators at occulted latitudes 
- SPectroscopy for Investigation of Characteristics of the Atmosphere of Venus (SPICAV):

Stellar occultations allow the determination of vertical profiles of $\mathrm{CO}_{2}$ abundances and derive the temperature from the $\mathrm{CO}_{2}$ number density (Bertaux et al., 2007)

- Venus Express Radio Science (VeRa): Radio occultations allow the derivation of vertical profiles of temperature, pressure and total neutral number density between $40 \mathrm{~km}$ and 100 km altitude (Häusler et al., 2006; 2007)

- Visible and Infra-Red Thermal Imaging Spectrometer (VIRTIS): VIRTIS observations provide thermal maps at medium spectral resolution and profiles from nadir and limb locations at high spectral resolution (Piccioni et al., 2007)

- VEnus eXpress Atmospheric Drag Experiment (VEXADE): VEXADE retrieved atmospheric mass density (i) between 130-140 km from accelerometer readings during aerobreaking (MüllerWodarg et al., 2006; 2016), (ii) from the torques acting on the solar panels by the atmospheric drag between $166 \mathrm{~km}$ to $186 \mathrm{~km}$ at high planetary latitudes (Persson, 2015), and (iii) from Precise Orbit Determination (POD) when the orbiter was between 166 - $186 \mathrm{~km}$ altitude (Rosenblatt et al., 2012).

The VEx and ground-based data sets which were considered in this study are described, as well as the experimental approaches, a discussion of the comparison and recommendations regarding future observations are given.

The altitude ranges of the post-VIRA experiments conducted at Venus and the spectral ranges of the experiments considered in this study are shown schematically in Figure 1. 

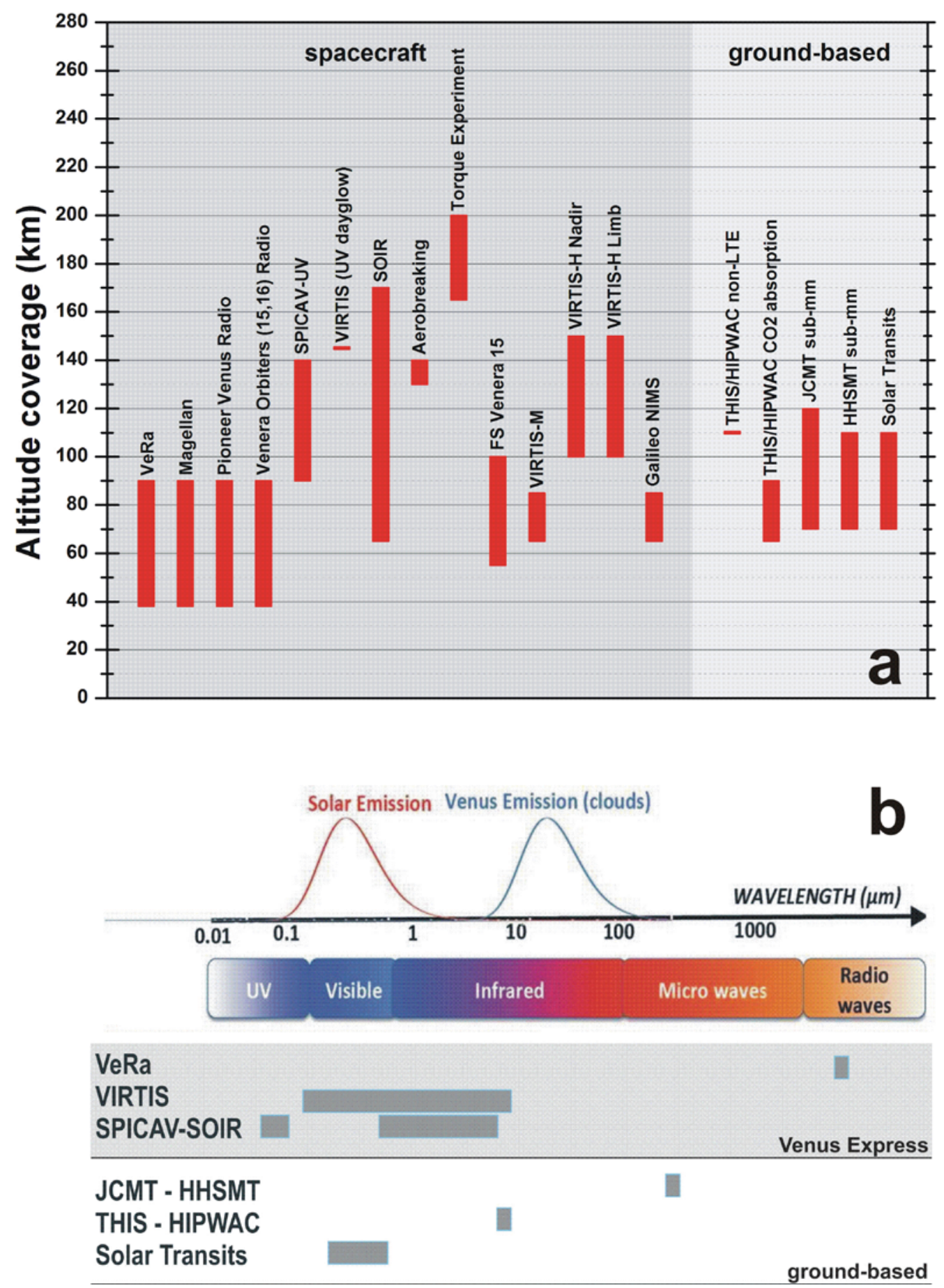

Figure 1: Panel (a): vertical coverage of the post-VIRA atmospheric structure experiments. Panel (b): spectral ranges of the experiments considered in this study 
Table 1: Observations of the vertical structure of the Venus atmosphere by spacecraft and ground based experiments (data from experiments in light lines are not used in the intercomparison)

\begin{tabular}{|c|c|c|c|c|c|c|c|c|c|c|c|}
\hline $\begin{array}{l}\text { Instrument I } \\
\text { Experiment }\end{array}$ & Method & $\begin{array}{l}\text { Years } \\
\text { covered }\end{array}$ & $\begin{array}{c}\text { Nominal } \\
\text { vertical } \\
\text { coverage } \\
{[\mathrm{km}]}\end{array}$ & $\begin{array}{l}\text { Pressure } \\
\text { range } \\
\text { [mbar] }\end{array}$ & $\begin{array}{c}\text { Vertical } \\
\text { resolution } \\
{[\mathrm{km}]}\end{array}$ & $\begin{array}{c}\text { Temperature } \\
\text { uncer- } \\
\text { tainties } \\
{[\mathrm{K}]}\end{array}$ & $\begin{array}{l}\text { Latitudinal } \\
\text { coverage }\end{array}$ & $\begin{array}{l}\text { Local } \\
\text { time } \\
\text { coverage }\end{array}$ & $\begin{array}{l}\text { Horizontal } \\
\text { resolution }\end{array}$ & $\begin{array}{c}\text { Sensitive } \\
\text { to } \\
\text { clouds? }\end{array}$ & section \\
\hline \multicolumn{12}{|c|}{ Active remote sensing observations from spacecraft } \\
\hline VeRa/VEx & radio occultation & $\begin{array}{l}2006- \\
2014\end{array}$ & $38-100$ & $\begin{array}{l}3000- \\
0.03\end{array}$ & $0.5-1$ & $0.1-1$ & $\begin{array}{c}\text { both } \\
\text { hemispheres }\end{array}$ & $\begin{array}{l}\text { night \& day } \\
\text { side }\end{array}$ & $\begin{array}{l}\text { slant paths, } \\
400 \mathrm{~km}\end{array}$ & NO & 2.3.1.2 \\
\hline Magellan & radio occultation & 1992 & $38-100$ & $\begin{array}{l}3000- \\
0.03\end{array}$ & $0.5-1$ & $0.1-1$ & $\begin{array}{c}\text { both } \\
\text { hemispheres }\end{array}$ & $\begin{array}{l}\text { night } \& \text { day } \\
\text { side }\end{array}$ & $\begin{array}{l}\text { slant paths, } \\
\text { 400km }\end{array}$ & NO & $\mathrm{n} / \mathrm{a}$ \\
\hline Pioneer Venus & radio occultation & $\begin{array}{l}1978- \\
1991\end{array}$ & $38-100$ & $\begin{array}{l}3000- \\
0.03\end{array}$ & $0.5-1$ & $0.1-1$ & $\begin{array}{c}\text { both } \\
\text { hemispheres }\end{array}$ & $\begin{array}{l}\text { night \& day } \\
\text { side }\end{array}$ & $\begin{array}{l}\text { slant paths, } \\
400 \mathrm{~km}\end{array}$ & NO & 2.3 .1 \\
\hline $\begin{array}{l}\text { Venera } 15,16 \\
\text { orbiters }\end{array}$ & radio occultation & 1983 & $38-100$ & $\begin{array}{l}3000- \\
0.03\end{array}$ & $0.5-1$ & $1-10$ & $\begin{array}{c}\text { both } \\
\text { hemispheres }\end{array}$ & $\begin{array}{l}\text { night \& day } \\
\text { side }\end{array}$ & $\begin{array}{l}\text { slant paths, } \\
400 \mathrm{~km}\end{array}$ & NO & 2.3.1.1 \\
\hline SPICAV-UV/VEX & stellar occultation & $\begin{array}{l}2006- \\
2014\end{array}$ & $90-140$ & $10^{-1}-10^{-7}$ & $0.5-7$ & $\begin{array}{c}<25 \% \\
1-20 \mathrm{~K} \\
\text { Altitude } \\
\text { dependent }\end{array}$ & $\begin{array}{l}\text { both } \\
\text { hemispheres }\end{array}$ & night side & $\begin{array}{l}\text { slant paths, } \\
400 \mathrm{~km}\end{array}$ & NO & 2.3 .3 \\
\hline SOIR/VEX & solar occultation & $\begin{array}{l}2006- \\
2014\end{array}$ & $70-170$ & $100-10^{-8}$ & $\begin{array}{l}0.3 \text { - } 5 \text { (lat. } \\
\text { dep.) }\end{array}$ & $1-20$ & $\begin{array}{c}\text { both } \\
\text { hemispheres }\end{array}$ & terminator & $\begin{array}{l}\text { slant paths, } \\
\text { 400km }\end{array}$ & NO & 2.3 .2 \\
\hline $\begin{array}{l}\text { VEXADE- } \\
\text { AER/VEX }\end{array}$ & Aerobraking & 2014 & $130-140$ & $10^{-5}-10^{-6}$ & 0.3 & 23 & $70^{\circ} \mathrm{N}-80^{\circ} \mathrm{N}$ & $\begin{array}{l}\text { morning } \\
\text { terminator }\end{array}$ & $10 \mathrm{~km}$ & NO & 2.1.2.1 \\
\hline $\begin{array}{l}\text { VEXADE- } \\
\text { TRQ/VEX }\end{array}$ & $\begin{array}{l}\text { Spacecraft torque } \\
\text { measurement }\end{array}$ & $\begin{array}{l}2008- \\
2013\end{array}$ & $165-200$ & $10^{-7}-10^{-9}$ & 1.0 & $\sim 30 \mathrm{~K}$ & $70^{\circ} \mathrm{N}-90^{\circ} \mathrm{N}$ & $\begin{array}{c}78-98^{\circ} \\
\text { Solar } \\
\text { Zenith } \\
\text { Angle }\end{array}$ & Slant paths & NO & 2.1.2.2 \\
\hline $\begin{array}{l}\text { VEXADE- } \\
\text { POD/VEX }\end{array}$ & $\begin{array}{l}\text { Precise Orbit } \\
\text { Determination }\end{array}$ & $\begin{array}{c}2008- \\
2013\end{array}$ & $175-185$ & $10^{-8}$ & $\mathrm{n} / \mathrm{a}$ & $\mathrm{n} / \mathrm{a}$ & $70^{\circ} \mathrm{N}-90^{\circ} \mathrm{N}$ & terminators & $\mathrm{n} / \mathrm{a}$ & NO & 2.1.2.2 \\
\hline \multicolumn{12}{|c|}{ Passive Remote Sensing (IR/Microwave) from spacecraft } \\
\hline $\begin{array}{c}\text { FS } \\
\text { VENERA-15 }\end{array}$ & $\begin{array}{c}15 \mu \mathrm{m} \mathrm{CO}{ }_{2} \\
\text { temperat.-aerosol, }\end{array}$ & 1983 & $55-100 \mathrm{~km}$ & $300-0.03$ & $\begin{array}{l}3-5 \\
\text { (scale }\end{array}$ & $\begin{array}{c}2 \text { - } 5 \\
\text { (altitude }\end{array}$ & $\begin{array}{c}\text { mostly } \\
\text { Northern }\end{array}$ & $\begin{array}{l}4-10 \text { AM } \\
4-10 \text { PM }\end{array}$ & $\begin{array}{l}60 \mathrm{~km} \text { at } \\
\text { pericenter }\end{array}$ & $\begin{array}{l}\text { YES, self- } \\
\text { consistent } \\
\text { retrieved } \\
\end{array}$ & 2.1 .1 \\
\hline
\end{tabular}




\begin{tabular}{|c|c|c|c|c|c|c|c|c|c|c|c|}
\hline & $7-30 \mu \mathrm{m}$ & & & & height) & dependent) & & & & $\begin{array}{l}\text { from each } \\
\text { spectrum }\end{array}$ & \\
\hline VIRTIS-M/VEx & $4.3 \mu \mathrm{m} \mathrm{CO} 2$ band & $\begin{array}{l}2006- \\
2008\end{array}$ & $65-85$ & $100-0.1$ & 8 & $<5$ & $\begin{array}{c}\text { mostly } \\
\text { southern } \\
\text { hemisphere }\end{array}$ & night side & $\begin{array}{l}60 \mathrm{~km} \text { at } \\
\text { pericenter }\end{array}$ & YES & 2.2.3.1 \\
\hline $\begin{array}{c}\text { VIRTIS-H/VEx } \\
\text { Nadir }\end{array}$ & $4.3 \mu \mathrm{m}$ CO band & $\begin{array}{l}2006- \\
2012\end{array}$ & $65-80$ & $100-4$ & 8 & $<5$ & $\begin{array}{c}\text { both } \\
\text { hemispheres }\end{array}$ & night side & $\begin{array}{c}50 \mathrm{~km} \\
\text { footprint } \\
\text { (individual } \\
\text { retrievals) }\end{array}$ & YES & 2.2.3.2 \\
\hline $\begin{array}{l}\text { VIRTIS-H/VEX } \\
\text { Limb }\end{array}$ & $4.7 \mu \mathrm{m} \mathrm{CO} 2$ band & $\begin{array}{l}2006- \\
2012\end{array}$ & $100-150$ & $0.03-10^{-7}$ & $\begin{array}{c}15-25 \\
\text { (altitude } \\
\text { dependent) }\end{array}$ & $>30$ & $\begin{array}{c}\text { North } \\
\text { hemisphere }\end{array}$ & day side & $115 \times 38 \mathrm{~km}$ & likely & 2.2.3.2 \\
\hline Galileo NIMS & $4.3 \mu \mathrm{m} \mathrm{CO} 2$ band & 1990 & $65-85$ & $100-0.1$ & 8 & $<5$ & $\begin{array}{c}\text { South } \\
\text { hemisphere }\end{array}$ & night side & $\mathrm{n} / \mathrm{a}$ & NO & 2.2 .2 \\
\hline \multicolumn{12}{|c|}{ Ground-based observations } \\
\hline THIS / HIPWAC & $\mathrm{CO}_{2}$ absorption & 2012 & $65-90$ & $100-0.8$ & 10 & $<10$ & $\begin{array}{c}\text { both } \\
\text { hemispheres }\end{array}$ & night side & $0.9^{\prime \prime}$ to $1.6 "$ & NO & 3.2 \\
\hline $\begin{array}{l}\text { JCMT sub/mm } \\
\text { line absorption }\end{array}$ & CO absorption & $\begin{array}{l}2001- \\
2015\end{array}$ & $75-120$ & $20-10^{-4}$ & $\begin{array}{c}4 \\
10 \text { above } \\
100 \mathrm{~km} \\
\text { altitude }\end{array}$ & 7 & $\begin{array}{c}\text { both } \\
\text { hemispheres }\end{array}$ & $\begin{array}{l}\text { mapping } \\
\text { PM/AM } \\
\text { night side } \\
\text { Dayside } \\
\text { PM/AM } \\
\text { average }\end{array}$ & $\begin{array}{l}13.5 " \text { to } 14.5 " \\
4000 \mathrm{~km} \text { sub- } \\
\text { earth footprint }\end{array}$ & NO & 3.1 .1 \\
\hline $\begin{array}{l}\text { HHSMT sub/mm } \\
\text { line absorption }\end{array}$ & CO absorption & 2007 & $75-110$ & $20-0.002$ & $\begin{array}{c}4 \\
10 \text { above } \\
100 \mathrm{~km} \\
\text { altitude }\end{array}$ & $<15$ & $\begin{array}{c}\text { both } \\
\text { hemispheres }\end{array}$ & $\begin{array}{l}\text { PM night \& } \\
\text { day side } \\
\text { averages }\end{array}$ & $\begin{array}{l}13.5 " \text { to } 14.5 " \\
13.5 " \text { to } 14.5 " \\
10000 \mathrm{~km} \\
\text { sub-earth } \\
\text { footprint }\end{array}$ & NO & 3.1 .2 \\
\hline
\end{tabular}

Venus Thermal Structure - Intercomparison of Venus Express and Ground Based Results 


\section{Spacecraft Observation Methods}

\subsection{Direct (in-situ) measurements}

\subsubsection{Entry Probes/Landers and Balloons}

Atmospheric in-situ measurements after the observations by the Venera 13 and Venera 14 entry probes in 1982 were made by the two VeGa balloons (Sagdeev et al., 1986) and by the VeGa landers in 1985 (Linkin et al., 1987). Each of the two VeGa spacecraft consisted of a carrier spacecraft with a Venus lander descending to the surface and a balloon that was deployed from a separate entry capsule at an altitude of about $50 \mathrm{~km}$. VeGa-1 entered the Venus atmosphere on 11 June 1985, VeGa-2 followed four days later. The VeGa 1 lander communications failed and no data could be transferred. The two carrier spacecraft went on to rendezvous with comet Halley in 1986.

\subsubsection{VeGa balloons}

The VeGa 1 balloon entered the atmosphere at $8.1^{\circ} \mathrm{N}$ latitude, $176.9^{\circ} \mathrm{E}$ longitude, and the VeGa 2 balloon at $7.45^{\circ} \mathrm{S}$ latitude and $179.8^{\circ} \mathrm{E}$ longitude. All measurements on the VeGa balloons were performed successfully during their journey through the middle clouds at an altitude of about $54.5 \mathrm{~km}$ (Linkin et al., 1986, Sagdeev et al., 1986). The two balloons observed a near constant temperature difference of about $6.5 \mathrm{~K}$ when carried westward by the ambient winds at average speeds of $69 \mathrm{~m} / \mathrm{s}$ and $66 \mathrm{~m} / \mathrm{s}$. The VeGa-I balloon moved almost exactly along at $8^{\circ}$ North latitude and travelled nearly $8,500 \mathrm{~km}$ in the darkness of the Venus night before crossing the morning terminator. The trajectory of VeGa-2 was shifted by about $500 \mathrm{~km}$ southward and floated at a mean altitude of $53.6 \mathrm{~km}$ ( $535 \mathrm{mbar}$ ) and experienced temperatures ranging from $308 \mathrm{~K}$ to $316 \mathrm{~K}$. The communication with the balloons was lost when the batteries drained after 40 hours of operations. The values of pressure and temperature along the trajectories of the balloons are given in Table 2 . 
Table 2: VeGa-1 and VeGa-2 balloons

\begin{tabular}{|c|c|c|c|c|c|c|c|c|c|}
\hline & \multicolumn{5}{|c|}{ Start of operation } & \multicolumn{4}{|c|}{$\begin{array}{c}\text { Temperature and pressure } \\
\text { at the balloon altitude }\end{array}$} \\
\hline & \multirow[t]{2}{*}{ Date } & \multirow{2}{*}{$\begin{array}{c}\text { time } \\
\text { (hours UT) }\end{array}$} & \multirow[t]{2}{*}{ latitude } & \multirow[t]{2}{*}{ Longitude } & \multirow{2}{*}{$\begin{array}{c}\text { LT } \\
\text { (hours) }\end{array}$} & \multicolumn{2}{|c|}{$\begin{array}{c}\text { pressure } \\
\text { (mbar) }\end{array}$} & \multicolumn{2}{|c|}{$\begin{array}{c}\text { temperature } \\
\text { (K) }\end{array}$} \\
\hline & & & & & & $(*)$ & $(* *)$ & $(*)$ & $\left({ }^{* *}\right)$ \\
\hline VeGa-1 & $\begin{array}{c}11 \text { June } \\
1984\end{array}$ & 02:06 & $8^{\circ} \mathrm{N}$ & $77^{\circ}$ & 00:18 & 540 & 630 & 308 & 322 \\
\hline VeGa-2 & $\begin{array}{c}15 \text { June } \\
1984\end{array}$ & 02:06 & $7.5^{\circ} \mathrm{S}$ & $180^{\circ}$ & 01:00 & 535 & 900 & 302 & 338 \\
\hline
\end{tabular}

* at maximum floating altitude $(54 \mathrm{~km})$

** at minimum floating altitude (VeGa-1: $53 \mathrm{~km}$, VeGa-2: $50 \mathrm{~km}$ )

The pressure dependence of the temperature is close to adiabatic at the floating altitude of both balloons, with a temperature difference of a few Kelvins. This was interpreted as an indication of the existence of sufficiently extended non-mixing atmospheric masses (Linkin et al., 1986). Each balloon during the flight was inside its own region of this type.

\subsubsection{VeGa-1 and -2 Landers}

The VeGa-1 $\left(7.2^{\circ} \mathrm{N}, 177.8^{\circ} \mathrm{E}\right.$ entry location into the atmosphere) and VeGa-2 (8.5 ${ }^{\circ} \mathrm{S}, 164.5^{\circ}$ entry location) landers were designed like the earlier Venera landers and carried well calibrated and redundant temperature sensors. The VeGa-1 lander experienced a strong updraft during its descent, well before reaching the surface, causing the control electronics to believe that it had landed and thus some instruments were deployed prematurely and consequently not all the planned measurements were successfully acquired.

The VeGa-2 lander remains the only probe of all Venus landers which observed the atmospheric temperature all the way from $64 \mathrm{~km}$ down to the surface accurately (Linkin et al., 1987). VeGa-2 landed at $6.45^{\circ} \mathrm{S}$ latitude and $181.08^{\circ}$ longitude, which implies a drift toward the equator during its descent through the atmosphere. Pioneer Venus probes did not return temperature data below $12 \mathrm{~km}$ and surface temperatures were extrapolated adiabatically from the last values (Seiff et al., 1985). 


\subsubsection{Mass Density Measurements from the Venus Express Atmospheric Drag Experiment}

Thermosphere densities were measured in-situ by the Venus Express Atmospheric Drag Experiment (VEXADE), which itself consisted of 3 separate experiments, aerobraking (VExADE-AER), Precise Orbit Determination (VEXADE-POD) and torque measurements (VExADE-TRQ). Both the POD and TRQ experiments were carried out during the main science phase of Venus Express (2008-2013) during campaigns when pericentre altitude ranged from 165-190 km, while aerobraking (VExADE-AER) was performed in June/July 2014, at the end of the nominal science mission when the pericentre altitude was lowered to $130 \mathrm{~km}$. For pericentre altitudes of $165-190 \mathrm{~km}$ the atmospheric drag experienced by the spacecraft is strong enough to affect its orbit and be measured by radio tracking techniques (POD), though too weak to be detected by the onboard accelerometers. A series of Atmospheric Drag Experiments (ADE) was performed by lowering the pericentre to altitudes between $165 \mathrm{~km}$ and $190 \mathrm{~km}$. By tracking the spacecraft at high resolution with the Deep Space Network and subsequently modeling the spacecraft orbits, the integrated deceleration experienced during each pericentre pass was derived, and thereby a single density value for the pericentre location of each spacecraft pass (Rosenblatt et al., 2012). This provided the first in-situ measurements of thermospheric mass density at high latitudes $\left(75^{\circ} \mathrm{N}-90^{\circ} \mathrm{N}\right)$ and at low solar activity, finding mean densities to be around $60 \%$ of those predicted for the same latitudes by the VTS3 model (Rosenblatt et al. 2012). The spacecraft torque measurements (TRQ) were carried out during the same campaigns but consisted in analyzing the response of the spacecraft's Inertial Mass Unit (IMU) to the torque experienced by asymmetric orientation of the two solar panels relative to the ram direction. Thereby, the torque experiment obtained vertical density profiles from $165-190 \mathrm{~km}$, similar to what the aerobraking experiment obtained for lower altitudes (130-140 km), while the POD experiment gave a single density value at the pericentre altitude during every orbit of the POD campaign.

All three VEx drag datasets - i.e. thermospheric densities from radio tracking, from torque, and from aerobraking - show considerable and significant diurnal variability, with day-to-day mass densities often varying by over $100 \%$. The aerobraking and torque data show significant variability even within each pass, with horizontal wavelengths on the order of $100-200 \mathrm{~km}$ which may be associated with gravity waves. Both the day-to-day and the intra-orbit variability are similar to phenomena which have been observed at similar pressure levels in the Martian thermosphere (e.g. Fritts et al. 2006).

The PVO, Magellan and VEx missions obtained atmospheric drag data, but at different locations and local times. While the PVO-ONMS mass spectrometer and PVO-aerobraking sampled the thermosphere at low latitudes, the in-situ data from VEx were taken at polar latitudes. The local solar time coverage is also 
different: PVO mass spectrometry and aerobraking covered all local times, while VEx sampled the terminators, with Solar Zenith Angle (SZA) in the range $80-100^{\circ}$.

\subsubsection{Venus Express aerobraking (VEXADE-AER)}

Vertical profiles of total mass densities in the thermosphere were inferred from accelerometer measurements on Venus Express during the aerobraking campaign from 24 June to 11 July 2014 (MuellerWodarg et al., 2016). ESA planned this campaign in the final months of the mission in view of the risk of losing the spacecraft due to the enhanced atmospheric drag at decreasing altitude. The pericentre of the highly eccentric VEx orbit ( $e=0.84$ ) was located at $75^{\circ} \mathrm{N}$ at local solar times of $04: 30$ to $06: 12$ and altitudes of 130 to $134 \mathrm{~km}$. Data from the on-board accelerometers could not be used at higher altitudes for the derivation of mass densities because of the insufficient sensitivity of the (engineering) instrument.

The raw accelerometer data taken at 8 samples per second around the pericentre were averaged over $2 \mathrm{~s}$, and resampled at $1 \mathrm{~Hz}$ in the density processing. Density profiles at $1 \mathrm{~Hz}$ sampling extending about $3^{\circ}$ in latitude before and after the pericenter have been obtained for each of the 18 consecutive days of the aerobreaking campaign in 2014. The general method of the derivation of mass densities from accelerometer measurements is described by Bruinsma et al. $(2004,2006)$.

The uncertainty of the derived mass densities was computed from a systematic part caused by the uncertainty in the spacecraft aerodynamic coefficient which was estimated to be $10 \%$, plus the measurement noise and bias of the accelerometer. This systematic uncertainty had no impact on the analysis of the relative variations within a single orbit, for example wave structures. The (formal) 1- $\sigma$ noise of the accelerometer data averaged over two seconds was found to be $0.001 \mathrm{~m} / \mathrm{s}^{2}$. The bias of the accelerometer was estimated to $2 \cdot 10^{-4} \mathrm{~m} / \mathrm{s}^{2}$ to $5 \cdot 10^{-4} \mathrm{~m} / \mathrm{s}^{2}$ from measurements outside the sensitivity range of $2 \cdot 10^{-3} \mathrm{~m} / \mathrm{s}^{2}$ at higher altitudes. Taking this uncertainty into account, the density data can be used on average to an altitude of $139 \mathrm{~km}$, which corresponds to profiles of about 80 seconds duration.

The mass densities observed by VEx are compared with an empirical model. Ratios of the observed VEX mass density with those from the VTS3 model by Hedin et al. (1983) were computed for each profile (Figure 2). Valid observed mass densities are on average about $30 \%$ smaller than densities from the VTS3 model, that means in better agreement with the Hedin model than the mass densities obtained by the Precise Orbit Determination from radio tracking (Rosenblatt et al., 2012) at higher altitudes (160 km $170 \mathrm{~km}$ ). A high variability of the ratio of $\sim 10 \%$ is seen in form of wave-like features along the orbit. The ratio of observed densities to modelled densities is altitude-dependent, being smaller than 1 at lower altitudes (about 0.78 , or $78 \%$ near $130 \mathrm{~km}$ altitude) and decreasing with altitude (60\% near $140 \mathrm{~km}$ 
altitude). This demonstrates a systematic difference between the neutral scale heights of the observed densities and the VTS3 model densities. These differences are most likely caused by temperature differences in the polar thermosphere and possibly uncertainties in our knowledge of the polar atmospheric composition.

Temperatures are derived from the neutral atmospheric scale heights $H=k \cdot T /(m \cdot g)$ where $T$ is the temperature, $k$ is the Boltzmann constant, $g=8.49 \mathrm{~m} / \mathrm{s}^{2}$ is the gravity acceleration, and $m$ is the mean molecular weight of the atmospheric species which is estimated using the VTS3 model. VTS3 predicts a mean molecular mass $m=34.7-41.8$ atomic mass units (amu) for the latitude range $71.5^{\circ} \mathrm{N}$ to $79.0^{\circ} \mathrm{N}$, the local solar time (LST) range $04: 30 \mathrm{~h}$ to $06: 18 \mathrm{~h}$ and $F 10.7$ mean $=130.7-134.0$ using the $10.7 \mathrm{~cm}$ radio flux as a proxy for the solar flux. The daily F10.7 proxy varied between 93.4 and 200.7 during the time of observations. A mean temperature of $114 \pm 23 \mathrm{~K}$ was derived from the observed mass density profiles. The VTS3 model temperatures are higher for the same observing conditions: $141 \mathrm{~K}-159 \mathrm{~K}$. This temperature difference is consistent with the differences in scale height mentioned above.

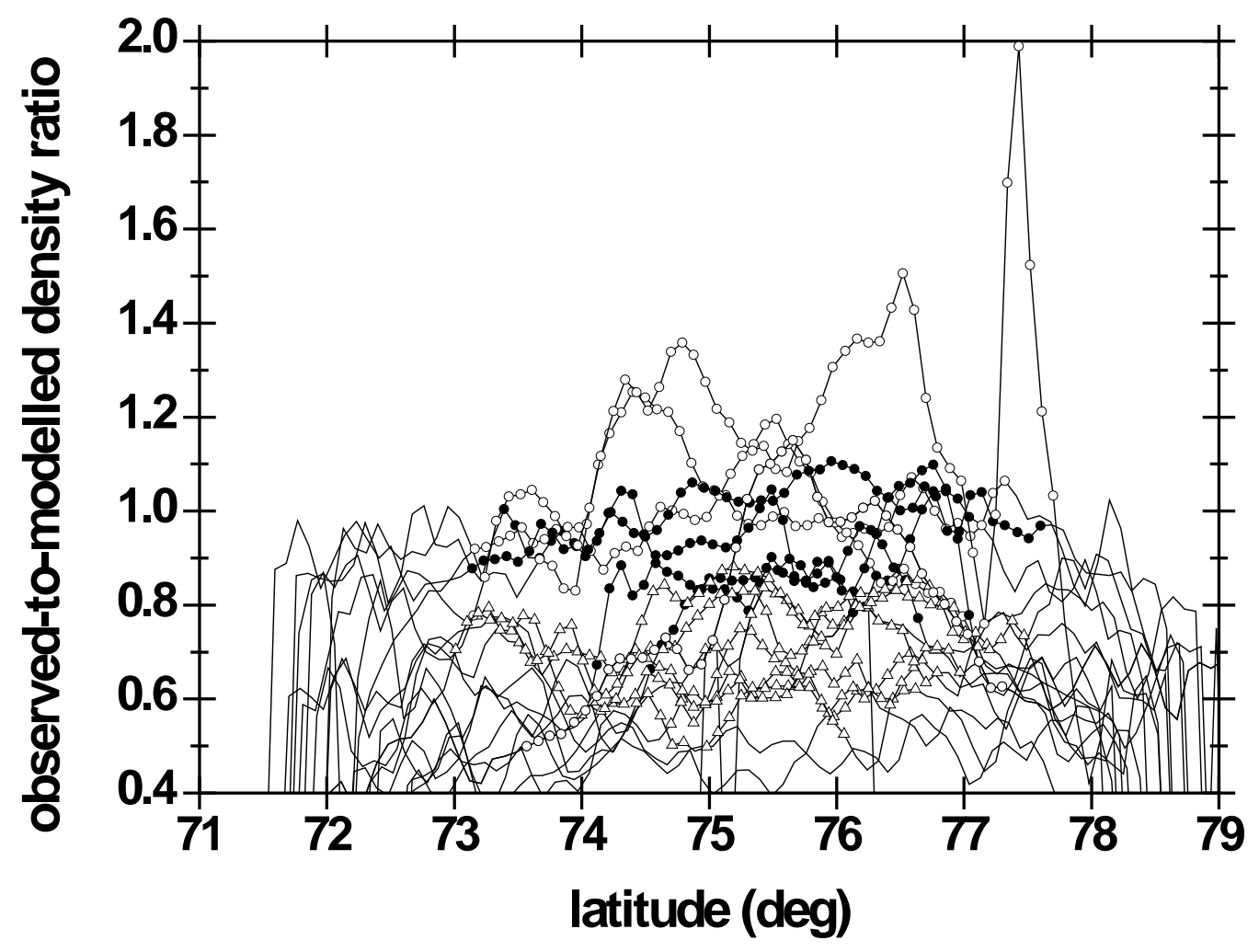

Venus Thermal Structure - Intercomparison of Venus Express and Ground Based Results 
Figure 2: Ratio of observed VEXADE mass densities versus VTS3 model mass densities. Only accelerations above 0.003 $\mathrm{m} / \mathrm{s}^{2}$ (3-sigma) are shown. Symbols mark those ranges where the acceleration is $>0.01 \mathrm{~m} / \mathrm{s}^{2}$. The profiles are observations from 24 June to 11 July 2014. The ratios are computed using a 16-data point average.

\subsubsection{Venus Express Torque Experiment (VExADE-TRQ)}

In addition to calculating thermospheric densities from spacecraft tracking and from accelerometry, atmospheric density can be calculated by measuring aerodynamic torque exerted on the spacecraft as it travels through the thermosphere, as measured by the spacecraft's attitude control system. The total torque acting on the spacecraft also includes contributions from gravity field gradients and the solar radiation pressure: These two terms need to be modelled and subtracted from the total measured torque. The remaining torque is then caused by the atmospheric drag force acting on the solar panels. This technique was first demonstrated using the Magellan orbiter (Croom \& Tolson, 1994), initially with the spacecraft in a normal flight configuration but later with its solar arrays set in asymmetrical orientations in order to create larger torque forces on the spacecraft at a given atmospheric density (the so-called "windmill" experiment, see Tolson et al., 1995). This technique was then further developed during the Venus Express mission; the observation and data reduction procedure for VEx, and its validation by comparison with using radio tracking data are described in detail by Damiani et al., 2012 and Persson, 2015. The torque experiment allowed calculation of atmospheric densities at altitudes of $165-200 \mathrm{~km}$.

Venus Express torque measurements were performed during approximately 100 pericentre passes below $200 \mathrm{~km}$ altitude between 2008 and 2014 at latitudes between $75^{\circ} \mathrm{N}$ and $90^{\circ} \mathrm{N}$. Like the density measurements from VEx aerobraking, discussed above, all density measurements from the VEx torque investigation were carried out near the terminator (SZA of $80-100^{\circ}$ ); since, for thermal and operational reasons, pericentre-lowering for aerobraking or torque measurements was only carried out when the orbital plane was nearly perpendicular to the Sun-Venus vector.

Figure 3 shows one example of atmospheric mass densities derived by the torque method during a single pericentre passage on 18 May 2011 (Persson, 2015). The reader is reminded that Venus Express had a highly elliptical polar orbit, with a pericentre at high northern latitudes. In this particular orbit, the pericentre was at a latitude of $84.8^{\circ} \mathrm{N}$ above the dayside near the evening terminator (Local Solar Time $=$ 16:38); the spacecraft approached pericentre travelling northwards above the dayside, crossing the terminator to the nightside 133 seconds after pericentre. It can be seen that the densities measured after pericentre, when the spacecraft is approaching the terminator, are markedly lower than those measured 
before pericentre; this sharp density gradient near the terminator is consistent with previous observations such as those from Pioneer Venus Orbiter [Keating et al. 1980]. Strong oscillations in the atmospheric mass density are evident in many torque passes (Persson, 2015), with horizontal wavelength typically in the range $100-300 \mathrm{~km}$, similar to those observed at 130-145 km altitude in aerobraking data (MüllerWodarg et al., 2016).

The density profile from all of the torque passes was binned by altitude; due to the strong gradient with respect to SZA all data were also normalized to $90^{\circ}$ SZA (for details, see Persson 2015). The resulting vertical profiles, binned separately for morning and evening terminators, are shown in Figure 4. The error bars denote the measurement error as a function of altitude; the solid lines show the +/- 1 sigma dispersion of measured densities in each altitude bin, i.e. the standard deviation of mass density variability in each altitude bin. Any differences in density between morning and evening terminators are smaller than the measurement error.

For all the VEx torque data, mass densities were found to be 40 to $45 \%$ less than those predicted by the Hedin model, as was found in results from aerobraking at 130-140 km altitude (Sec. 2.1.2.1); this again indicates a lower thermospheric mass density at polar latitudes than at low latitudes observed by Magellan and PVO missions (Keating \& Hsu 1993).

\subsection{Passive Near-Infrared Observations}

\subsubsection{Venera-15 and Pioneer Venus}

First maps of the atmospheric thermal structure were produced by the Orbiter Infrared Radiometer (OIR) on Pioneer Venus using a six channel filter radiometer (Taylor et al., 1980; Schofield and Taylor, 1983). The Fourier Spectrometer (FS-V15) on the Venera 15 orbiter (Oertel et al. 1985, 1987, Moroz et al., 1986) observed emitted radiation from the Venus atmosphere in the range $250-1650 \mathrm{~cm}^{-1}(6-40 \mu \mathrm{m})$ at a resolution of 4.5 or $6.5 \mathrm{~cm}^{-1}$. Its measurements yielded atmospheric properties above the clouds (Schaefer et al. 1987, 1990; Spänkuch et al. 1990). Spectral profiles derived from the $15 \mu \mathrm{m} \mathrm{CO}$ band (and also from both the $\mathrm{CO}_{2}$ hot 950 and $1050 \mathrm{~cm}^{-1}$ bands and the isotopic $1260 \mathrm{~cm}^{-1}$ band) and from spectral ranges which are free from gaseous absorptions were used to retrieve the vertical temperature and aerosol profiles from $55 \mathrm{~km}$ to 95 - $100 \mathrm{~km}$ altitude (Zasova et al., 1999, 2004, 2006, 2007). 

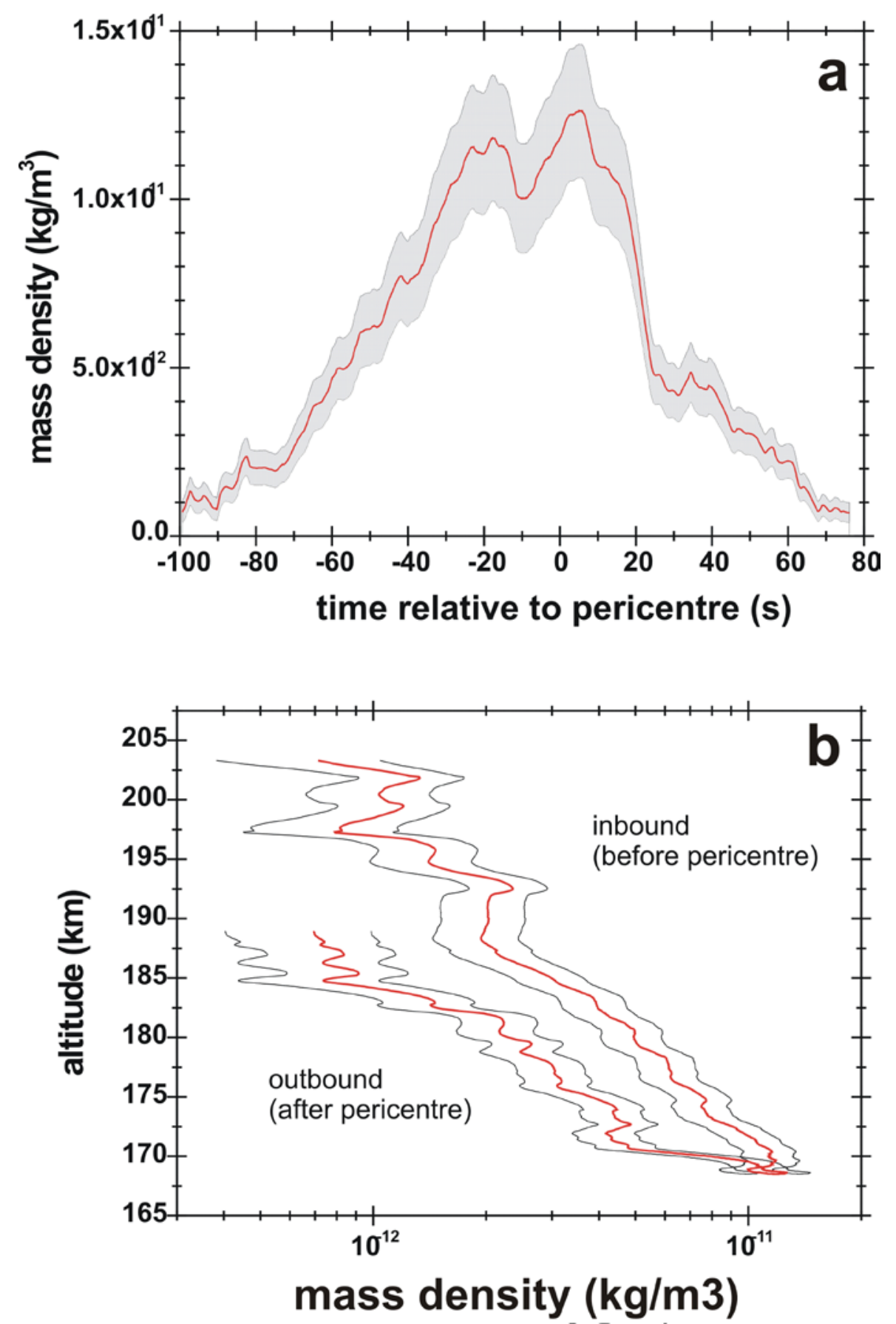

Figure 3: Thermospheric neutral mass density derived from VEx torque measurements on 18 May 2011. Panel (a) derived mass density as a function of time relative to the pericentre (dashed vertical line) on 18 May 2011. Panel (b): derived mass density versus altitude. (Persson, 2015). 


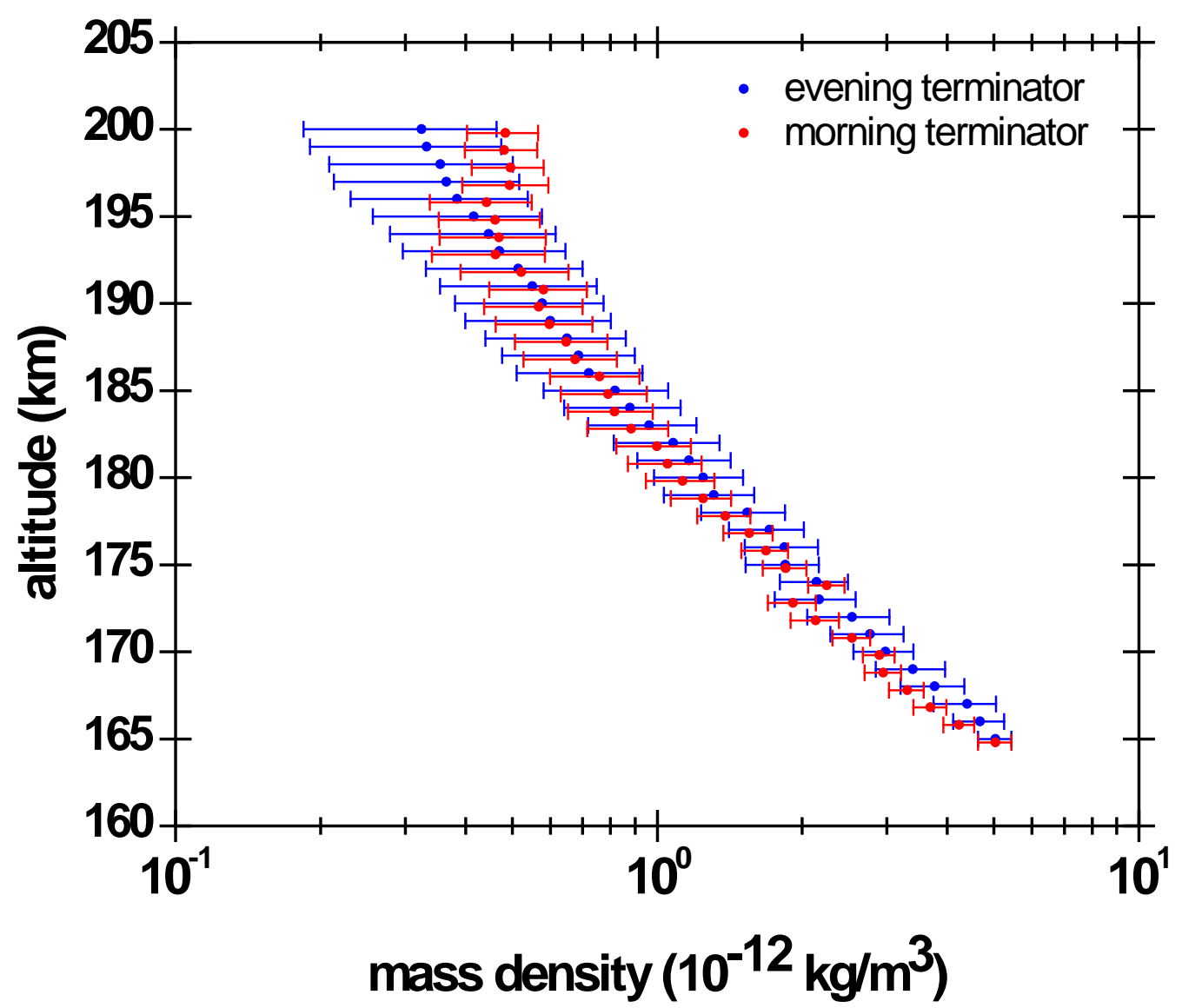

Figure 4. Mean mass densities along the morning (red) and evening (blue) terminator averaged over $1 \mathrm{~km}$ altitude bins. Error bars show measurement errors for individual measurements (Persson, 2015).

\subsubsection{Galileo NIMS}

The first space-based spectral maps of the Venus night side at a fairly high phase angle were produced by the NIMS experiment on the Galileo spacecraft (Carlson and Taylor, 1993; Roos-Serote et al., 1995) during its flyby at Venus in 1990. Temperature profiles were retrieved from the $4.7 \mu \mathrm{m}$ band (Roos-Serote et al., 1995) between 75 and $91 \mathrm{~km}$ altitude and latitudes between $59^{\circ} \mathrm{S}$ and $64^{\circ} \mathrm{N}$. The temperatures were found to be about $10 \mathrm{~K}$ higher at $91 \mathrm{~km}$ and about $4 \mathrm{~K}$ cooler between 74 and $83 \mathrm{~km}$ when compared with the VIRA model, which was well within the variability of the VIRA model.

\subsubsection{VEx VIRTIS}

The Visible and InfraRed Thermal Imaging Spectrometer (VIRTIS) on Venus Express operates in two infrared modes in addition to a visible channel (200-1000 nm, M-vis channel) (Piccioni et al., 2007): a high 
spectral resolution mode ( $\mathrm{H}$ channel) and a lower spectral resolution mapping mode ( $\mathrm{M}$ channel). Temperature profiles and spatial maps were derived by different groups using slightly different retrieval methods from the $\mathrm{H}$ and $\mathrm{M}$ channels (Grassi et al., 2008; Migliorini et al., 2011; Arnold et al., 2012, Gilli et al. 2015; Haus et al, 2014, Grassi et al., 2014; Garate-Lopez et al., 2015).

Radiation with wavelengths $\lambda>4 \mu \mathrm{m}$ which is observed on the night side of Venus is driven by the thermal emission of the atmosphere. The VIRTIS-M spectral range covers in particular the strong $\mathrm{CO}_{2} \mathrm{~V}_{3}$ band. The resolution of VIRTIS-M in this spectral region is such that for the different points on the spectral sampling grid of the instrument unit optical thickness is achieved at various altitudes between the cloud deck top $(62-70 \mathrm{~km})$ up to $80-85 \mathrm{~km}$. This allows reconstructing the vertical temperature profile from the observed radiance at different wavelengths inside the band. The non-LTE emission by $\mathrm{CO}_{2}$ induced by direct solar radiation, however, does not allow daytime observations. Numerical experiments of simulated observations demonstrated how the random component of the retrieval error remains below $2 \mathrm{~K}$ in the range 3 - 50 mbar ( 81 - $68 \mathrm{~km}$ altitude) and below $5 \mathrm{~K}$ for pressures below $1.2 \mathrm{mbar}(\sim 85 \mathrm{~km})$ and above 90 mbar ( $65 \mathrm{~km}$ ). The main source of error in the upper atmosphere (above $85 \mathrm{~km}$ ) is defined by the instrumental random noise and residual calibration misfits because the band is so opaque that an expected radiation level falls below the noise level. The retrieval becomes more and more difficult in the lower mesosphere (below $65 \mathrm{~km}$ ) due to the opacity induced by the clouds. The retrieval results are sensitive to intrinsic vertical smearing related to the finite width of the weighting functions: the vertical resolution of the retrieval is roughly in the order of $7.5 \mathrm{~km}$. The methods to constrain the air temperatures at different altitudes from VIRTIS-M data are described by Haus et al. $(2013,2014)$, Grassi et al. (2014) and references therein.

\subsubsection{Temperature and Cloud Parameter Retrievals from VIRTIS-M-IR Data}

VIRTIS-M is a mapping spectrometer like NIMS on Galileo, capable of acquiring simultaneously spectra at each of the 256 spatially-contiguous pixels along a line of the incident image. These so-called 'cubes' are acquired with multiple exposures, scanning the line over the disk of the planet by either using the instrument pointing mirror or directly by the spacecraft motion (when closer to the orbit pericenter). The cubes provide a spectrum for each pixel of the image, each pixel covering an instantaneous field-of-view of $250 \mu \mathrm{rad}$. This implies an area of $16.5 \times 16.5 \mathrm{~km}$ on the Venus cloud deck for measurements acquired at the VEx apocenter in nadir viewing mode. VIRTIS-M operates simultaneously in the visible and near infrared spectral ranges, but only the latter being relevant for the thermal structure reported here. The infrared spectral channel covers the range $1-5.1 \mu \mathrm{m}$ with an effective spectral resolution of $12 \mathrm{~nm}$. 
VIRTIS-M-IR data were collected between 14 April 2006 and 29 October 2008 which corresponds to about 930 Earth days or 8 Venus solar days. The local time distribution of the measurements during the mission however remained quite irregular due to operational and orbital constraints which limited the downlink capability. Most of the cube data were acquired at the apocenter (located above the South Pole) covering large areas of the southern hemisphere. A small fraction of the cubes (about 5\%) are long and narrow stripes over the equatorial region and the northern hemisphere at much higher spatial resolution.

Haus et al. $(2013,2014)$ followed an elaborated data pre-processing pipeline that includes refinements of data calibration procedures, new approaches for an effective stray light removal (Kappel et al., 2012), and data binning into a local time (LT) and latitude (lat) grid for grid spacing of $\Delta \mathrm{LT}=(0.5 \pm 0.1) \mathrm{h}$ and $\Delta$ lat $=$ $(5 \pm 1)^{\circ}$. New methodical approaches for self-consistent temperature profile and cloud parameter retrievals are applied where combined radiative transfer and multi-window retrieval techniques simultaneously process information from different spectral ranges of an individual spectrum. The radiative transfer model is based on DISORT (Stamnes et al., 1988). Mesospheric temperature altitude profiles $(58-90 \mathrm{~km})$ are determined from $4.3 \mu \mathrm{m} \mathrm{CO}$ absorption band signatures using Smith's relaxation method (Smith, 1970). Specific parts of the $4.3 \mu \mathrm{m}$ band wings as well as of the deep atmosphere transparency window at $2.3 \mu \mathrm{m}$ are utilized to derive cloud parameters (cloud top altitude, mode abundance factors, opacity). Cloud parameter retrievals are based on a four-modal initial cloud model (Haus et al., 2013) where all modes are assumed to consist of spherical $\mathrm{H}_{2} \mathrm{SO}_{4}$ aerosols at 75 wt\% solution. Wavelength-dependent microphysical parameters of each mode are calculated applying a Mie scattering algorithm (Wiscombe, 1980) and log-normal size distributions and dispersions according to Pollack et al. (1993). Refractive index data is taken from Palmer and Williams (1975) and Carlson and Anderson (2011). Quasi-monochromatic gaseous absorption cross-sections are calculated on the basis of a line-by-line procedure considering spectroscopic parameters from the Venus-HiTemp and CDSD line databases (Pollack et al., 1993; Tashkun et al., 2003) in the case of $\mathrm{CO}_{2}$.

Zonal averages of derived temperature profiles at mid and high latitudes are in good agreement with VIRA profiles while, however, lower temperatures are found at low latitudes. The temperature decreases with increasing latitude polewards in both hemispheres starting at $30^{\circ}$ latitude for fixed altitudes below the cold collar $\left(50^{\circ}-75^{\circ}, 58-70 \mathrm{~km}\right)$ while it increases above $70 \mathrm{~km}$ polewards starting at $40^{\circ}-50^{\circ}$. The cold collar and the polar vortex regions show the strongest temperature variability with standard deviations of up to $8.5 \mathrm{~K}$ at $75^{\circ} \mathrm{S}$ and $63 \mathrm{~km}$ altitude. The mesospheric temperature field depends strongly on local 
time. The atmosphere is essentially warmer at early night and colder at late night by about $8 \mathrm{~K}$ in the cold collar. The temporal temperature trend reverses at higher altitudes.

Grassi et al. (2014) averaged pixels in the spatial domain on a $4 \times 4$ pixel basis before deriving the temperature: this step allowed to substantially increase the signal-to-noise ratio at the lower limit of the band and to mitigate spatial non-uniformity in the treatment of instrumental response. The resulting averaged spectra were processed using a Bayesian retrieval method (Rodgers, 2000) in order to derive air temperatures at a fixed pressure grid, an altitude-independent $\mathrm{CO}$ mixing ratio and a scalar multiplier for aerosol densities and to model variations at the cloud deck altitude. The retrieval method requires an initial guess to derive the temperature profile. This initial guess is taken as the mean value of the Venera15 FTS temperature estimates. In order to cope with the limitations of the simplified forward radiative transfer model adopted for the computations, the retrievals were limited to cases with emission angles smaller than $30^{\circ}$. The retrieval method considers all four aerosol modes described by Knollenberg and Hunten (1980). Final retrievals were eventually classified on the basis of latitude and local time and averaged in order to produce global maps suitable to identify phenomena such as the cooler temperature in the cold collar just after local midnight, or the warmer air at the dawn terminator at altitudes around $80 \mathrm{~km}$.

\subsubsection{VIRTIS-H High Spectral Resolution Observations}

Migliorini et al. (2012) discuss the thermal structure resulting from the VIRTIS-H data acquired during the period May 2006 - January 2010 for a total of $3 \times 104$ analyzed spectra. The thermal retrieval code applied to the VIRTIS-H data is described in Grassi et al. (2008). The Northern and Southern hemispheres were observed by VIRTIS-H at a better spatial coverage in the South because of the spacecraft orbit. Despite the low VIRTIS-H data volume in the Northern hemisphere, a comparison between the thermal behavior of the two hemispheres at all Solar Local Times at the night side of the planet is possible. A recent reanalysis of VIRTIS-H data (Grassi, personal communication) was eventually able to detect a systematic calibration offset within the $4.3 \mu \mathrm{m} \mathrm{CO}$ band. This effect induced a bias in the derived temperatures that increases with altitude. Preliminary estimates indicate that the systematic offsets reported in Migliorini et al. (2012) are caused by this effect and are less than $3 \mathrm{~K}$ below the 10 bar level.

The retrieval procedure is complicated by non-LTE emissions during daytime whose contributions should be properly modeled and implemented into the retrieval code. A non-interactive retrieval method that includes non-LTE forward model simulations is used to derive daytime temperature between $100 \mathrm{~km}$ and $150 \mathrm{~km}$ from VIRTIS-H CO limb emissions around 4.7 um (Gilli et al., 2015). The method used by Gilli et al. 
(2015) is summarized by two steps: 1) minimization of data-minus-model differences and 2) a linear inversion around the solution of the first step. A selection of limb measurements (FOV smaller than $10 \mathrm{~km}$ ) has been used for the retrieval. Measurements below $100 \mathrm{~km}$ and above $170 \mathrm{~km}$ have been excluded to avoid possible scattering effects and because of signal-to-noise limitations, respectively. Those measurements were taken between June 2006 and October 2008 with a total of about 14,000 spectra.

The vertical resolution of the profile has been estimated by the full width at half maximum of the averaging kernels at four pointing altitudes $(100,115,130$ and $140 \mathrm{~km})$ which is $15-20 \mathrm{~km}$ in the upper mesosphere and up to $25 \mathrm{~km}$ in the lower thermosphere. The maximum information region for the retrieval, given by the peak of the averaging kernels, occurs at about $5 \mathrm{~km}$ above each tangent altitude.

The observation data were averaged in latitude/local time/altitude/SZA bins before applying the retrieval method (see details in Gilli et al. (2015)). The results show large errors (> $30 \mathrm{~K}$ ) despite the averaging. The main contribution to the error is the measurement noise (particularly large in the analyzed spectral range). The daytime thermal structure observed by VIRTIS provides a valuable piece of information to the knowledge of the upper mesosphere and lower thermosphere. There is a temperature maximum around $115 \mathrm{~km}$ at equatorial latitudes near the terminator which is not present at noon. This is challenging to be interpreted by the current GCMs which in contrast predict an upper mesosphere in pure radiative balance with higher temperatures at the sub solar point (Brecht and Bougher, 2012).

\subsection{Occultation methods}

Three experiments on Venus Express use the occultation method to retrieve atmospheric properties VeRa, SOIR and SPICAV. The stellar and solar occultations are spectral measurements in the infrared and ultraviolet by SOIR and SPICAV which rely on atmospheric extinction for profiling along the limb as a function of altitude. The radio occultation method by VeRa relies on the refraction of the radio ray path defined by the index of refraction as a function of altitude. SOIR observes $\mathrm{CO}_{2}$ spectral lines to obtain the $\mathrm{CO}_{2}$ number density as a function of the altitude. The SOIR observations are thus conducted necessarily at the morning and evening sides of the terminator, but do occur at all latitudes because of the pericenter and apocenter of Venus Express are located above the North and South poles respectively. The SPICAV stellar occultations are performed on the night side to avoid contamination by the scattered sunlight and cover also all latitudes. The locations and local times of the VeRa radio occultations are defined by the orientation of the Venus Express orbit plane relative to the Venus-Earth geometry.

Venus Thermal Structure - Intercomparison of Venus Express and Ground Based Results 
All three methods share some common assumptions: spherically symmetric atmosphere, hydrostatic equilibrium and a known composition. The composition is assumed to be constant in a spherically homogeneous well-mixed atmosphere below the altitude of the homopause $(<\sim 125 \mathrm{~km}$, Mahieux et al., 2015a). The $\mathrm{CO}_{2}$ volume mixing ratio changes with altitude between $100 \mathrm{~km}$ and the homopause which affects the SOIR observations slightly. The temperature is obtained from the $\mathrm{CO}_{2}$ density profile only above the homopause, i.e. the composition does not need to be assumed (Mahieux et al., 2010; Keating et al., 1985).

The occultation experiments require specific pointing directions in order to perform the measurements. This is not feasible on every orbit, therefore the temporal and spatial coverage of each experiment is not optimal. SOIR observes the density and temperature between $65 \mathrm{~km}$ to $170 \mathrm{~km}$ altitude, SPICAV between $85 \mathrm{~km}$ to $140 \mathrm{~km}$, and VeRa between $40 \mathrm{~km}$ to $100 \mathrm{~km}$. All three experiments need initial "guess" temperature values at their respective upper boundary for the derivation of the profiles. The altitudes of the respective boundary conditions are different but the solutions converge a few kilometers below the boundary altitude. There is some overlap in the altitude coverage of the three experiments but little overlap in latitude-longitude locations or local times.

One important result from the SPICAV and SOIR occultations is that the range of the homopause altitude, estimated from the inferred $\mathrm{CO}_{2}$ number densities and temperatures, is between $119 \mathrm{~km}$ and $138 \mathrm{~km}$ above the mean surface, with weak latitudinal dependences: higher altitudes are observed on the night side past the morning side of the terminator and lower values near the evening terminator. The derived profiles are based on assumed $\mathrm{CO}_{2}$ mixing ratios from earlier models below $100 \mathrm{~km}$ (Zasova et al., 1996) and VIRA between $100 \mathrm{~km}$ to $140 \mathrm{~km}$ which have not been explicitly validated for the encountered atmospheric conditions during the Venus Express occultation seasons.

\subsubsection{Radio Occultations}

The propagation of the radio carrier through the ionosphere and atmosphere, before and after the spacecraft disappearance behind the planetary disc as seen from the Earth, leads to a bending of the signal ray path. The bending in the dense deep Venus atmosphere is so strong that it requires a special 3-axis spacecraft antenna steering to compensate partially for this effect. Vertical profiles of refractivity versus radius are obtained using standard geometrical optics methods and Abel inversion strategies (e.g. Fjeldbo, et al., 1971; Jenkins et al., 1994). Additional information on the derivation of atmospheric profiles is given in Tellmann et al. (2009).

Venus Thermal Structure - Intercomparison of Venus Express and Ground Based Results 
The spacecraft High Gain Antenna (HGA) is pointing towards the ground station antenna on Earth. It is generally necessary to adjust the high gain antenna pointing during the occultation in order to recover as much of the altitude range as possible before the signal is lost due to atmospheric absorption or critical refraction. An accurate prediction of the radio carrier frequency not perturbed by the propagation through the atmosphere based on the ephemerides of the spacecraft, Venus and Earth and other forces acting on the spacecraft, is required to separate the atmospheric frequency shift from the Doppler-shifted received sky-frequency. In the neutral atmosphere the refractivity is directly proportional to the neutral number density. The standard retrieval method assumes a constant mean atmospheric mixing ratio for the derivation of vertical number density profiles (Fjeldbo et al., 1971; Tellmann et al., 2009). These density profiles can be converted to pressure and temperature profiles assuming hydrostatic equilibrium and using the ideal gas law. This requires the implementation of an upper boundary condition for the integration of the temperature (or pressure) profiles. Usually, three different temperature boundary conditions are assumed at an altitude of $100 \mathrm{~km}(170 \mathrm{~K}, 200 \mathrm{~K}, 230 \mathrm{~K})$. The dependency on the upper boundary condition strongly decreases with altitude and the three profiles merge into the same profile (Pätzold et al., 2007).

The altitude resolution is defined by the Fresnel radius of the occultation geometry which is typically in the order of $500 \mathrm{~m}$. Atmospheric temperature and density profiles were derived from dual-frequency (Xband at 8.4 GHz and S-band at 2.3 GHz) radio occultations from Mariner 5 (Mariner Stanford Group, 1967), Mariner 10 (Howard et al., 1974), Venera 9 and 10 (Vasilev et al., 1980), Pioneer Venus (Kliore et al., 1979), and Veneras 15 and 16 (Gubenko et al., 2008). Magellan performed 20 occultations in 1992 (Jenkins et al., 1994). Atmospheric profiles from Veneras 9 and 10 (Gubenko et al., 2008) were derived using a slightly different atmospheric composition $\left(97 \% \mathrm{CO}_{2}, 3 \% \mathrm{~N}_{2}\right)$ compared to the currently accepted values used to derive profiles from Magellan, PVO and Venus Express.

\subsubsection{Venera 15 and 16, Magellan}

The Venera 15 and 16 orbiters performed 42 occultations in total (Gubenko et al., 2008), mostly at polar latitudes from October 1983 to September 1984 within an altitude range between $42 \mathrm{~km}$ and $90 \mathrm{~km}$. The frequencies used by the Venera orbiters were L-band $(1 \mathrm{GHz})$ and S-band $(2.3 \mathrm{GHz})$. Tabulated results are not available at present.

The Magellan orbiter performed a few occultations which were, however, not part of the baseline mission (Steffes et al., 1994; Jenkins et al., 1994). Hinson and Jenkins (1995) discussed three profiles out of about 20 , covering the altitude region between $35-90 \mathrm{~km}$.

Venus Thermal Structure - Intercomparison of Venus Express and Ground Based Results 


\subsubsection{Venus Express VeRa}

The Venus Express Radio Science Experiment (VeRa) used one-way radio signals at two coherent frequencies (X-band; $8.4 \mathrm{GHz}$ and S-band; $2.3 \mathrm{GHz}$ ) to sound the Venus atmosphere and ionosphere during Earth occultations. The two coherent radio signals allowed separation of the classical Doppler shift from the dispersive media effects. An onboard ultra-stable oscillator (USO) provided a high quality reference frequency source for the coherent one-way downlinks. The radio signals were primarily recorded at the ESA ground station in New Norcia, Australia, but were also supported by the NASA Deep Space Network (DSN) antennas. A detailed experiment overview can be found in Häusler et al. (2006; 2007). The atmospheric profiles cover the upper troposphere and mesosphere of Venus ( $40-100 \mathrm{~km})$ at a high vertical resolution of only a few hundred meters depending on the distance between the spacecraft and the planetary limb. Atmospheric absorption and defocusing losses of the radio carriers strongly increase below $40 \mathrm{~km}$. At $\sim 32 \mathrm{~km}$ altitude the atmosphere becomes critically refractive, and therefore inaccessible for radio sounding.

More than 800 profiles of temperature, pressure and neutral number density were retrieved between April 2006 and January 2015 (see section 2.4). The measurements cover nearly all local times, latitudes and longitudes with a certain gap in the northern middle latitudes resulting from the geometry of the highly elliptical orbit of Venus Express.

Radio occultation studies can also be used to study the stability of the atmosphere by deriving the buoyancy or Brunt-Väisälä frequency (Hinson and Jenkins, 1995; Tellmann et al., 2009). The strong attenuation of the radio carrier strength caused by the absorption of the radio signal provides the additional opportunity to study the absorptivity distribution within the Venus cloud deck (Oschlisniok et al., 2012; Jenkins and Steffes, 1991; Steffes and Eshleman, 1982). The high vertical resolution of the profiles allows the investigation of atmospheric small scale atmospheric structures like the accurate determination of the tropopause (Kliore, 1985; Pätzold et al., 2007; Tellmann et al., 2009) or study of small-scale gravity waves (Hinson and Jenkins, 1995; Tellmann et al., 2012).

\subsubsection{Solar Occultation InfraRed (SOIR)}

The SOIR instrument is an infrared spectrometer on board the ESA Venus Express spacecraft. It uses the solar occultation technique to sound the mesosphere and the lower thermosphere of the Venus atmosphere (Nevejans et al., 2006; Mahieux et al., 2008, 2009). SOIR is sensitive to the 2.3 to $4.4 \mu \mathrm{m}$ wavelength range ( 2257 to $4430 \mathrm{~cm}^{-1}$ ) and uses an echelle grating at very high diffraction orders (from 101 to 194) to diffract the incoming infrared sunlight. The diffraction order (called simply order hereafter) 
is selected using an acoustic-optical tunable filter (AOTF). The full width at half maximum (FWHM) of the AOTF transfer function has a constant value of $24 \mathrm{~cm}^{-1}$, while the spectral width of an order on the detector varies between 19.3 and $37.1 \mathrm{~cm}^{-1}$, which causes an order overlapping on the detector, which needs to be taken into account when studying the SOIR spectra. Four orders are scanned during an occultation. The detector lines along its spatial direction need to be binned on board due to telemetry limitations: two bins are downlinked to the Earth for each order, leading to 8 spectral sets in a 4 wavenumber region during an occultation. Around 700 solar occultations measuring $\mathrm{CO}_{2}$ were performed during the VEX mission. All measurements always occur at the terminator, i.e. at 06:00 hours or 18:00 hours local solar time covering all latitudes well except for the $30^{\circ}-60^{\circ}$ North region due to the geometry of the spacecraft orbit. During an occultation, the measurements are taken at a $1 \mathrm{~s}$ sampling rate at successive tangent altitudes, which corresponds to the minimum altitude of the light path between the Sun and the instrument slit relative to the planet surface; it is also called the impact point. The vertical altitude within the atmosphere probed by SOIR varies from $65 \mathrm{~km}$ up to $170 \mathrm{~km}$. The calculation of the tangent altitude relies on the position and orientation of the spacecraft, and weakly on the light refraction in the atmosphere which can be neglected in the sounded altitude range. The uncertainty of the tangent altitude is always lower than $200 \mathrm{~m}$ and is latitude dependent.

The ASIMAT algorithm was developed to process the SOIR spectra by an iterative procedure. First, the logarithm of the number density profiles in each spectral set, i.e. for one given bin and order, is fitted using the Bayesian algorithm Optimal Estimation Method (OEM, Rodgers, 2000) in a so-called onionpeeling-configuration (Mahieux et al., 2012; 2015a; Vandaele et al., 2013). More than one species is fitted in each spectral set. Only those spectra that contain spectral information are considered in the procedure: with decreasing altitude, the first spectrum in a spectral set is the one in which the spectral lines are well above the noise, the last spectrum is the one in which the atmospheric saturation starts to set in. The baseline is fit as a $2^{\text {nd }}$ to $5^{\text {th }}$ order polynomial. Note that the temperature is not yet fit at this stage. The OEM algorithm uses a covariance equal to $25 \%$ of the a priori profile. The independent profiles for the various fitted species are combined after each global iteration by a weighted linear moving average procedure (averaging window \pm 2 scale heights) (Mahieux et al., 2012). Then, the temperature profiles are derived from the $\mathrm{CO}_{2}$ number density profiles using the hydrostatic law. The number density profiles are used as apriori for the next iteration which also uses the new temperature profile. The iteration is terminated when both number density and temperature profiles are within the uncertainty of the previous iteration step. The results of the inversion are the $\mathrm{CO}_{2}$ number density profile and the temperature profile. The total number density and the pressure profiles are also calculated assuming a 
$\mathrm{CO}_{2}$ volume mixing ratio from a modified Venus International Reference Atmosphere (VIRA) (Hedin et al., 1983; Zasova et al. ,2006).

Large variations of the $\mathrm{CO}_{2}$ number density for a given altitude level are observed by up to two orders of magnitude. The uncertainties of the $\mathrm{CO}_{2}$ number densities are in the order of $10 \%$, much lower than the observed variability. These variations seem to be day-to-day variations rather than latitude or local solar time (terminator side) variations (Mahieux et al., 2012, 2015a) which might indicate the strong influence of the atmospheric dynamics, of waves of all kinds and daily variations of the solar flux. These variations are also seen in the temperature profiles: for a given pressure level, day-to-day variations may rise up $80 \mathrm{~K}$, while the uncertainty on the temperature is in the order of $10 \mathrm{~K}$.

Rotational temperatures are derived from the $\mathrm{CO}_{2}$ ro-vibrational spectral structure measured by the SOIR instrument (Mahieux et al., 2015b). Hence, the rotational structure in a given vibrational band is function of the so-called rotational temperature, and may be derived from the spectra if the spectral resolution is sufficient to resolve the $\mathrm{CO}_{2}$ rotational spectral structure. The method developed to retrieve the rotational temperature is not as computing-time expensive as the procedure to derive both the $\mathrm{CO}_{2}$ number density and temperature profiles. There are, however, drawbacks, mostly because of some instruments characteristics, such as the order overlapping, the modulation by the AOTF function and the spectral noise which is the largest error source. The general shape of the terminator temperature profiles is confirmed by using this method. The rotational temperatures are in good agreement with the corresponding hydrostatic temperatures, but at larger uncertainties ranging from 20 to $100 \mathrm{~K}$. No rotational non-local thermodynamical equilibrium bifurcation has been observed in the datasets.

\subsubsection{Stellar Occultations from SPICAV}

The SPICAV (Spectroscopy for the Investigation of the Characteristics of the Atmosphere of Venus) instrument performs spectroscopy at ultraviolet $(110-320 \mathrm{~nm})$ and at near infrared $(650-1700 \mathrm{~nm})$ wavelengths in the limb, nadir, stellar and solar occultation mode. A detailed description of the SPICAV instrument and its scientific objectives can be found in Bertaux et al. (2007). The UV band spectroscopy enables(in the occultation mode) vertical profiling of $\mathrm{CO}_{2}, \mathrm{SO}_{2}, \mathrm{SO}, \mathrm{O}_{3}$, aerosols and temperature profiles in the 90-140 km region (Bertaux et al., 2007; Montmessin et al., 2006; 2011; Piccialli et al., 2015). The ultraviolet sensor of SPICAV has a spectral dispersion of $0.54 \mathrm{~nm}$ per pixel and a spectral resolution varying

from 1 to $2.5 \mathrm{~nm}$. The vertical resolution of a profile ranges from 0.5 to $\sim 7 \mathrm{~km}$ depending on the occultation grazing angle.

Venus Thermal Structure - Intercomparison of Venus Express and Ground Based Results 
As for the solar occultation, the stellar occultation technique relies on the computation of the atmospheric transmission obtained by dividing each spectrum affected by the presence of the atmosphere along the line of sight by the reference spectrum taken outside of the atmosphere. The reference spectrum is obtained by averaging all spectra (up to 1000) acquired above a tangential altitude of $250 \mathrm{~km}$. One advantage of the stellar occultation technique is the intrinsically accurate geometric registration: the uncertainty of the inferred altitude of the tangential point relies only on the precise knowledge of the spacecraft position in its orbit and not on the precise knowledge of the spacecraft pointing attitude.

Like for solar and radio occultations, each altitude position within the profile is at a slightly different latitude and longitude due to the tangential transect of the line of sight between the star and SPICAV. The difference of the geographical locations between the start and the end of the occultation may be as much as $\sim 2^{\circ}$ of latitude and/or longitude. Both entry and exit occultations are possible and were recorded and processed by SPICAV. A reference altitude of $85 \mathrm{~km}$ was defined.

The stellar occultation retrieval starts first by separating the nitric oxide airglow emission whose signature is superimposed on that of the stellar spectrum to be followed by the derivation of a wavelengthdependent atmospheric transmission at each sounded altitude. Using the same retrieval method as in Quémerais et al. (2006) and Montmessin et al. (2006), line of sight integrated densities (slant densities) for $\mathrm{CO}_{2}, \mathrm{O}_{3}$ and aerosols are first retrieved and then inverted to yield local density and temperature profiles by assuming hydrostatic equilibrium (see Piccialli et al. (2015) for details).

The observations cover all latitudes on the night side between 18:00 hours and 06:00 hours. The error of the SPICAV temperature retrievals varies with altitude: typical values are $1 \mathrm{~K}$ to $20 \mathrm{~K}$ in the altitude range $100 \mathrm{~km}-130 \mathrm{~km}$, and $5 \mathrm{~K}$ to $60 \mathrm{~K}$ at lower and higher altitudes (Piccialli et al., 2015).

\subsection{VEx dataset coverages and data averaging}

The majority of the data are from observations and experiments on board of Venus Express. It is necessary to consider the spatial and temporal coverage of each experiment for a data intercomparison. There is no uniformity in global and temporal coverage because of the different operational and orbital constraints. The spatial coverage from the various experiments and the data binning and averaging are presented in this section. 


\subsubsection{Geographical and temporal coverage of the VEX observations}

\subsubsection{VIRTIS coverage}

Most of VIRTIS limb data come from the Northern hemisphere because of the VEX operational strategy. The observation locations are not evenly distributed in local time and latitude as shown in Figure 5. For instance, observations between $10^{\circ} \mathrm{N}$ and $30^{\circ} \mathrm{N}$ are particularly scarce. The profiles are also not really vertical but each measurement point corresponds to a single spectrum at a given local time and latitude, with no particular geographical and vertical connection to the next data acquisition. The VIRTIS-H spectra on the night side (Figure 5) and day side (Figure 6) of Venus are analyzed separately. VIRTIS-M covers mostly the Southern hemisphere (Grassi et al., 2014).

\subsubsection{VeRa coverage}

Radio occultations occur in seasons when the constellation Venus, Earth and the spacecraft orbit plane is oriented such that the spacecraft disappears behind (and reappears from) the planetary disk as seen from the Earth. It is possible to observe the ingress as well as the egress occultation because of the one-way radio link. Both ingress and egress occur at opposite hemispheres. VeRa occultations cover all latitudes and local times (Figure 7). The atmospheric profiles derived from the profile of the index of refraction are slightly slanted and cover about $4^{\circ}$ along the meridian which means that the planetary latitude within the profile varies only slightly at constant local time. 


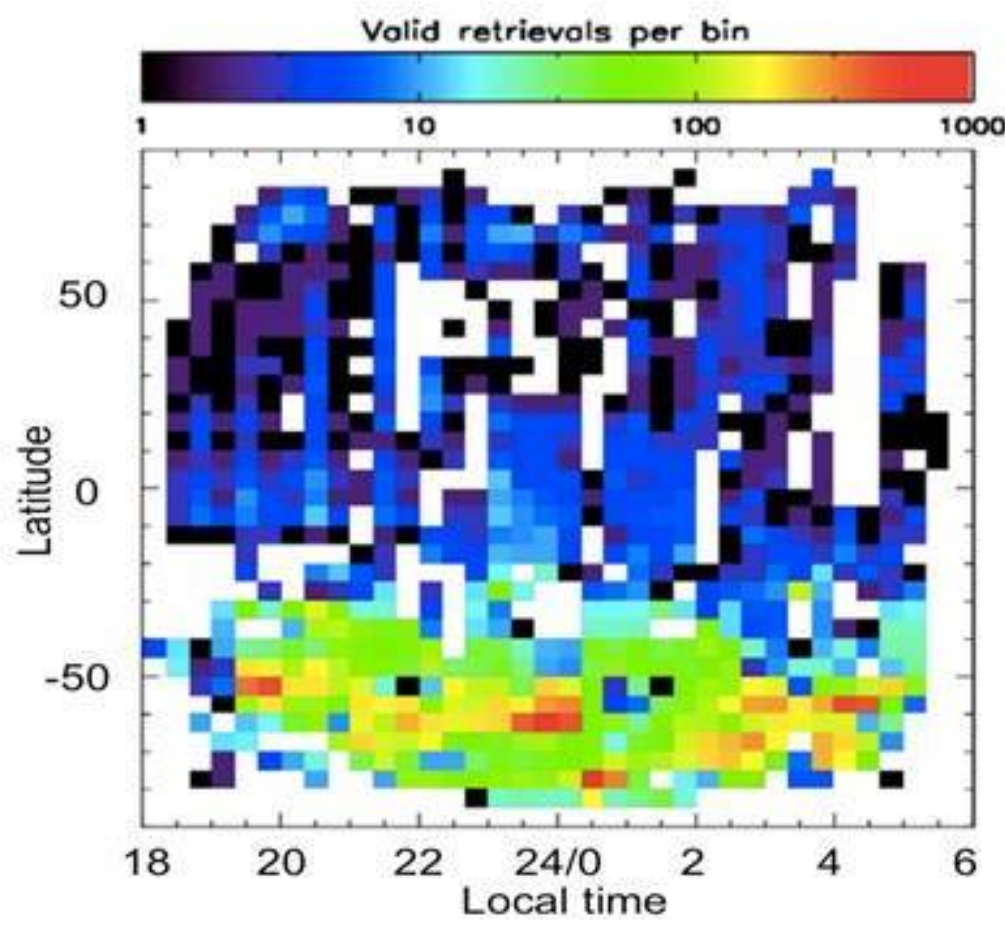

Figure 5: Number of VIRTIS-H spectra (about 30,000 spectra in total) used for the night time temperature retrieval, distributed over local time and latitude (from Migliorini et al., 2012). The southern hemisphere is much better covered than the northern hemisphere. Right panel: Local-time and latitude distribution of the VIRTIS-H daytime limb observations between 100 and $170 \mathrm{~km}$ altitude. The red crosses represent data with a field-of-view smaller than $10 \mathrm{~km}$ which were, used for the temperature retrieval (after Gilli et al., 2015). 


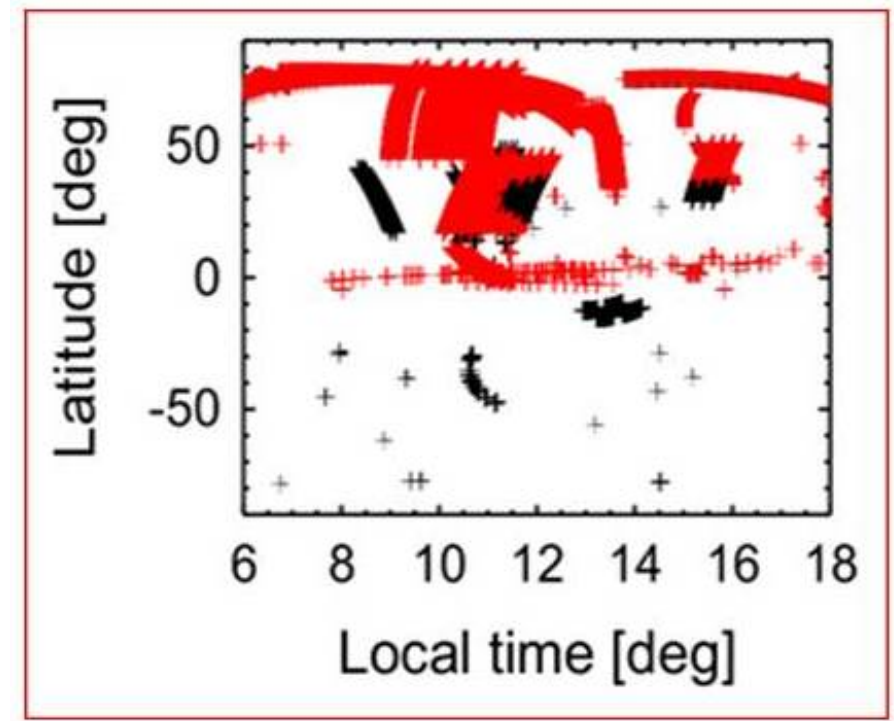

Figure 6: Local-time and latitude distribution of the VIRTIS-H daytime limb observations between 100 and $170 \mathrm{~km}$ altitude. The red crosses represent data with a field-of-view smaller than $10 \mathrm{~km}$ which were, used for the temperature retrieval (after Gilli et al., 2015).

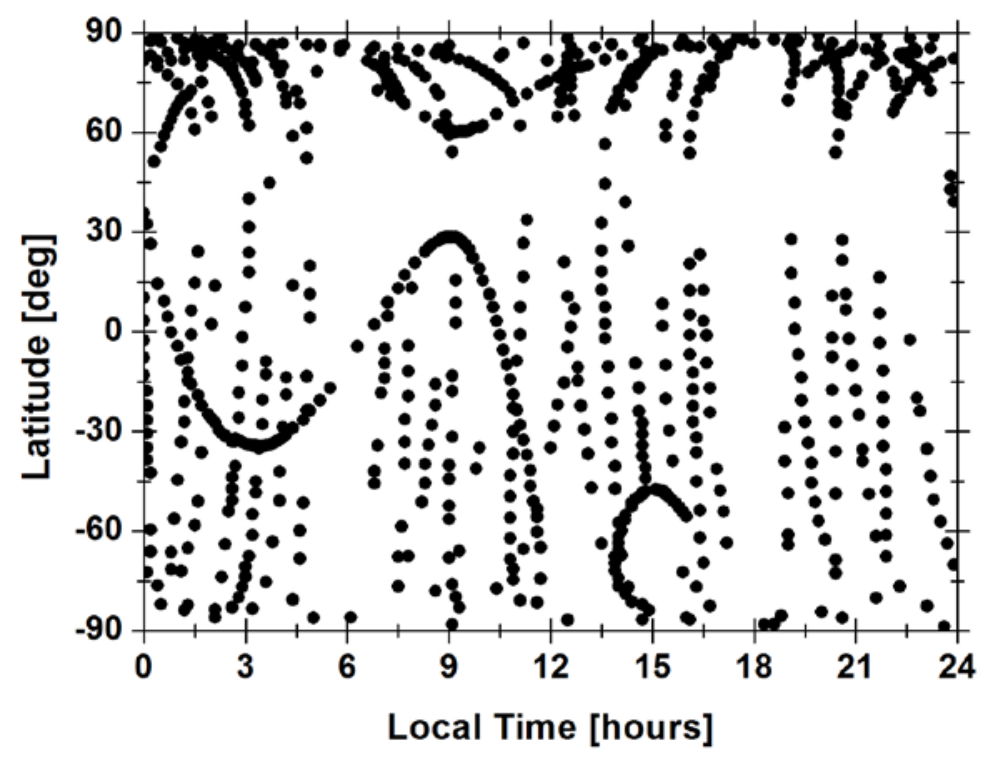

Figure 7: Spatial distribution of the VeRa occultation profiles as a function of local time and latitude represented by the ray pericentre at the 1 bar level (altitude $\sim 50 \mathrm{~km}$ ). 


\subsubsection{SPICAV/UV and SOIR coverage}

Although co-located in the same instrument box, stellar and solar occultations can only be observed at different times in orbit when the source of the radiation is occulted by the Venus atmosphere. Stellar occultations are performed on the nightside, to avoid contamination by stray light from the bright limb. Because of the many available UV bright stars, the stellar occultations are performed at different local times than the solar occultations. Both the solar and the stellar occultations can sample different latitudes. The vertical profiles are also slightly slanted similar to the radio occultations, each vertical location is at a slightly different latitude. Figure 8 shows the distribution of the SPICAV profile locations (latitude vs. local time) at an altitude of $85 \mathrm{~km}$. Figure 9 shows the SOIR profile locations similarly.

Figures 10 and 11 summarize the local time and latitudinal coverage from the SOIR, VeRa, VIRTIS and SPICAV experiments at specific latitude and local time bins that were used in this study.

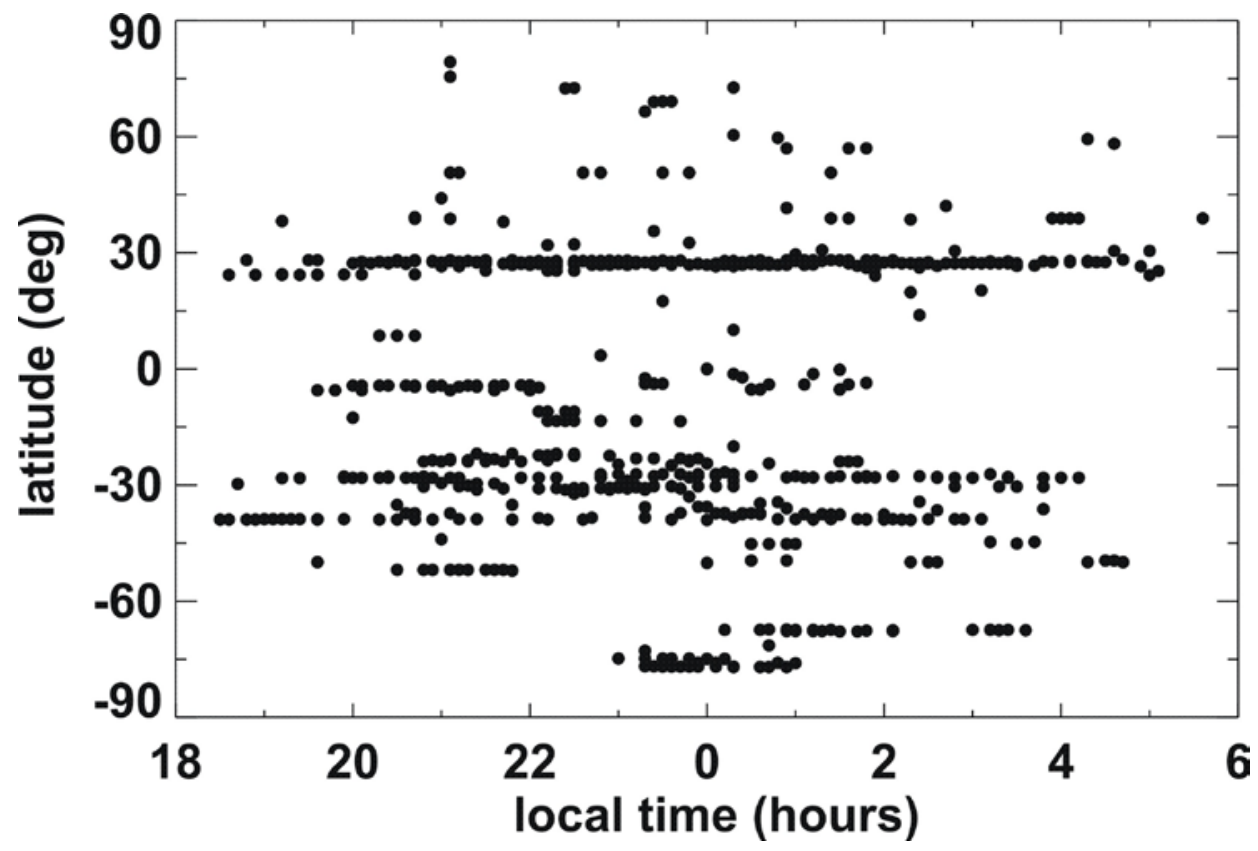

Figure 8: Latitudinal and local time distribution of the SPICAV stellar occultations. The latitude position and local time are represented by the ray pericentre at an altitude of $\sim 85 \mathrm{~km}$. 


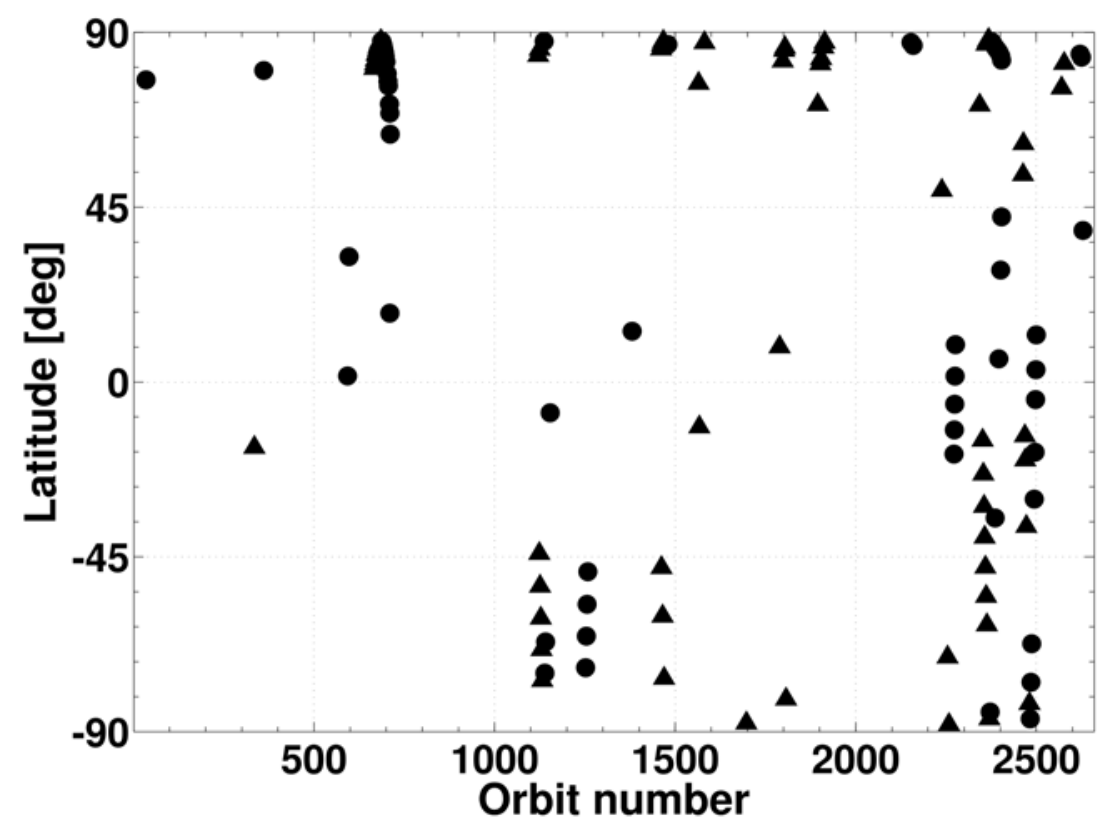

Figure 9: Latitude locations of the SOIR solar occultations when $\mathrm{CO}_{2}$ was observed at high altitudes.. Circles are for the morning terminator, triangles for the evening terminator.

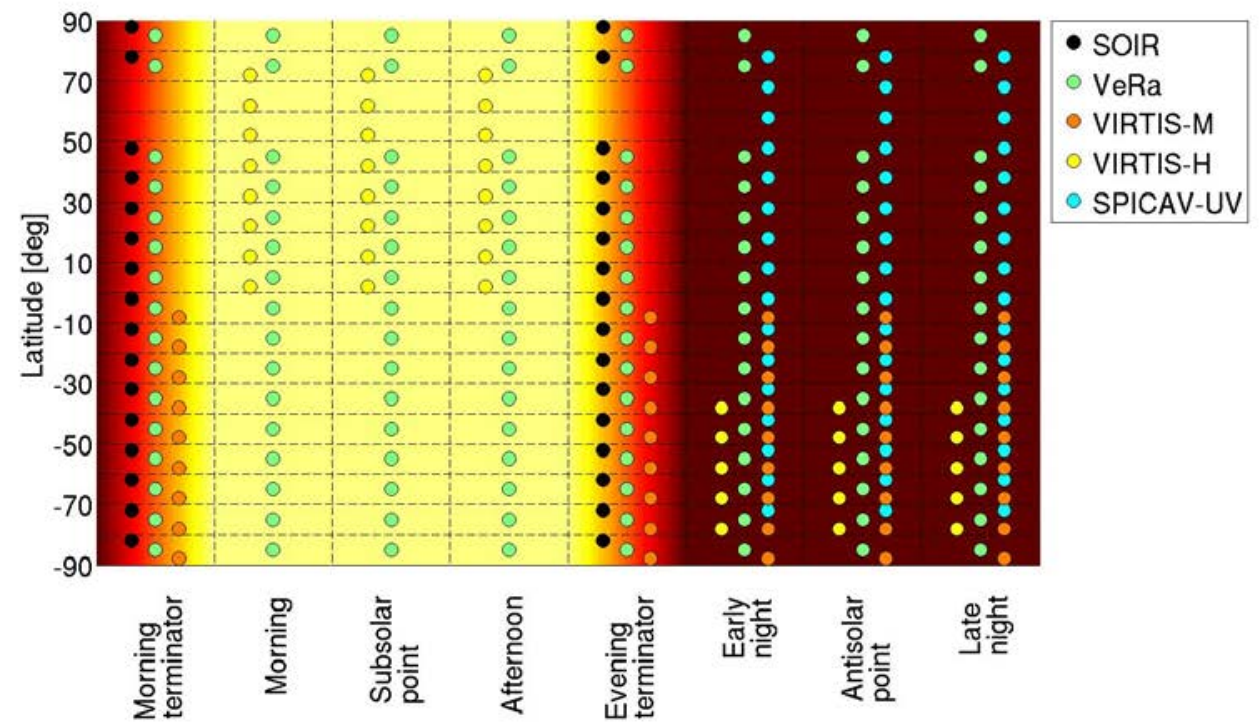

Figure 10: Local solar time versus latitude coverage for the Venus Express instruments. 


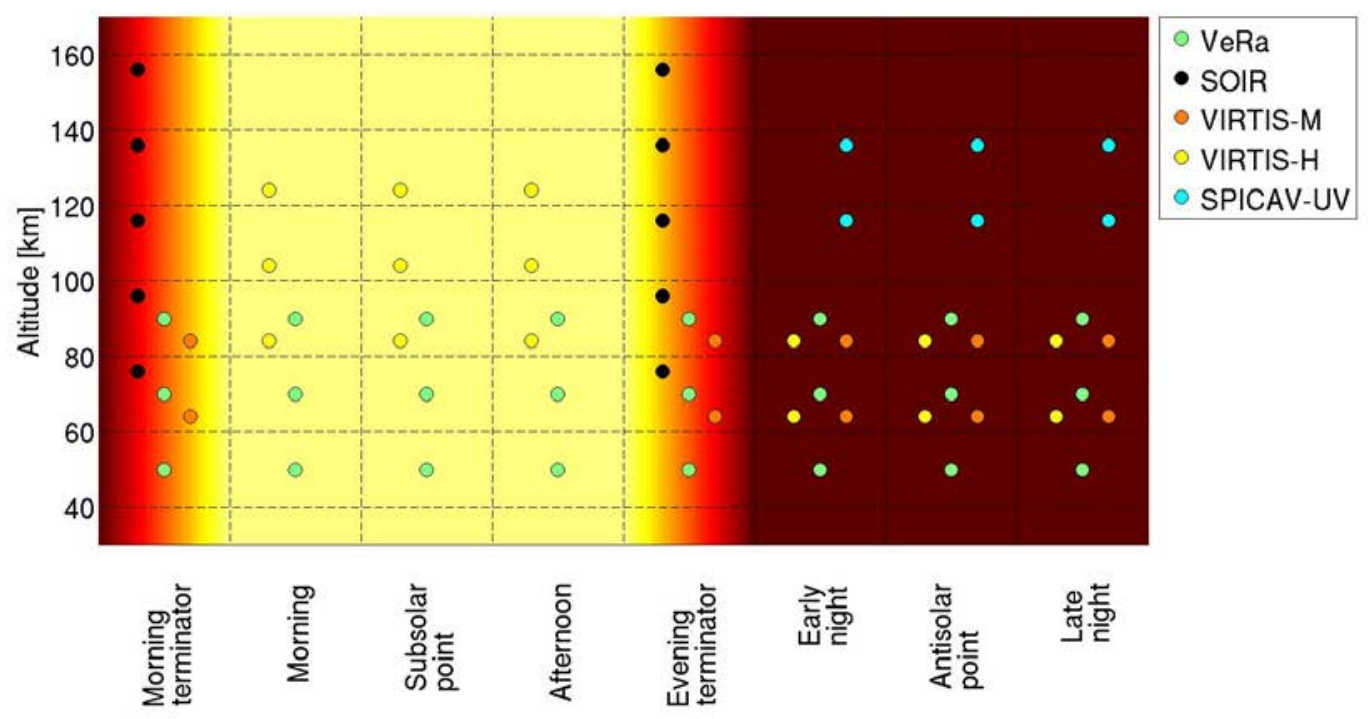

Figure 11: Local solar time versus altitude coverage for the Venus Express instruments.

\subsubsection{Averaging the spacecraft derived datasets}

An intercomparison of the results from the different experiments is only feasible if the data are averaged over time and latitude and/or local time bins because of the different temporal and spatial sampling, coverage and respective measurement errors and uncertainties. The number of measurements from each experiment is given in Table 3 for each latitude and local time bins.

When averaging individual and independent $N$ measurements of the same physical quantity with different uncertainties, assuming that these measurements obey a Gaussian distribution around the "true" value, the best estimate of that quantity is given by the weighted average $\mu_{w}$ :

$$
\mu_{w}=\frac{\sum_{i=1}^{N} w_{i} x_{i}}{\sum_{i=1}^{N} w_{i}}
$$

where each measurement $x_{i}$ at a given pressure/altitude level is multiplied by a weighting factor $w_{i}$ defined as the inverse square of the individual error $\varepsilon_{i}$. The standard deviation of a weighted sample with $M$ nonzero weights is given by:

$$
s t d_{w}=\sqrt{\frac{\sum_{i=1}^{N} w_{i} \cdot\left(x_{i}-\mu\right)^{2}}{\frac{M-1}{M} \cdot \sum_{i=1}^{N} w_{i}}}
$$


Table 3. Number of data sets

\begin{tabular}{|l|c|c|c|c|c|}
\hline & \multicolumn{5}{c|}{ Number of data sets per latitude range } \\
(North/South)
\end{tabular}

Assuming hemispheric symmetry and combining the data from the northern and southern hemispheres, the data from the different experiments are compared in five latitude bins - (i) $0^{\circ}-30^{\circ}$ latitude, (ii) $30^{\circ}$ - $50^{\circ}$ latitude, (iii) $50^{\circ}-70^{\circ}$ latitude, (iv) $70^{\circ}-80^{\circ}$ latitude, and (v) $80^{\circ}-90^{\circ}$ latitude. The data were grouped into three sets - Day, Night and Terminator (both morning and evening) in each latitude bin.

The ground based observations (see Section 3) have a very sparse temporal sampling and a very low spatial resolution. Those observations were therefore not included and compared as combined results from each experiment. 


\section{Ground-based observations}

Ground-based observations have the ability to provide coverage over a longer term but generally have lower spatial resolution compared to spacecraft measurements are constrained in the phase angle coverage. They do have the advantage of attaining higher spectral resolutions and using instruments that are not easily accommodated on spacecraft. Venus has been observed in the near-IR, submillimeter, millimeter wave and infrared atmospheric portions of the spectrum. In the near-IR, information about the thermal structure can be retrieved from the continuum maps and from the maps of the $\mathrm{CO}_{2}$ line depths (Encrenaz et al., 2013). High spectral resolution observations at short and long wavelengths from $1 \mu \mathrm{m}$ to $\mathrm{mm}$ wavelengths enable the probing of the Venus atmospheric thermal structure from $\sim 120 \mathrm{~km}$ to the cloud top level (Betz et al., 1976; Clancy and Muhleman 1991; Sonnabend et al., 2010; Rengel et al., 2008a; 2008b).

\subsection{Sub-mm observations}

Sub-mm observations of $\mathrm{CO}$ lines provide information about atmospheric conditions between approximately 70 and $110 \mathrm{~km}$. $\mathrm{CO}$ is produced in this region by the photolysis of $\mathrm{CO}_{2}$. The pressure broadened rotational lines of $\mathrm{CO}$ provide a means to infer atmospheric properties from high resolution spectroscopy yielding a temperature profile and a line-of-sight Doppler wind velocity and the CO abundance. An optimal retrieval of temperature and CO mixing profiles requires simultaneous radiative transfer (RT) analysis of the ${ }^{12} \mathrm{CO}$ and ${ }^{13} \mathrm{CO}$ line absorption measurements, whereby a single temperature and CO mixing profile over $75-120 \mathrm{~km}$ altitudes is derived to provide self-consistent fits to both spectral lines (e.g. Clancy et al., 2012).

Many observations have been made by various instruments at different observatories around the world in the recent years (Clancy et al., 2012; Lellouch et al., 2008; Rengel et al., 2008a ; 2008b; Sagawa et al., 2010) : using the James Clark Maxwell Telescope (JCMT, Hawaii), Kitt Peak (Arizona), National Radio Astronomy Observatory (NRAO, Virginia), IRAM (Spain), IRAM Pdb (France), Nobeyama Radio Observatory (Nagano, Japan) and Heinrich Hertz Sub-Millimeter Radio Telescope (HHSMT) on Mount Graham, Arizona.

\subsubsection{James Clark Maxwell Telescope (JCMT)}

The temperature profiles observed by the JCMT are retrieved from thermal (LTE) radiative transfer (RT) analyses of sub-millimeter optically thick $\left({ }^{12} \mathrm{CO}, 345 \mathrm{GHz}\right)$ and thin $\left({ }^{13} \mathrm{CO}, 330 \mathrm{GHz}\right)$ line absorptions formed in the mesosphere and lower thermosphere of Venus (Clancy et al., 2012). Detailed descriptions of submillimeter and millimeter $\mathrm{CO}$ line absorptions with respect to RT analysis for temperature profiles can be 
found in Clancy and Muhleman (1991), Lellouch et al. (1994), Rengel et al. (2008a;2008b), and Clancy et al. (2003; 2008; 2012). In ground-based (i.e., nadir viewing) observations, pressure-broadened ${ }^{12} \mathrm{CO}$ lines appear with $30-50 \%$ line center absorptions against the Venus thermal continuum, which arises from collisionally-induced $\mathrm{CO}_{2}$ opacity at altitudes of $\sim 45-65 \mathrm{~km}$ (e.g., Muhleman et al., 1979). Line center optical depths for ${ }^{12} \mathrm{CO}$ line absorptions support thermal profiling from $\sim 80-115 \mathrm{~km}$ in the Venus night side atmosphere versus $~ 80-105 \mathrm{~km}$ in the Venus dayside atmosphere. This day/night distinction regards the large diurnal variation in Venus CO mixing ratios above 80 - $90 \mathrm{~km}$ altitudes (see for example Clancy et al., 2003), such that the line center average optical depth for the $345 \mathrm{GHz}{ }^{12} \mathrm{CO}$ transition varies from $\tau_{\mathrm{o}} \sim 12$ at the night side to $\tau_{\mathrm{o}} \sim 4$ at the day side. CO mixing ratios in the night side in lower thermosphere exhibit strong temporal and spatial variations on top of this average diurnal variation, which reflect the strong night side variation in regional down-welling, which is also dramatically exhibited by $\mathrm{O}_{2}$ singlet delta nightglow variations, e.g., Bailey et al (2008).

Sub-millimeter ${ }^{12} \mathrm{CO}$ temperature profiling is very similar in principle to that employed by Pioneer Venus orbiter Infrared Radiometer for $15 \mu \mathrm{m}$ nadir temperature sounding for Venus with a $\mathrm{CO}_{2}$ opacity source (Taylor et al., 1980). However, the temperature dependence of sub-millimeter radiation is (nearly) linear and the CO opacity source is highly variable, in altitude, LT, and latitude. The latter distinction requires that the CO mixing profile be measured simultaneously, through CO profile retrievals from RT analysis of optically thin $\left(\tau_{\circ} \sim 0.1-0.3\right.$, at $\left.330 \mathrm{GHz}\right){ }^{13} \mathrm{CO}$ line absorptions. The pressure-broadened line shape supports such compositional profiling up to $\sim 105 \mathrm{~km}$. Temperature and CO contribution functions associated with sub-millimeter ${ }^{12} \mathrm{CO}(345 \mathrm{GHz})$ and ${ }^{13} \mathrm{CO}(330 \mathrm{GHz})$ profile retrieval analyses are presented in Figure 12, as reproduced from Clancy et al. (2012).

Vertical resolution for temperature profiles within the mesosphere (80 km - $100 \mathrm{~km})$ is roughly 1 scale height $(4-5 \mathrm{~km}$ ), sufficient to resolve $\pm 5 \mathrm{~K}$ solar thermal tides with good accuracy (Clancy and Sandor, 2011). This vertical resolution degrades by a factor-of-two into the lower thermosphere (100 - $120 \mathrm{~km})$, due to the transition of the contributed line shape from variable pressure to (nearly) fixed thermal broadening and to decreasing vertical gradients in the CO mixing ratio. The spatial/LT resolution of temperature profiling across the Venus disk is set by the diffraction-limited telescope beam, which is 14 arc-seconds for $345 \mathrm{GHz}$ JCMT observations. Hence, the large disk size of Venus when the full night side is viewed ( $\sim 0$ arc-seconds at inferior conjunction) provides $1-3$ hour LT and $20-40^{\circ}$ latitudinal resolution of night side temperature profiles up to $\sim 70^{\circ}$ latitude. Day side coverage is limited from full disk 
(superior conjunction) to half disk (elongation) resolution, such that night side (inferior conjunction) observations from JCMT are emphasized.

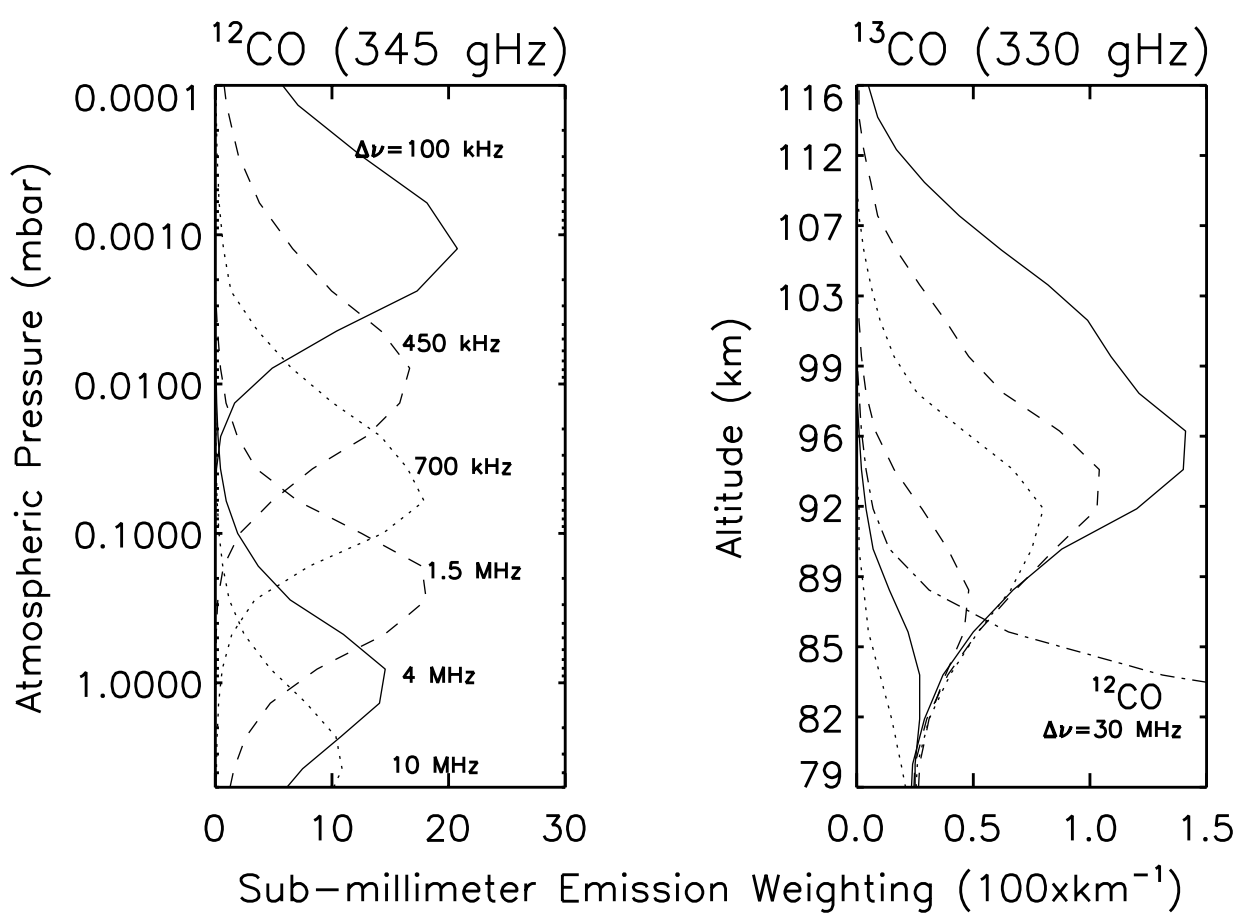

Figure 12: Representative ${ }^{12} \mathrm{CO}$ (left panel) and ${ }^{13} \mathrm{CO}$ (right panel) emission weighting functions are derived for different line center frequency offsets. Vertical axes indicate atmospheric pressure (left) and corresponding altitudes (right) associated with the temperature (left) and $\mathrm{CO}$ (right) solution profiles (reproduced from Clancy et al., 2012).

\subsubsection{Heinrich Hertz Submillimeter Telescope (HHSMT)}

The vertical thermal structure retrieved from HHSMT observations considered in this paper was derived from ${ }^{12} \mathrm{CO} \mathrm{J}=2-1$ at $230.54 \mathrm{GHz}$ at seven positions on the Venus disc and ${ }^{13} \mathrm{CO} \mathrm{J}=2-1$ at $220.4 \mathrm{GHz}$ at one position. Observations on the night and day sides of Venus were performed on 9 - 10 June and 14 - 15 June 2007, at $0^{\circ}$ latitude. The angular diameter of Venus was 23:44" at the beginning and 25:55" at end of the campaign, the approximate full width at half-maximum (FWHM) beam diameters are shown in Rengel et al. 2008b. These observations are a part of a coordinated ground-based Venus observational campaign in support of the ESA Venus Express mission (Rengel et al. 2008a, 2008b). The results indicate a temperature vertical distribution and CO distribution spatially and temporally variable in the mesosphere. 
The technique used to retrieve the temperature and CO profiles is described in Rengel et al. (2008a). The atmospheric model has a vertical resolution of $2 \mathrm{~km}$. Normalized temperature and $\mathrm{CO}$ weighting functions for ${ }^{12} \mathrm{CO} \mathrm{J}=2-1$, and temperature and $\mathrm{CO}$ weighting functions for ${ }^{13} \mathrm{CO} \mathrm{J}=2-1$ for several frequency offsets around each transition can be found in Rengel et al. (2008a). Temperature and CO sensitivity are listed in Table 4.

There is evidence of changes in the thermal structure of the Venus mesosphere occurring on short time scales: small day-to-night temperature variations and short-term (Earth day to Earth day) on a time scale as short as one Earth day.

Table 4: Vertical range where the temperature and CO density retrieved from HHSMT observations are sensitive.

\begin{tabular}{|r|c|c|}
\hline \multirow{2}{*}{ Quantity } & \multicolumn{2}{|c|}{ Spectral Line } \\
\cline { 2 - 3 } & ${ }^{12} \mathbf{C O}(\mathbf{J}=\mathbf{2}-\mathbf{1})$ & ${ }^{13} \mathrm{CO}(\mathrm{J}=\mathbf{2}-\mathbf{1})$ \\
\hline Temperature & $75-110 \mathrm{~km}$ & $80-90 \mathrm{~km}$ \\
\hline CO distribution & $70-100 \mathrm{~km}$ & $80-95 \mathrm{~km}$ \\
\hline
\end{tabular}

\section{$3.2 \mathrm{CO}_{2}$ Heterodyne Observations}

Heterodyne spectroscopy of $\mathrm{CO}_{2}$ at mid-infrared wavelengths is a powerful tool to study temperatures and the dynamical behavior of the atmospheres of the terrestrial planets. In general, heterodyning means mixing the received signal at the telescope with a local oscillator which is usually done by a laser at IR wavelengths. The mixing yields the difference between the received frequency and the laser frequency, both typically at $\mathrm{THz}$ frequencies, with preserved spectral information. The down-converted signal, now at $\mathrm{GHz}$, is easily amplified and analyzed with extraordinary spectral resolution. There are currently worldwide two instruments which use infrared heterodyne receivers to investigate the Venusian atmosphere. One of them is the Cologne Tunable Heterodyne Infrared Spectrometer (THIS) which was developed at the I. Physikalisches Institut, Universität zu Köln, Cologne, Germany. It operates at wavelengths between 7 and $14 \mu \mathrm{m}$. The other instrument is the Heterodyne Instrument for Planetary Wind And Composition HIPWAC developed and operated by the Goddard Space Flight Center in Maryland, USA. Both receivers are transportable and can be shipped to any telescope with IR receiving capabilities. 
Data presented in this paper were taken at the McMath Pierce Solar Telescope, Kitt Peak, Arizona and the NASA InfraRed Telescope Facility, Mauna Kea, Hawaii. Detailed information about the instrumentation can be found in previous work on the development of the THIS receiver and in publications on the observations accomplished with HIPWAC (Sonnabend et al., 2008; Sornig et al., 2009; Kostiuk and Mumma, 1983; Kostiuk et al., 2006).

Mesospheric non-local thermodynamic equilibrium (non-LTE) emission of $\mathrm{CO}_{2}$ near $10 \mu \mathrm{m}$ is observed in the Venus atmosphere, a phenomenon first discovered in 1976 by Betz et al. (1976). The modeling of the processes which lead to the non-LTE emission (Deming et al., 1983; Roldan et al., 2000) has recently advanced (Lopez Valverde et al., 2011) and is a significant step forward on the way to a self-consistent model of the Venusian atmosphere. The kinetic temperature can be calculated from the width of the observed lines and is a good probe for the physical temperature of the emitting gas as long as stimulated emission is negligible. The high spectral resolution allows the determination of the Doppler shift of the observed $\mathrm{CO}_{2}$ emission line which corresponds to the line-of-sight velocities and provides therefore a direct wind measurement. The exact altitude of the emitting region is determined by the ratio of collisionally-induced emissions to the probability of spontaneous emission for the excited $\mathrm{CO}_{2}$ molecules. The excitation is controlled by solar irradiation (Deming et al., 1983; Roldan et al., 2000). A recent study by Lopez-Valverde et al. (2011) finds a maximum for the non-LTE emission with a half width of $10 \mathrm{~km}$ at the 0.15 Pa pressure level which is equivalent to an altitude of $\sim 110 \mathrm{~km}$ using a VIRA pressure-altitude profile. IR heterodyne spectroscopy offers a much higher spatial resolution in contrast to existing sub-mm observations allowing the detailed study of temperature variations as a function of latitude and local time. The observations are, however, limited to the day side and $~ 110 \mathrm{~km}$ altitude.

The heterodyne receivers THIS and HIPWAC have observed Venus during several campaigns in 1990/1991 and between 2007 and 2014 resulting in a comprehensive set of wind and temperature data. The data presented in this paper are temperature measurements derived between 2007 and 2014. A total of 371 individual observations were performed in 11 campaigns. An overview of the measurements and relevant observational conditions for the different campaigns is given in Table 5. The latitude-local time coverage of both instruments is shown in Figure 13. The day side of Venus is very well covered. In particular, there are a number of high quality observations at the equator.

Figure 14 illustrates the observing geometries of all targeted positions (black circles) on the planetary disk. The black circles are the size of the telescope beam relative to the diameter of the Venus apparent disk. The planetary disk is well resolved during the Venus quadrature, compared to the beam size, and allows 
many independent observation locations (Figure 14a, d, e, g, h, j, k). The beam size relative to the planetary disk is, however, large and observation locations do overlap during superior solar conjunction (Figure $14 \mathrm{f}$ and $\mathrm{i})$.

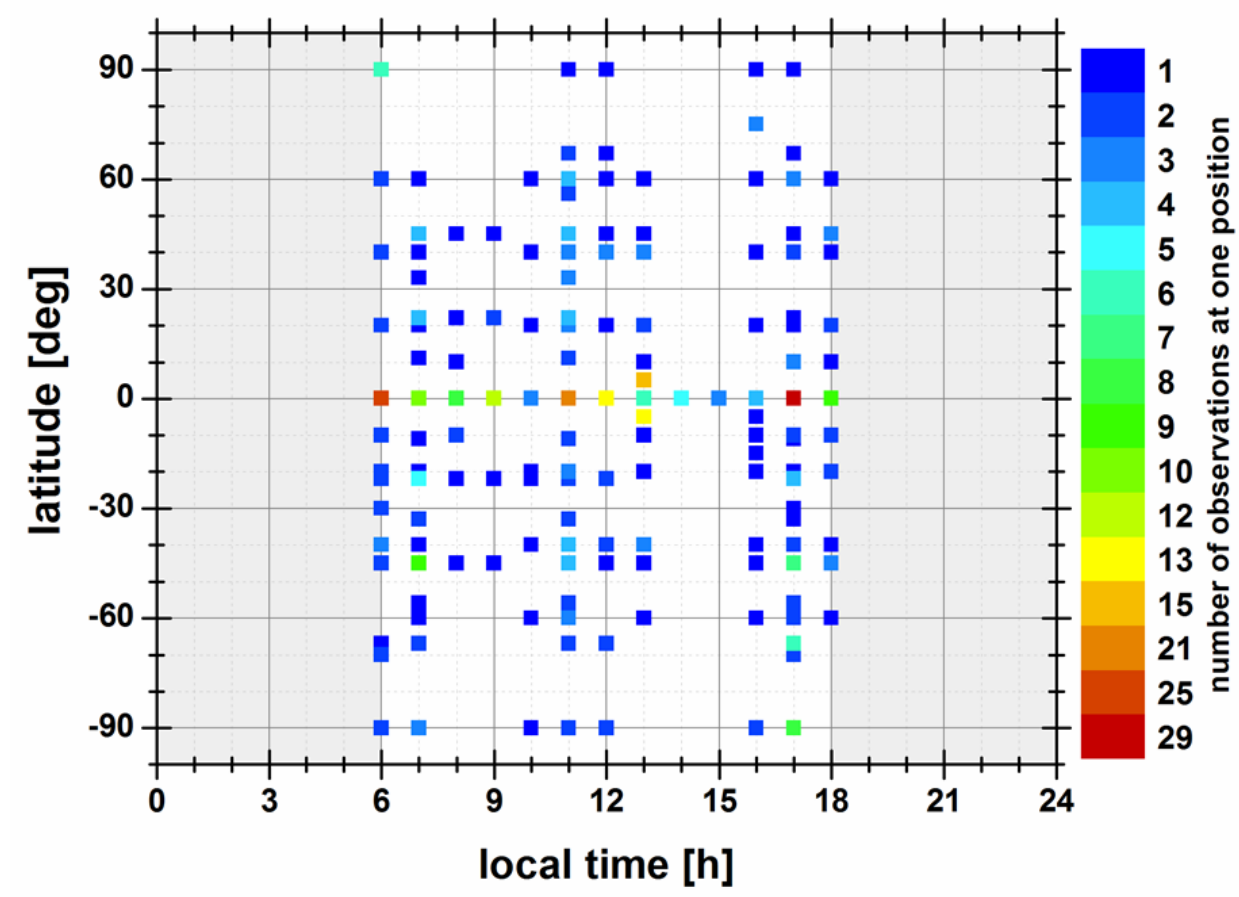

Figure 13. Latitude-local time coverage of both the THIS and the HIPWAC instruments. The color-code gives the number of observations. 
Table 5: THIS and HIPWAC observing campaigns from 2007 to 2014.

\begin{tabular}{|c|c|c|c|c|c|c|}
\hline Campaign & Date & $\begin{array}{c}\text { Venus } \\
\text { apparent } \\
\text { diameter } \\
\text { (arcsec) }\end{array}$ & $\begin{array}{c}\text { Venus disk } \\
\text { illumination } \\
(\%)\end{array}$ & $\begin{array}{c}\text { Earth and } \\
\text { Venus } \\
\text { Doppler } \\
\text { velocity } \\
\text { (km/s) }\end{array}$ & $\begin{array}{c}\text { FoV } \\
\text { (arcsec) }\end{array}$ & $\begin{array}{c}\text { number of } \\
\text { observations }\end{array}$ \\
\hline 1 & $22 .-24.10 .2007$ & 25 & 47 & 13 & 0.9 & 14 \\
\hline 2 & $16 .-22.03 .2009$ & 57 & 4 & -4.8 & 1.6 & 19 \\
\hline 3 & $02 .-06.04 .2009$ & 57 & 3 & 3.6 & 1.6 & 32 \\
\hline 4 & $02 .-06.06 .2009$ & 24 & 50 & 13.9 & 1.6 & 58 \\
\hline 5 & $09 .-22.08 .2010$ & 22 & 55 & -13.8 & 1.6 & 13 \\
\hline 7 & $20 .-25.06 .2011$ & 10 & 97 & 5.1 & 1.6 & 57 \\
\hline 8 & $24 .-30.03 .2012$ & 23 & 21 & -13.3 & 1.6 & 56 \\
\hline 9 & $17 .-24.05 .2012$ & 51 & 7 & 7.3 & 0.9 & 23 \\
\hline 10 & $11 .-16.03 .2013$ & 10 & 100 & 1.4 & 1.6 & 60 \\
\hline 11 & $23.11-04.12 .2013$ & 35 & 33 & -12.3 & 1.6 & 22 \\
\hline
\end{tabular}




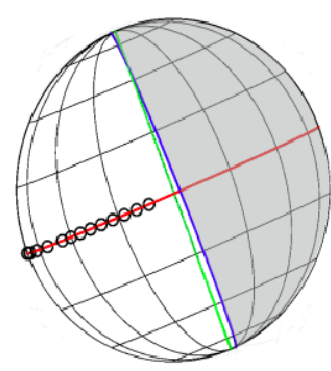

(a) 2007 October (25)

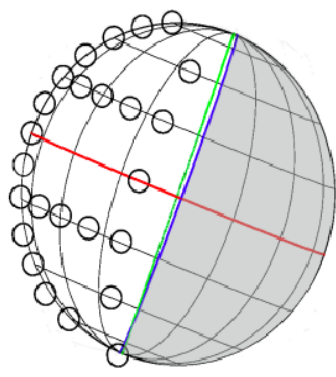

(d) 2009 June (24")

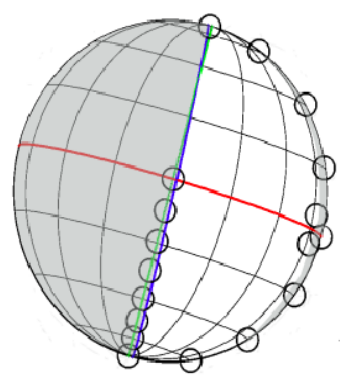

(g) $2012 \mathrm{M}$ arch (23")

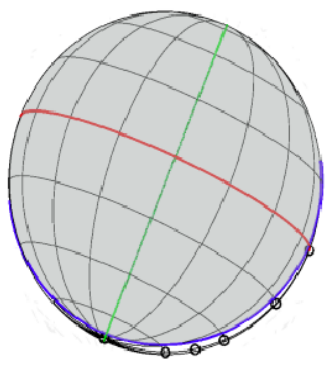

(b) $2009 \mathrm{M}$ arch (5r)

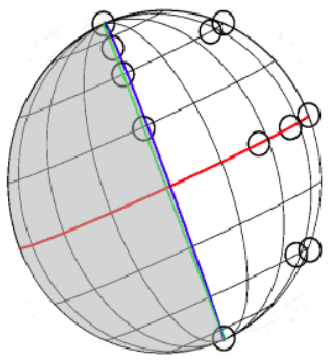

(e) 2010 A ugust (22)

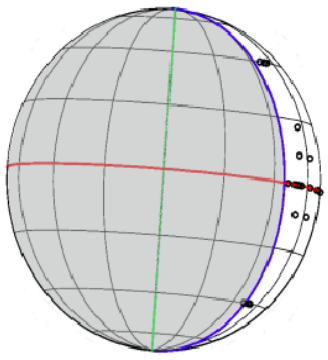

(h) $2012 \mathrm{May}\left(51^{*}\right)$

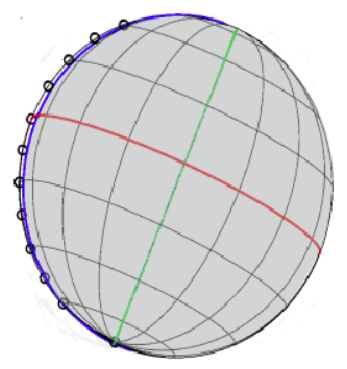

(c) 2009 April (57)

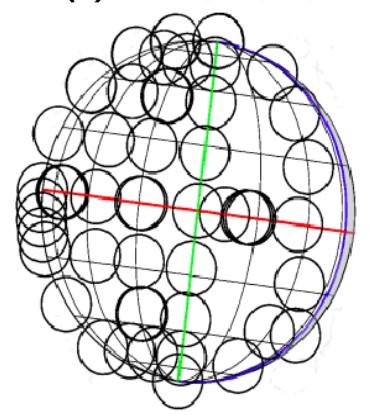

(f) 2011 June (10")

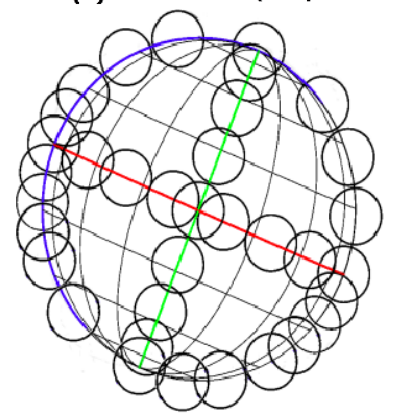

(i) $2013 \mathrm{M}$ arch $\left(10^{\mathrm{N}}\right)$

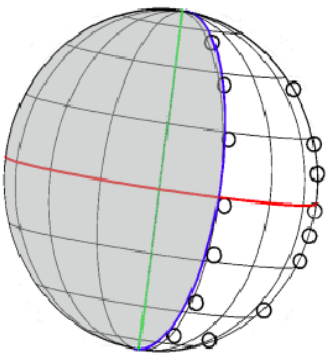

(j) 2013 November (35)

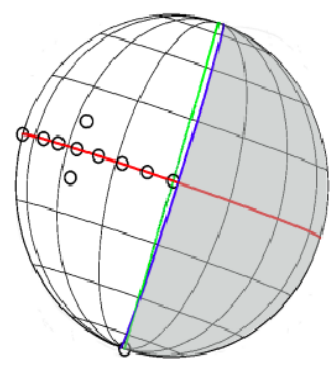

(k) 2014 March (23")

Figure 14: Geometries for all Venus observing campaigns. The equator (red), the terminator (blue) and the central meridian (green) are indicated. The black circles indicate the relative size of the telescope beam to the planetary disk. The number behind the date gives the apparent diameter of Venus in arcseconds. 


\subsection{Temperatures inferred from Night Time Airglow}

The $\mathrm{O}_{2}\left(a^{1} \Delta \rightarrow X^{3} \Sigma\right)$ infrared atmospheric nightglow emission is produced by three-body recombination of two $\mathrm{O}$ atoms in the presence of a third body. Constraints on the local temperature at the altitude of the $\mathrm{O}_{2}$ nightglow emission have been derived from the analysis of the intensity distribution within the rotational structure of the $(0-0)$ band at $1.27 \mu \mathrm{m}$. These measurements do not always have sufficient resolution to resolve individual lines. However, comparisons between observed spectra and synthetic spectra accounting for the Earth atmospheric transmission and convolved to the observed resolution of the ground-based instruments, have provided reliable estimates of the temperature. It is assumed that, in the upper mesosphere region of the emission, the rotational temperature is essentially equal to the temperature of the ambient gas.

The first measurements were made by Connes et al. (1979) who obtained high-resolution Fourier transform spectra yielding $T=185 \pm 15 \mathrm{~K}$. Crisp et al. (1996) also resolved rotational lines in the $\mathrm{P}$ and $\mathrm{R}$ branches using the same technique, and deduced a temperature of $186 \pm 6 \mathrm{~K}$ at $15^{\circ} \mathrm{S}$. Without any measurements of the altitude distribution of the airglow layer, it was not possible to precisely assign these temperatures to a given altitude or pressure level. Ohtsuki et al. (2008) deduced temperatures from observations made during three different years. The average rotational temperatures from their observations were $193 \pm 9 \mathrm{~K}, 182 \pm 25 \mathrm{~K}$, and $185 \pm 20 \mathrm{~K}$. They showed cases suggesting some correlation with the regions of bright nightglow. Bailey et al. $(2008 \mathrm{a}, \mathrm{b})$ derived temperatures from 181 to $196 \mathrm{~K}$ and also showed some relations between higher temperatures and $\mathrm{O}_{2}$ nightglow bright patches. Krasnopolsky (2010) retrieved temperatures showing a broad minimum of $171 \mathrm{~K}$ centered at $4^{\circ} \mathrm{S}$ increasing to $195 \mathrm{~K}$ at $35^{\circ} \mathrm{S}$ and $212 \mathrm{~K}$ at $35^{\circ} \mathrm{N}$ with an uncertainty of about $5 \mathrm{~K}$. No correlation was observed between the nightglow intensity and temperature. By contrast, Bailey at al. (2008) and Ohtsuki et al. (2008) found that their measurements support the idea that compressional heating of downwelling gas heats the region of the airglow layer. They argued that dynamical effects on the nighttime thermal structure in the mesosphere-thermosphere transition region are stronger than the chemical energy released by the association of $\mathrm{O}$ atoms.

VIRTIS-M/VEx nightglow observations did not have sufficient spectral resolution to infer rotational temperature, however, the limb observations indicated that the peak of the $\mathrm{O}_{2}$ emission at $1.27 \mu \mathrm{m}$ at the limb in the northern hemisphere is located at $96 \pm 2.7 \mathrm{~km}$ (Piccioni et al., 2009). Soret et al. (2012) determined the peak altitude of the volume emission rate by an Abel inversion. These results now make it possible to assign an altitude range to the source region, which is useful to interpret the ground-based 
observations. Summarizing these observations, ground-based nightglow measurements yield a mean rotational temperature of $186 \pm 6 \mathrm{~K}$ at an altitude of $97.4 \pm 2.5 \mathrm{~km}$. These values are $15-20 \mathrm{~K}$ higher than temperatures listed in the VIRA model (170 K).

\subsection{The Venus Transit on 6 June 2012 across the Solar Disk}

The transit of Venus in June 2012 provided a unique case study of Venus' atmosphere transiting the Sun, while at the same time Venus Express observed the evening terminator at solar ingress and solar egress (Wilson et al. 2012). This was the first time in history that a transit of Venus occurred while a spacecraft was simultaneously in orbit around Venus. Transit observers in the past gave detailed descriptions of the telescopic aspect of Venus. In particular, during transit ingress and egress, the portion of the planet's disk outside the solar photosphere has been repeatedly perceived as outlined by a thin, bright arc ("aureole"). On June 8th, 2004, fast photometry based on electronic imaging devices allowed the rediscovery and first quantitative analysis of the phenomenon (Tanga et al., 2012). On June 5 and 6, 2012, several observers used a variety of acquisition systems to image the event - thus collecting for the first time a large amount of information on this atmospheric phenomenon. Tanga et al. (2012) had shown that the aureole photometry reflects the local density scale height at the limb and the altitude of the refracting layer. The lightcurve of each spatial resolution element of the aureole has been compared to a limb refraction model to constrain the mesospheric structure / scale height at terminator. The latitude probed by SOIR on Venus Express during orbit $2238\left(+49^{\circ}\right)$, at the time Venus transited the Sun as seen from Earth, provided a suitable validation to this approach (Pere et al. 2016).

The analysis of the images obtained by the Helioseismic and Magnetic Imager of the Solar Dynamics Observer yield temperature data at the evening terminator covering the altitude range from 70 to $110 \mathrm{~km}$. The accuracy of the average latitudinal temperature is comparable to SOIR. The best-measured aureole signal is produced at layers at an altitude of $80-90 \mathrm{~km}$. Table 6 lists the results obtained at $90 \mathrm{~km}$. (Widemann et al., 2014; Tanga et al., 2016) 
Table 6: Temperatures at the $\mathbf{9 0} \mathbf{~ k m}$ altitude level from aureole observations during the 2012 Venus Transit (Widemann et al., 2014)

\begin{tabular}{|c|c|c|}
\hline Latitude & $\begin{array}{c}\text { Temperature } \\
\text { (K) }\end{array}$ & $\begin{array}{c}\text { Error } \\
\text { (K) }\end{array}$ \\
\hline $0^{\circ}-30^{\circ}$ & 161.0 & 19.5 \\
\hline $30^{\circ}-50^{\circ}$ & 151.0 & 18.5 \\
\hline $50^{\circ}-70^{\circ}$ & 154.0 & 11.0 \\
\hline $70^{\circ}-80^{\circ}$ & 167.0 & 16.6 \\
\hline $80^{\circ}-90^{\circ}$ & 157.2 & 13.7 \\
\hline
\end{tabular}

\section{Comparison of the Venus Express and Ground-based Temperature and Density Observations}

\subsection{Description of the Datasets}

The temperature datasets available from the Venus Express VIRTIS-M, VIRTIS-H, VeRa, SOIR and SPICAV instruments were sorted in latitudinal bins, assuming a symmetry of the Northern and Southern hemisphere, as well as in local time bins. The datasets were averaged as discussed in Section 2.4.2. Figures 16 to 20 combine the temperature profiles from the VEX instruments, some Venera and Magellan profiles and the profiles from the ground-based observations as a function of vertical pressure and altitude.

The VIRTIS-M datasets were analyzed using the two different methods by Grassi et al. $(2008,2014)$ and by Haus et al. (2013, 2014). Dayside temperatures were also derived from the VIRTIS-H non-LTE emissions (Gilli et al., 2015). These results are obtained by averaging a large number of spectra taken at same altitude/local time/latitude bins from different observations during the VEx mission. For this reason, they do not represent a real vertical profile, but an average value for each bin. The SOIR temperature profiles (Mahieux et al., 2015) were derived from observations at the evening and morning terminators.

Ground-based observations by the JCMT (Clancy et al., 2008, 2012), the HHSMT (Rengel et al., 2008a,b), HIPWAC and THIS (Sonnabend et al., 2008, 2010; Krause et al., 2014) have been binned in a similar way. 
The mean temperature profile observed at the evening terminator during the Venus transit (Tanga et al., 2012) is also given, as well as the average temperature deduced from $\mathrm{O}_{2}$ airglow observations.

The combined temperature profiles in Figures 16 to 20 are presented in five latitude bins $0^{\circ}-30^{\circ}$ (Figure 15) $30^{\circ}-50^{\circ}$ (Figure 16) $50^{\circ}-70^{\circ}$ (Figure 17), $70^{\circ}-80^{\circ}$ (Figure 18) and $80^{\circ}-90^{\circ}$ (Figure 19) latitude and three local times bins:

(i) day side from $07 \mathrm{~h} \mathrm{LST}$ to $17 \mathrm{~h}$ LST (panel a in Figures 15 to 19)

(ii) night side from $19 \mathrm{~h}$ LST to $05 \mathrm{~h}$ LST (panel b in Figures 15 to 19)

(iii) terminator zones: 05 h LST - 07 h LST and 17 h LST - 19 h LST (panel c in Figures 15 to 19)

The shaded color coded regions in Figures 16 to 20 mark one standard deviation for the respective experiment's averaged profile. Error bars are given for VIRTIS-H non-LTE, HIPWAC and THIS, Venus transit and $\mathrm{O} 2$ airglow profiles which represent the total error. Error bars with respect to altitude are shown for the airglow and transit profiles.

The profiles resulting from the two different analyses are plotted for the VIRTIS-M datasets. The SOIR profiles are averaged from all available data in the latitudinal bin. Morning and evening terminator temperature profiles were computed separately for the SPICAV and SOIR datasets.

Figures 15 to 19 illustrate the significant contributions of Venus Express (particularly at higher altitudes) and the ground-based observations to the investigation of the Venus atmosphere since the publication of VIRA. The new observations are in very good agreement with those temperature values which are addressed by VIRA and provide new information about the atmospheric structure above $100 \mathrm{~km}$.

\subsection{The Troposphere and Middle Mesosphere Below $90 \mathrm{~km}$ Altitude}

Figures 15 to 19 illustrates the generally good agreement (with some exceptions) between the datasets in each latitudinal bin for the night side and the terminator below $0.5 \mathrm{mbar}(90 \mathrm{~km})$ and within the observed variability, considering that the measurement techniques have different fields of view, are taken from ground or from space, are obtained at different times and have different spatial resolutions. The foot prints of the field of view of Venus Express instruments are all latitude dependent because of the highly elliptic orbit. This affects the temperature profiles like smoothing at increasing field of view.

The cold collar which was first detected by Pioneer Venus is identified at latitudes poleward of $50^{\circ}$ and seen in all available datasets. Some small temperature differences appear to be present when comparing 
the VeRa and VIRA profiles in particular at the day side. These might be at least partially caused by differences in the spatial distribution and the sampling of the two data sets.

A systematic difference between the two analyses of the VIRTIS-M dataset (Haus et al., 2013; 2014; Grassi et al., 2015) is evident in particular around the $1 \mathrm{mbar}$ level. There are several explanations: Discrepancies in the final VIRTIS results may be explained by differences in the retrieval methods (described in section 2.2.3.1), by the forward radiative transfer codes and/or the pre-processing procedures (required to address residual calibration issues) adopted by the two VIRTIS teams (Haus et al., 2013; 2014; Grassi et al., 2008). 

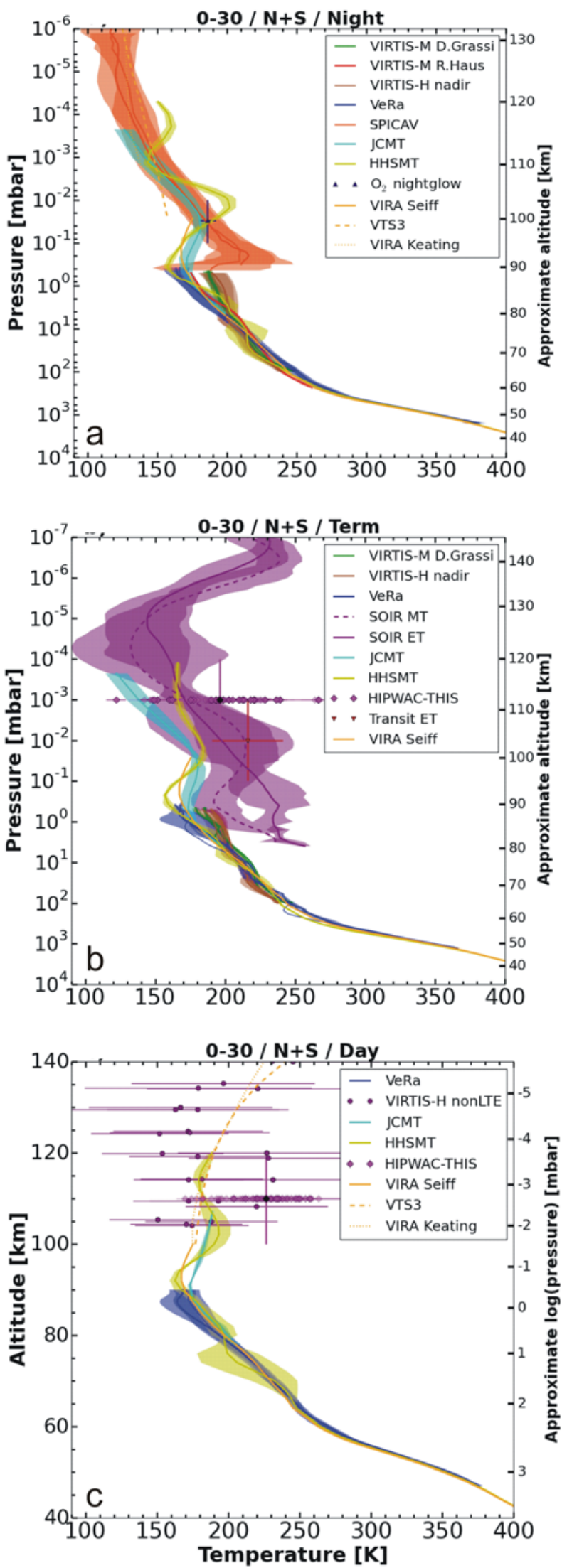
2 Figure 15: combined temperature profiles from the Northern and Southern hemispheres between the 3 equator and $30^{\circ}$ latitude. Panel (a): night side, panel (b): terminators, panel (c) day side. Temperature 4 profiles are combined from the Venus Express instruments, ground-based observations, and empirical 5 models (VIRA Seiff; VIRA Keating; VTS3). The height above the mean planetary radius is given as pressure 6 for the night side and terminator data (panels (a) and (b)) and in altitude for the day side observations in 7 order to ease the comparison with VIRTIS-H data. Corresponding approximate values for altitude/pressure 8 are also given on the right-hand side of each panel. Uncertainties (one standard deviation) are either 9 plotted as colored areas for averaged profiles in the same bin (Venus Express datasets, JCMT, HHSMT, and 10 Venera-15) or as error bars. The VIRTIS-H non-LTE, $\mathrm{O}_{2}$ airglow and Venus transit horizontal error bars 11 represent the total retrieval error. The vertical error bars represent the uncertainty in altitude/pressure.

12 

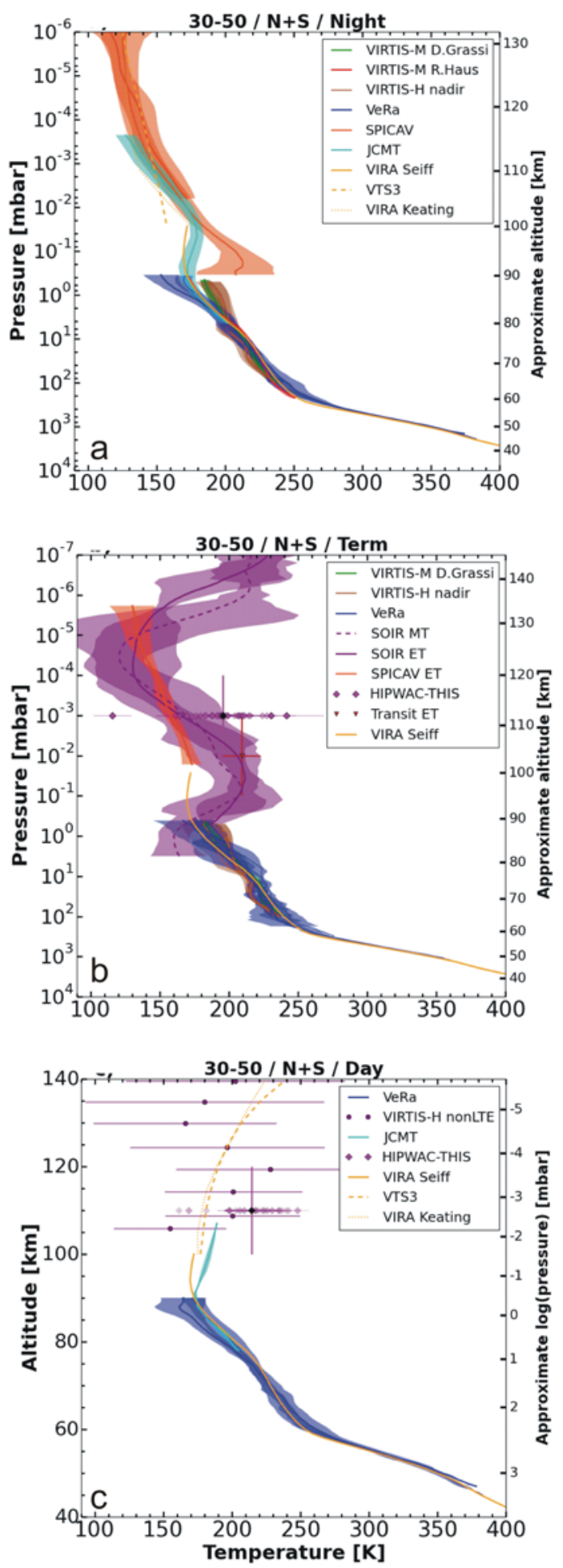

15 Figure 16: same as Figure 15 but for combined temperature profiles from the Northern and Southern hemispheres between $30^{\circ}$ and $50^{\circ}$ latitude. Panel (a): night side, panel (b): terminators, panel (c) day side. 

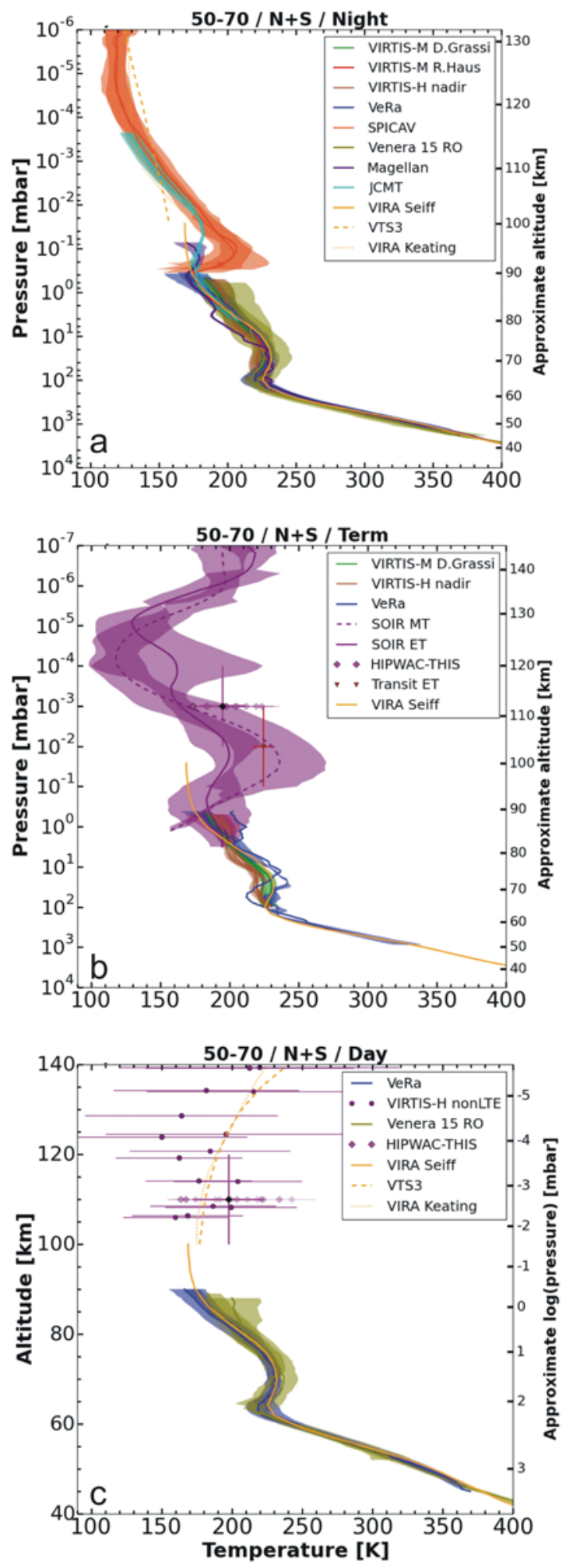

Figure 17: same as Figure 15 but for combined temperature profiles from the Northern and Southern hemispheres between $50^{\circ}$ and $70^{\circ}$ latitude. Panel (a): night side, panel (b): terminators, panel (c) day side. 

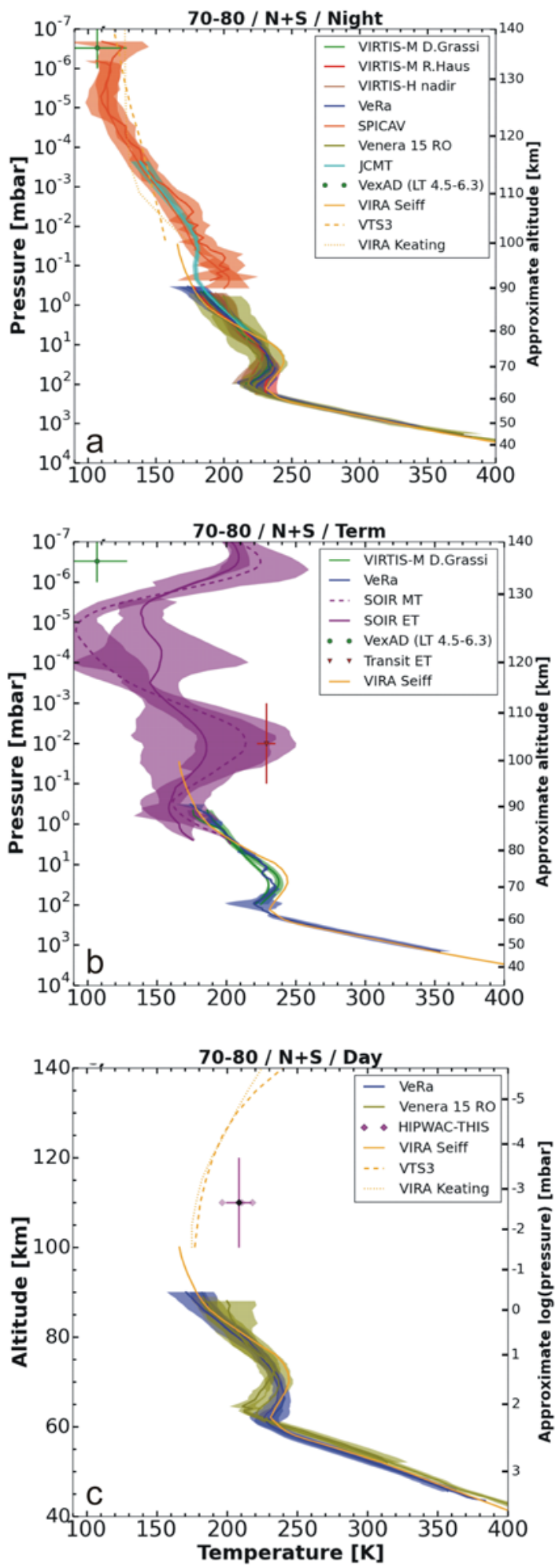

Figure 18: same as Figure 15 but for combined temperature profiles from the Northern and Southern side. 

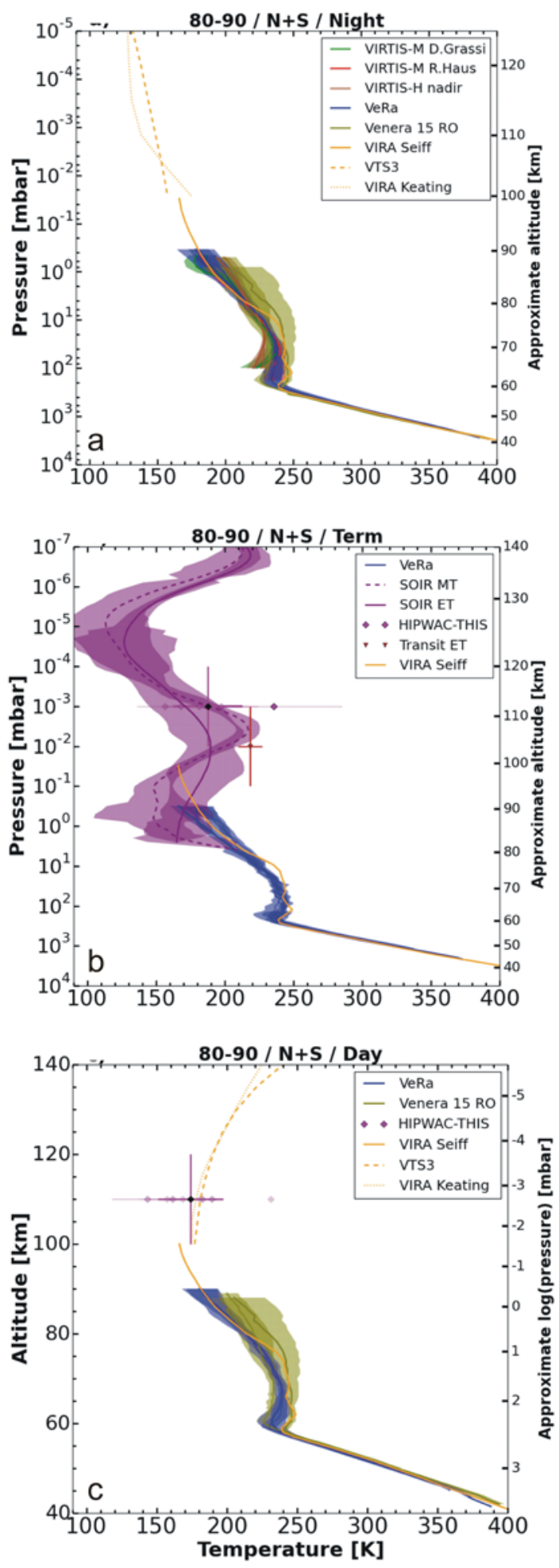

Figure 19: same as Figure 15 but for combined temperature profiles from the Northern and Southern hemispheres between $80^{\circ}$ and $90^{\circ}$ latitude. Panel (a): night side, panel (b): terminators, panel (c) day side. 


\subsection{Upper Mesosphere and Thermosphere ( $90 \mathrm{~km}$ to $150 \mathrm{~km}$ )}

The combined profiles (Figures 15 to 19) show a complicated thermal structure in the $90 \mathrm{~km}$ to $150 \mathrm{~km}$ altitude range with alternating warm and cool layers rather than a gradual increase or decrease of temperature. The cold temperatures seen by SOIR, about $120 \mathrm{~K}$ and lower were seen also by the Pioneer Venus Orbiter drag experiments but at higher altitudes (Keating et al., 1980). A much higher variability of temperatures at each pressure level is observed by SPICAV and SOIR. The corresponding density variations are also large, up to two to three orders of magnitude. The largest temperature difference is seen in the terminator zones at all latitudes (Figures 16b, 17b, 18b, 19b, 20b) which may be caused by short-term temporal variability (all kinds of atmospheric waves) at altitudes above $100 \mathrm{~km}$. The uncertainty in the SOIR temperatures peak is larger compared to the other experiments which provide results at lower altitudes. The temperature inversions are seen in the terminator zones at slightly different altitudes as a function of latitude (about $100 \mathrm{~km}$ at $0^{\circ}-30^{\circ}$ latitude, $95 \mathrm{~km}$ at $30^{\circ}-50^{\circ}, 105 \mathrm{~km}$ at $70^{\circ}-80^{\circ}$ and about $110 \mathrm{~km}$ at $\left.80^{\circ}-90^{\circ}\right)$, which may be caused by the descending circulating flow. Large variations in the vertical flow may influence the mixing of the species which in turn may affect the radiative balance. This is discussed in Section 5.

Temperatures derived from the VIRTIS-H (non-LTE), HHSMT, JCMT and HIPWAC-THIS experiments are on average in good agreement at the day side for latitudes lower than $70^{\circ}$ (Figures 16c, 17c, 18c), but show a very large variability. Almost no data are available from the ground based experiments for latitudes $>70^{\circ}$, except for a few observations by the HIPWAC-THIS experiment (Figures 19c and 20c). Compared to other observations which give averaged values the given HIPWAC-THIS data are single measurements. The variability of this single measurement is in the same range than the VEX instruments even though variability of the spatial field-of-view with the various observing runs have to be taken into account.

The situation is more complex above the 0.5 mbar pressure level $(90 \mathrm{~km})$. The SPICAV and JCMT temperatures are in good agreement above $0.03 \mathrm{mbar}(100 \mathrm{~km})$ on the night side (panel (a) of Figures 16 to 20) and also agree with the average temperatures from the $\mathrm{O}_{2}$ nightglow observations at low latitudes (Figure 16a). The SPICAV profiles, however, show a maximum temperature in the 0.03 mbar to $1 \mathrm{mbar}$ ( 85 $\mathrm{km}-100 \mathrm{~km}$ ) range which is more pronounced and located at lower altitudes than the JCMT profiles. The HHSMT profiles are in agreement with the JCMT profiles below $1 \mathrm{mbar}(85 \mathrm{~km})$ but tend to show a higher variability than the SPICAV and the JCMT profiles above this altitude. 
57 The temperature profiles from all experiments do not generally overlap temporally and spatially at the

58 terminator zones (panel (b) of Figures 16 to 20 ) and the temperature variability is very high. The SOIR

59 profiles are much warmer than the JCMT and the HHSMT profiles but agree roughly with the HIPWAC-

60 THIS temperatures and those from the Venus 2012 transit. The SOIR, HIPWAC-THIS observations are close

61 to the terminator $(<=2 \mathrm{~h}$ ) addressing illuminated day side only, while the sub-mm temperature

62 observations have a larger field-of-view. Differences between both the evening and morning terminators

63 are also apparent.

\subsection{Atmospheric Density}

65 The three occultation experiments on board of Venus Express, SPICAV-UV, SOIR and VeRa, return 66 measurements of the total neutral number density. SPICAV-UV and SOIR measure directly the $\mathrm{CO}_{2}$ number 67 density from its absorption structure, and thus have to assume a $\mathrm{CO}_{2}$ volume mixing ratio, which was taken from VIRA. The neutral number density profiles from SPICAV, SOIR and VEXADE were achieved only at the terminator zones and at the night side. VeRa covered the day side as well as the night side.

The SPICAV, SOIR (morning and evening) and VeRa neutral number density profiles are in very good agreement at the terminator zones from about $10^{3}$ mbar to $10^{-7} \mathrm{mbar}(40 \mathrm{~km}$ to $150 \mathrm{~km}$ ) for all latitude bins (Figures 20 to 26). The profiles at the night side, however, show some differences between VeRa and SPICAV at pressure levels where the profiles overlap. The uncertainties of the SPICAV profiles are significantly larger compared to VeRa. There is also a noticeable offset in the near-equatorial $\left(0^{\circ}\right.$ to $\left.30^{\circ}\right)$ latitude bin (Figure 21) and the mid-latitude $\left(30^{\circ}\right.$ to $\left.50^{\circ}\right)$ bin (Figure 22). Similar differences are also seen in the Figures 26 to 30 (altitude versus neutral number density) which implies a change in neutral scale heights in the near-equatorial $\left(0^{\circ}-30^{\circ}\right)$ latitude bin (Figure 26) and the mid-latitude $\left(30^{\circ}-50^{\circ}\right)$ bin (Figure 27).

The density values from the drag experiments at $170 \mathrm{~km}$ to $200 \mathrm{~km}$ altitude appear to be in very good agreement to an extrapolation of smoothed SOIR profiles in the high $\left(70^{\circ}-80^{\circ}\right)$ and polar $\left(80^{\circ}-90^{\circ}\right)$

81 latitude bins (Figures 28b and 29b). The pressure in this altitude range is extremely low and a variability

82 by a factor of two or more is seen in the density values from orbit to orbit. This is much lower than the 83 variability seen in the SOIR or SPICAV profiles in other latitude bins. The reason for these differences are 84 not yet understood. Some possible causes are discussed in Section 6. 

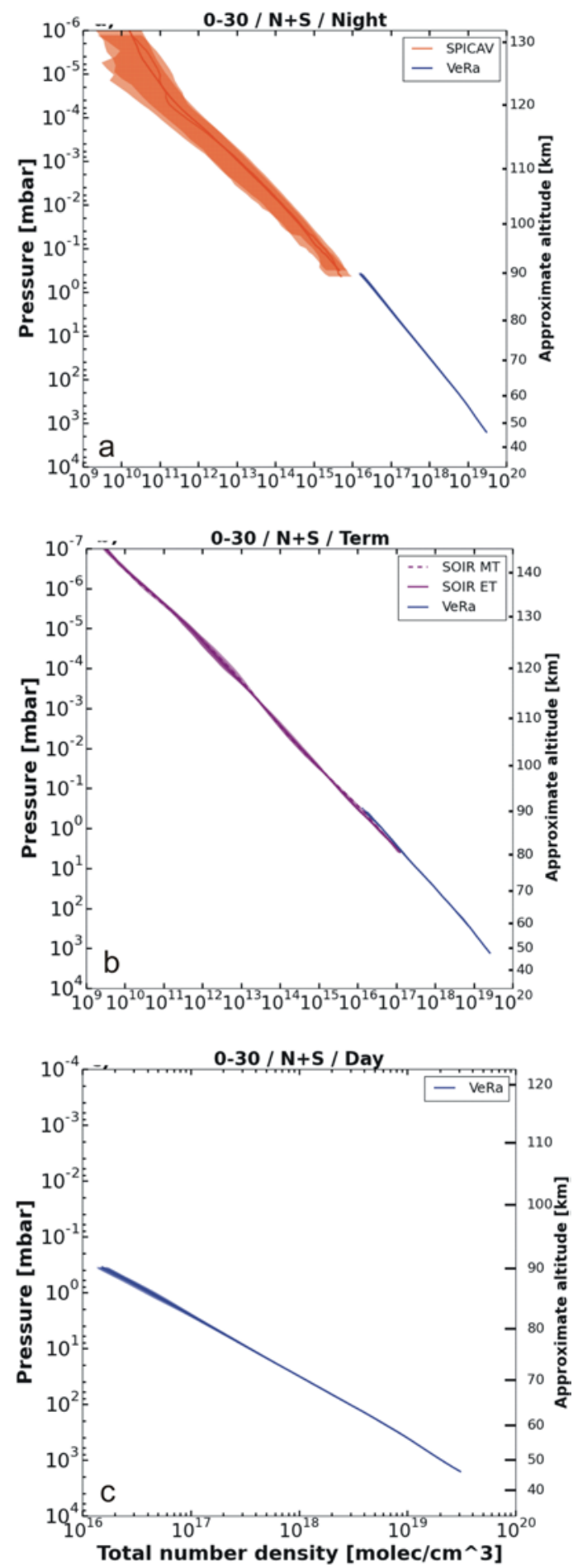

Figure 20: Comparison of atmospheric mean total density profiles from SOIR, SPICAV and VeRa and from 87 the atmospheric drag measurements as a function of pressure for the near equatorial latitude bin $0^{\circ}$ to $8830^{\circ}$. Panel (a): night side, panel (b): terminator zones, panel (c): day side. The colored areas mark one 89 standard deviation uncertainty of the average profiles for each experiment. Approximate altitudes are 90 shown on the right hand vertical axis. 

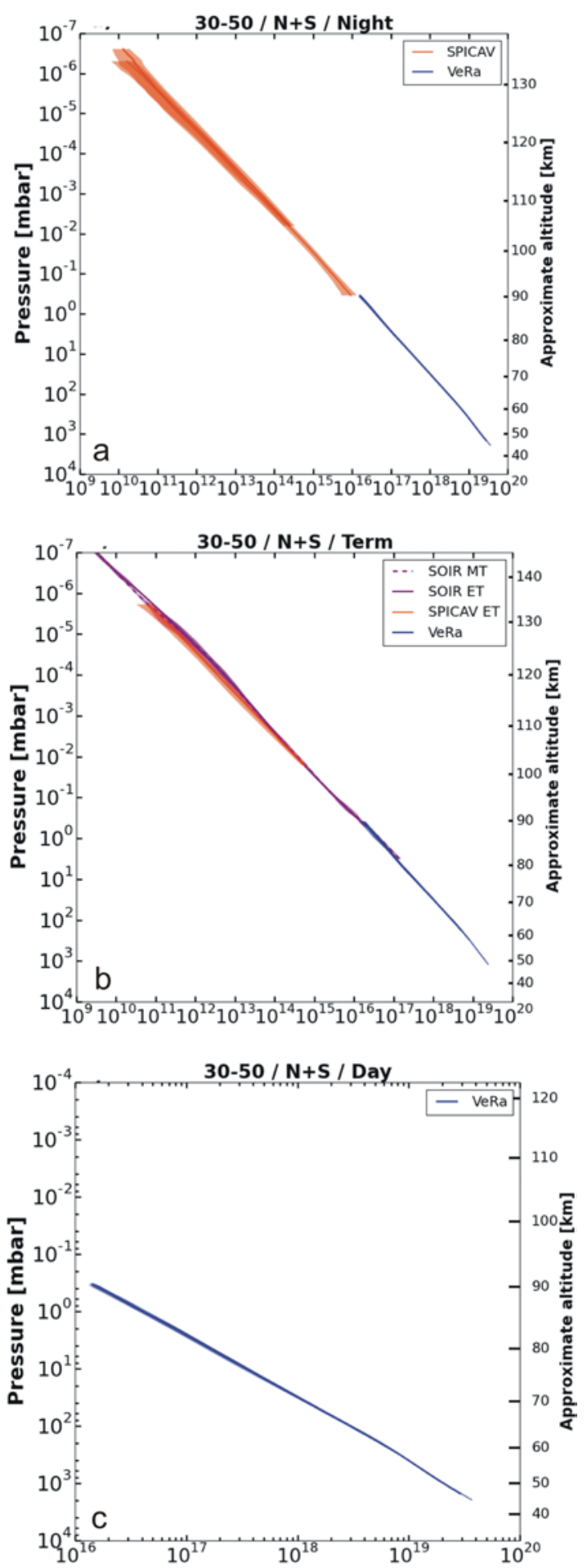

92 Figure 21: same as Figure 20 but for the latitude bin $30^{\circ}$ to $50^{\circ}$. Panel (a): night side, panel (b): terminator 93 zones, panel (c): day side. The colored areas mark the one standard deviation uncertainty of the average 94 profiles for each experiment. Approximate altitudes are shown on the right hand vertical axis. 

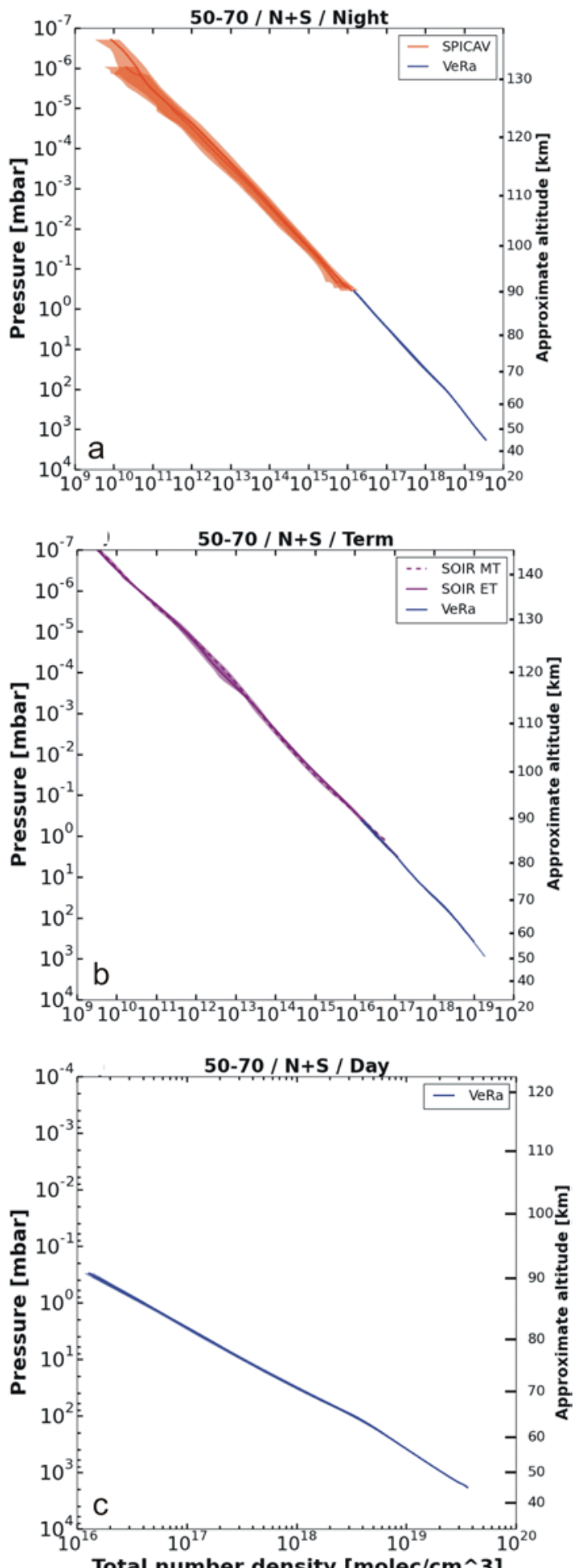

96 Figure 22: same as Figure 21 but for the latitude bin $50^{\circ}$ to $70^{\circ}$. Panel (a): night side, panel (b): terminator 97 zones, panel (c): day side. The colored areas mark the one standard deviation uncertainty of the average 98 profiles for each experiment. Approximate altitudes are shown on the right hand vertical axis. 

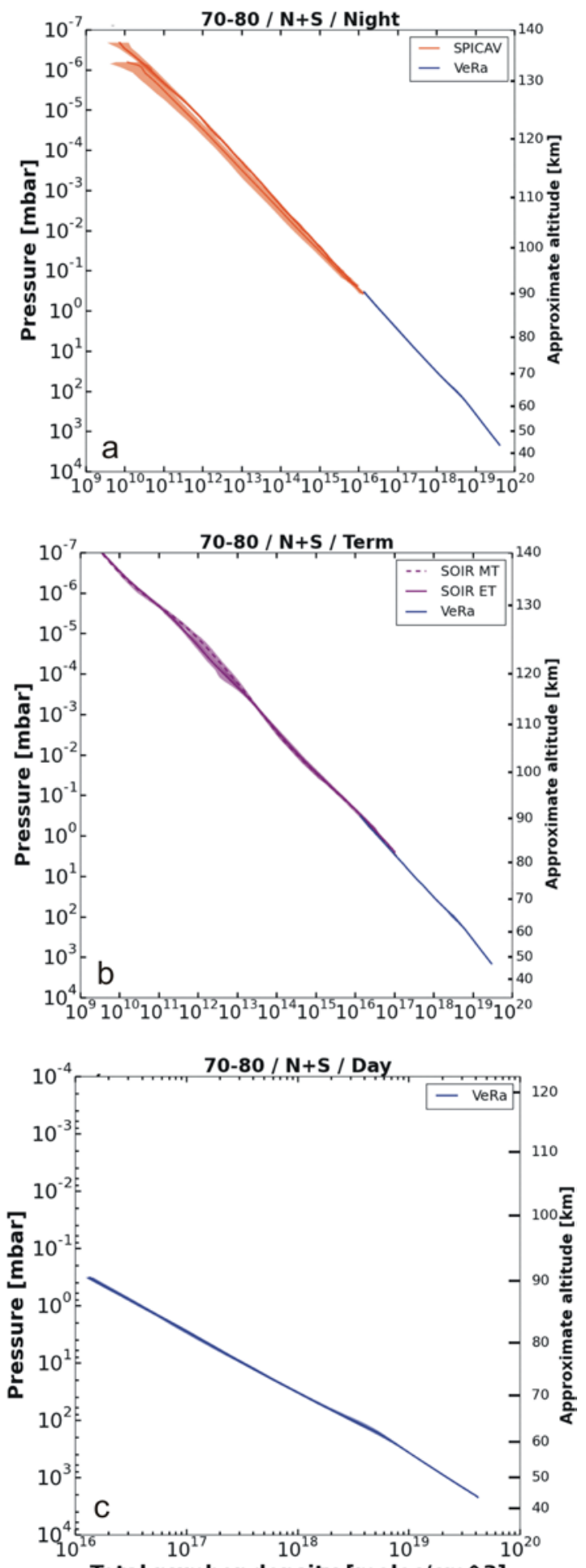

Total number density [molec/cm^3]

100 Figure 23: same as Figure 21 but for the latitude bin $70^{\circ}$ to $80^{\circ}$. Panel (a): night side, panel (b): terminator 101 zones, panel (c): day side. The colored areas mark the one standard deviation uncertainty of the average 102 profiles for each experiment. Approximate altitudes are shown on the right hand vertical axis. 

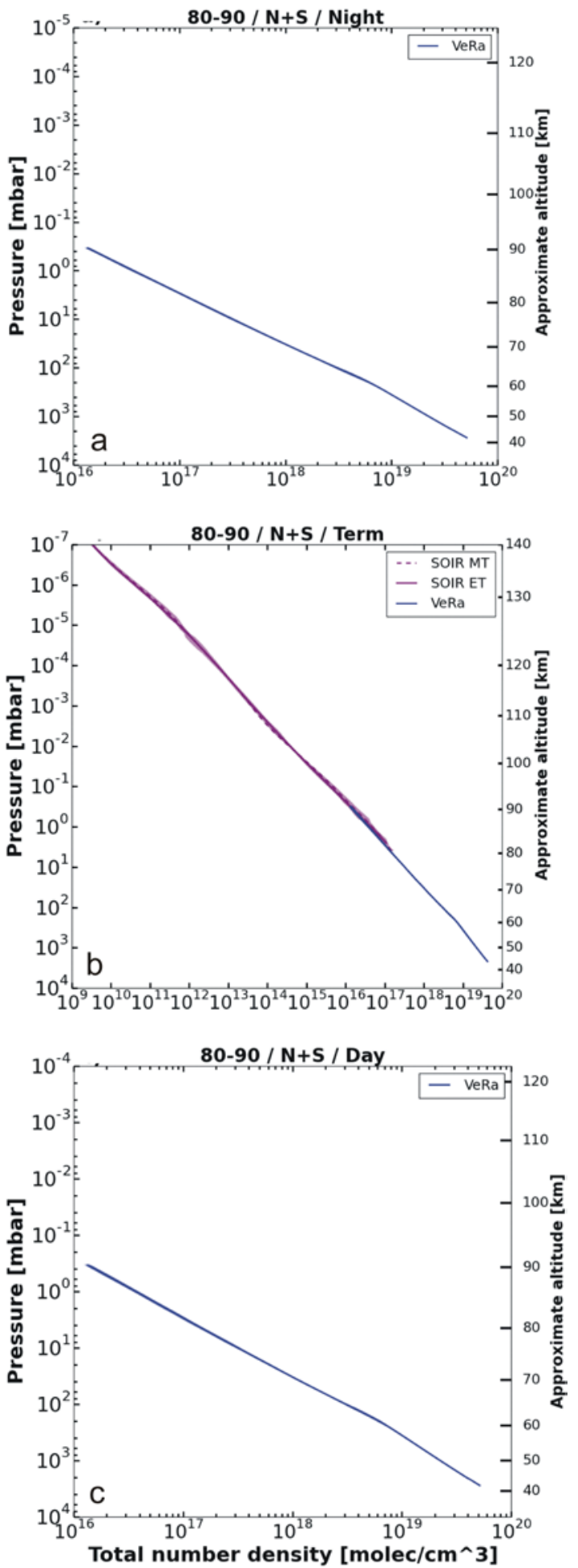

Figure 24: same as Figure 21 but for the latitude bin $80^{\circ}$ to $90^{\circ}$. Panel (a): night side, panel (b): terminator zones, panel (c): day side. The colored areas mark the one standard deviation uncertainty of the average profiles for each experiment. Approximate altitudes are shown on the right hand vertical axis. 

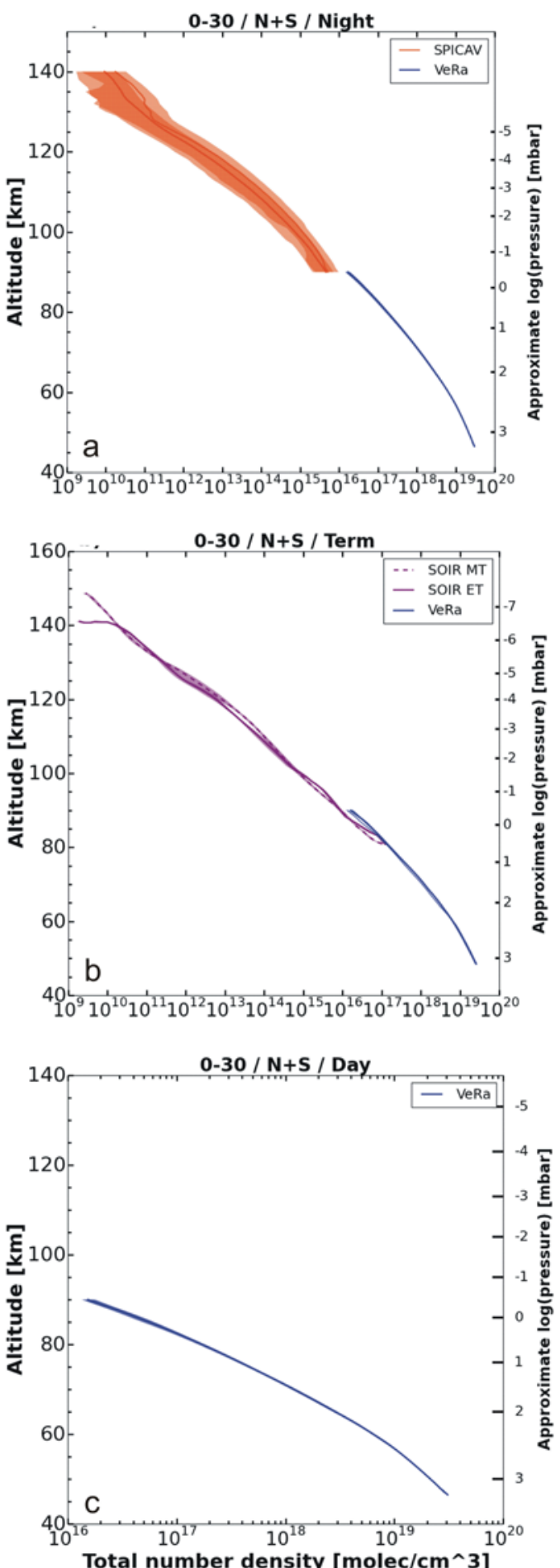

108 Figure 25: Comparison of atmospheric mean total density profiles from SOIR, SPICAV and VeRa as a 109 function of altitude for the near-equatorial latitudes $\left(0^{\circ}\right.$ to $\left.30^{\circ}\right)$. Panel (a): night side, panel (b) terminator 110 zone, panel (c) day side. The colored areas mark the uncertainty of the respective average profile as one 111 standard deviation. Approximate pressure is shown at the right hand side vertical axis. Night side SPICAV 112 profiles are shown separately for the Northern and Southern hemispheres. 

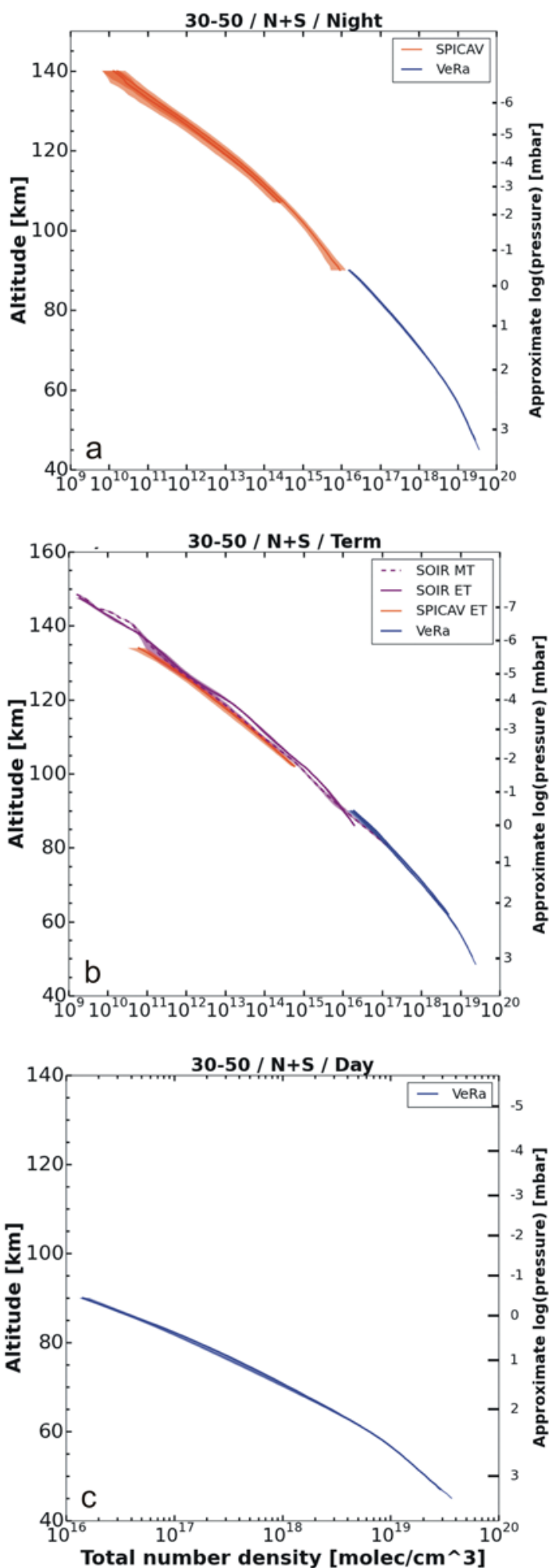

Total number density $\left[\mathrm{molec} / \mathrm{cm}^{\wedge} 3\right]$

114 Figure 26: same as Figure 25 but for the mid-latitudes $\left(30^{\circ}\right.$ to $\left.50^{\circ}\right)$. Panel (a): night side, panel (b) 115 terminator zone, panel (c) day side. 

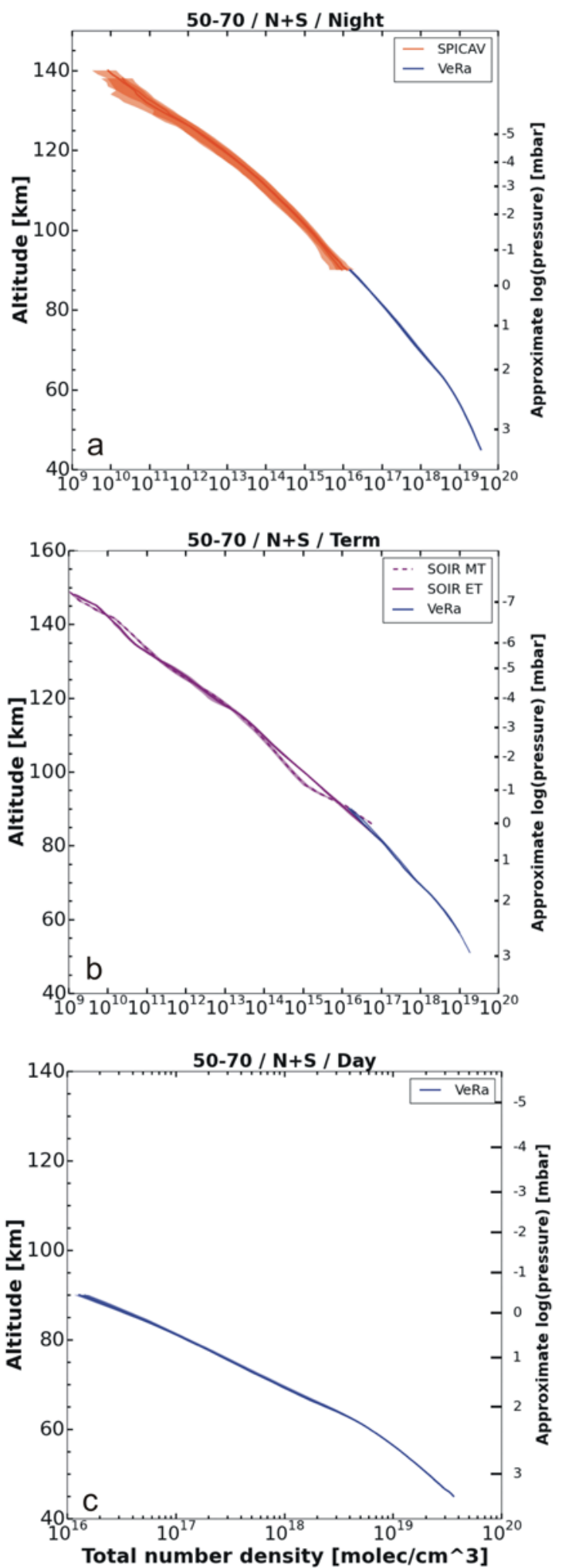

Total number density $\left[\mathrm{molec} / \mathrm{cm}^{\wedge} 3\right]$

117 Figure 27: same as Figure 26 but for the mid-latitudes $\left(50^{\circ}\right.$ to $\left.70^{\circ}\right)$. Panel (a): night side, panel (b) 118 terminator zone, panel (c) day side. 

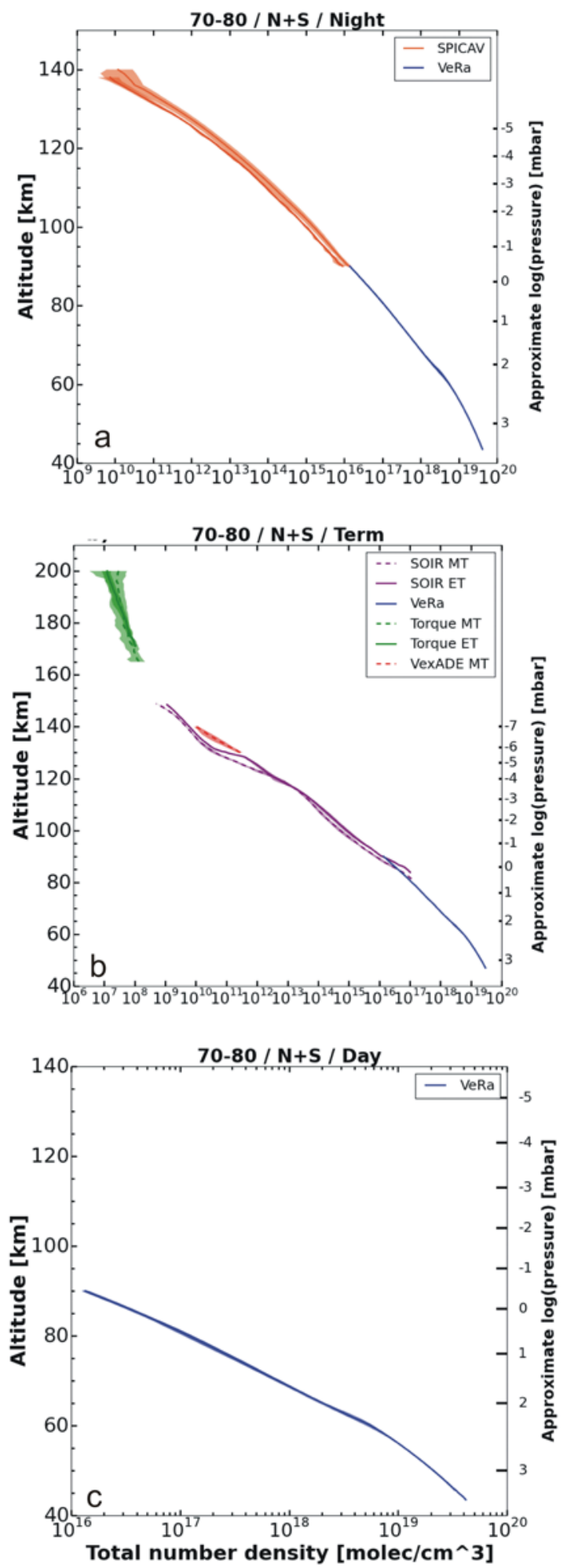

Figure 28: same as Figure 26 but for the high latitudes $\left(70^{\circ}\right.$ to $\left.80^{\circ}\right)$. Panel (a): night side, panel (b) terminator zone, panel (c) day side. 

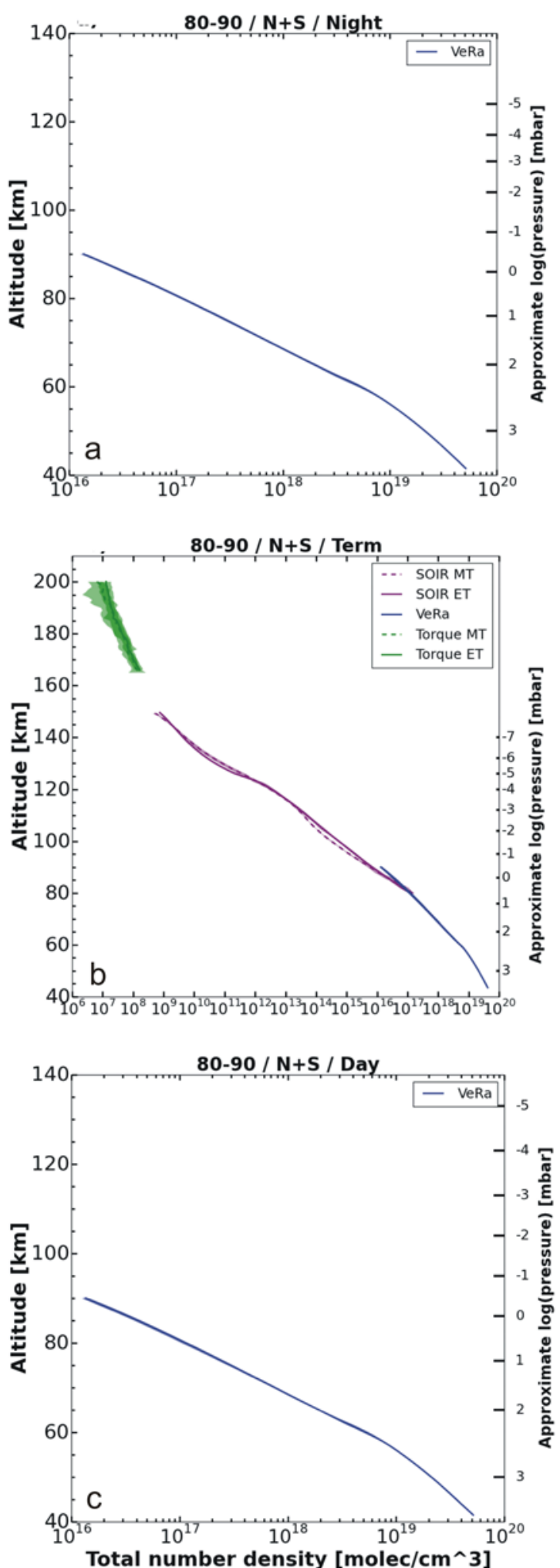

123 Figure 29: same as Figure 26 but for the polar latitudes $\left(80^{\circ}\right.$ to $\left.90^{\circ}\right)$. Panel (a): night side, panel (b) 124 terminator zone, panel (c) day side. 
126

127

128

129

130

131

132

133

134

135

136

137

138

139

140

141

142

143

144

145

146

147

148

149

150

151

152

153

154

155

\section{Comparison between Observations and Numerical Simulations}

It is proof of a good understanding of the thermal atmospheric structure if the observed physical and spectral properties of the atmosphere along with clouds, hazes and the insolation are reproduced by numerical simulations. Numerical models were developed based on observations by Venera, Pioneer Venus and Venus Express in order to compute the solar and thermal fluxes within the atmosphere and to determine the energy balance. The typical output products of these numerical models are temperature and neutral number density profiles (Crisp, 1986; 1989; Crisp \& Titov, 1997; Bullock \& Grinspoon, 2001; Eymet et al., 2009; Lee \& Richardson, 2011; Lee et al., 2012; Mendonca et al., 2015). Reviews of the radiative balance of the Venus atmosphere are in Titov et al. $(2007,2013)$. An important $a$ priori input parameter to the simulations is the opacity distribution function and a first-guess temperature profile, usually taken from the VIRA model. The opacities are computed from the cloud properties and structures, the gas composition of the atmosphere, and the spectral properties of the different gas constituents.

It would be worthwhile to compare the output products of the various models in order to assess their capabilities. It was decided not to do so because the various models are progressively evolving. Only key aspects of the on-going modeling efforts shall be described below. The computation of atmospheric opacities is a crucial part of the modeling of the radiative transfer. Gas opacities are derived from line-byline models which are based on spectroscopic databases such as HITRAN (Rothman et al., 2009, 2013) and HITEMP (Rothman et al., 2010) and on assumptions of profiles of the atmospheric composition, in particular profiles of $\mathrm{CO}_{2}, \mathrm{H}_{2} \mathrm{O}$ and $\mathrm{SO}_{2}$ which play an important role for the radiative transfer. The computation of the gas opacities requires assumptions on the line shapes and procedures in the line-byline models. The continuum is highly uncertain between the dominant absorption bands, and difficult to determine experimentally (Wordsworth et al., 2010; Snels et al., 2014).

The cloud opacity is computed from a cloud distribution model and from assumed cloud particle properties (Knollenberg \& Hunten, 1980; Zasova et al., 1999; 2007). These properties were determined from space observations mostly in equatorial regions. It is well known, however, that the cloud structure varies with latitude, with the vertical distribution (e.g. Ignatiev et al., 2009) and with the particle size (Wilson et al., 2008). The analysis of the VIRTIS-M data by Haus et al. $(2013 ; 2014)$ determined the cloud structure as a function of latitude. Work is currently on-going to improve the understanding of the cloud structure and their properties and characteristics ("Venus cloud structure" team supported by ISSI; Wilson et al. (2014)).

Venus Thermal Structure - Intercomparison of Venus Express and Ground Based Results 
The properties and the distribution of the so-called unknown UV absorber within the clouds are very important for the computation of the vertical profiles of the solar flux absorption. This distribution is based on the mode-1 particles (smallest mode in the cloud particle distribution) in the upper cloud deck in many models (Crisp, 1986; Lee and Richardson, 2011; Mendonca et al., 2015), except for the most recent one (Haus et al., 2015).

Different techniques were used to compute the thermal cooling rates and the solar heating rates based on these opacities and the vertical structure of the atmosphere. The various radiative transfer algorithms may yield differences in the derived profiles of radiative heating and cooling rates and may therefore influence the modeled temperature structure. Large day/night variations are possible above the clouds due to short radiative time scales. Non-LTE processes and EUV heating have to be considered in order to compute correctly the thermal balance above approximately $100 \mathrm{~km}$. The atmosphere is heated below $140 \mathrm{~km}$ by the absorption of solar radiation due to $\mathrm{CO}_{2}$ near-infrared bands ( $2.7 \mu \mathrm{m}, 4.7 \mu \mathrm{m}$ and 1-2 $\left.\mu \mathrm{m}\right)$. The EUV absorption by $\mathrm{CO}_{2}, \mathrm{O}$ and a number of minor species dominates above that altitude. Thermal cooling occurs via $\mathrm{CO}_{2}$ non-LTE transitions around $15 \mu \mathrm{m}$ which competes with the heating terms together with thermal conduction (above about $150 \mathrm{~km}$ ) to control the temperature. The modeling of these processes is quite complex, because it involves the non-LTE distribution of $\mathrm{CO}_{2}$ energetic states and their associated ro-vibrational transitions. This requires models which consider the theory properly which solve simultaneously the statistical equilibrium and radiative transfer equations, very time expensive computations for the currently most advanced GCMs. Parameterizations of the $15 \mu \mathrm{m}$-cooling and the NIR non-LTE heating based on results by Roldan et al. (2000) were already implemented into GCMs. The various authors, however, used different formulations (Brecht and Bougher; 2012; Gilli et al.; 2014). Bougher at al. (1986) used off-line simulated "look-up tables" for the solar heating rates and a parameterized scheme for the cooling which implements a line-by-line model of $\mathrm{CO}_{2} 15 \mu \mathrm{m}$ rates (taken from Roldan et al., 2000). Gilli et al. (2014) applied an analytical formula to reproduce the solar heating rates in those upper regions, and a complete but simplified non-LTE model for the $15 \mu \mathrm{m}$ cooling, as it was also developed for the Mars Climate Data Base (MCD) GCM (Gonzalez-Galindo et al., 2009; 2013). It is assumed that the net absorption depends mainly on the density of the atmosphere, and to a smaller degree on the solar zenith angle, thermal structure and atomic oxygen abundance. The EUV absorption is also parameterized assuming an efficiency of 20-22 \%. The variation of the UV solar flux with the solar cycle is also taken into account. 
One-dimensional radiative-convective equilibrium (RCE) procedures define the vertical temperature profile, e.g. for globally averaged conditions. Although Bullock \& Grinspoon (2001) could achieve an excellent agreement with VIRA, most other RCE models could not (e.g. Lee \& Richardson, 2011; Mendonca et al., 2015). The solar flux absorption, the cloud particle distribution and selected opacity parameters (Lebonnois et al.; 2015) as a function of altitude have a direct influence on the derivation of the temperature profile (e.g. Lee et al., 2012). Current GCM simulators indicate that both radiative and dynamical effects play a crucial role in the determination of the upper atmosphere thermal structure. The observed high variability of atmospheric quantities by the VEX instruments was not reflected in previous empirical models (e.g. VIRA and VTS3).

EUV absorption above 140 - $150 \mathrm{~km}$ altitude generates high temperatures above a cold layer around 125$130 \mathrm{~km}$ where the NIR heating is weak. A local maximum produced by solar absorption due to $\mathrm{CO}_{2} \mathrm{IR}$ bands during daytime is advected to the terminator below $125 \mathrm{~km}$ (Brecht and Bougher, 2012; Gilli et al., 2014). This S-shaped structure with minima and maxima at the terminator is also observed by SOIR (Mahieux et al., 2015a). The pressure levels and magnitudes of modeled and observed temperatures, however, do not always agree. A warm region at the night side resulting from the subsidence of the dayto-night circulation air is predicted at $110-115 \mathrm{~km}$ altitude and indeed observed by SPICAV (Piccialli et al., 2015) but at lower altitudes.

Mahieux et al. (2016) attempted to reproduce the thermal structure observed by SOIR at the terminator. They developed a one-dimensional conductive radiative model which considers the heating and cooling terms of the main Venus atmospheric species $\mathrm{CO}_{2}, \mathrm{~N}_{2}, \mathrm{O}, \mathrm{CO}, \mathrm{H}_{2} \mathrm{O}, \mathrm{HCl}$ and $\mathrm{SO}_{2}$ extending from $80 \mathrm{~km}$ to $180 \mathrm{~km}$ altitude. The modes 1 and 2 of the aerosols are considered in order to reproduce correctly the temperature profile in the mesosphere. The vertical number density profiles of the aerosols are in good agreement with the SOIR (Wilquet et al., 2009) and SPICAV-UV observations up to $100 \mathrm{~km}$. The aerosol profiles show constant values for both modes between 100 and $120 \mathrm{~km}$ which rapidly decrease at higher altitudes. The neutral number density is unfortunately lower than the detection sensitivity of both instruments, and thus cannot be confirmed by spacecraft measurements.

Several sources of uncertainties are investigated to improve the comparison between modeled and observed temperature profiles above the clouds: the ratio between $\mathrm{O}$ and $\mathrm{CO}_{2}$ and its role in the cooling rate, the parameterization implemented to simulate non-LTE radiative processes, potential heat sources 
above the cloud tops (including aerosols, upper haze layer, and unknown UV absorber), and tides, gravity waves or other sources (Zalucha et al., 2013; Gilli et al., 2016).

The cloud and haze particle distributionand the continuum gas opacity in the 3-7 microns spectral range for the extreme conditions in the deep atmosphere need to be sufficiently known in order to model the temperature profile. The latitudinal cloud distribution is also important to improve the understanding of the formation of the "cold collar" feature. The formulation of the non-LTE processes is still an approximation and a more accurate description is required for a GCM. Their implementation, however, considerably improved the knowledge of the energy budget in the upper atmosphere. The uncertainty of typical rate coefficients used in non-LTE simulations is still very large which is true for the uncertainty of the $\mathrm{O}-\mathrm{CO}_{2}$ collisional relaxation rate important for the cooling of the atmospheres of terrestrial planets in general.

The understanding of the 3-dimensional temperature structure and its variability requires a General Circulation Model which fully considers the dynamical interactions within the atmosphere. Significant progress has been achieved within the most recent Venus GCM models (Sugimoto et al., 2014a; 2014b; Ando et al., 2016; Lebonnois et al., 2016), but it is still on-going work.

\section{Discussion}

The Venus Express mission has considerably increased the knowledge of the Venus atmospheric structure above $\sim 40 \mathrm{~km}$ and provided enough new information above $100 \mathrm{~km}$ to trigger new ideas for the interpretation of the observations. Three kinds of occultation experiments were performed for the first time to provide temperature profiles over a wide range of altitudes from 40 to $170 \mathrm{~km}$. Considerable temperature variability is seen above $100 \mathrm{~km}$. Certain features appear to be systematically present, such as a succession of warm and cool layers. Models support the existence of such layers consistent with a large scale circulation, but they are still in the process of being improved.

Although there is general agreement between the various experiments which observed the vertical and latitudinal temperature structure of the Venus atmosphere, the differences between individual experiments are larger than the measurement errors. Especially above $100 \mathrm{~km}$ the temperature variation is large and the difference between the individual experiments seems to be higher. As mentioned before temperatures of the upper mesosphere are highly variable even on short time scales. Therefore the variation seen by the individual experiments may be reasonable considering that the thermosphere can respond rapidly to thermal forcing. 
245 The processing of the occultation data is based on the common assumption of a spherically symmetric 246 atmosphere - assuming that the atmospheric properties are the same in a given altitude region regardless 247 of location or local time. This assumption is certainly violated at the terminators or in the presence of clouds. Vertical profiles of cloud particle sizes obtained from the Venera entry probes and balloons show significant differences when compared with the Pioneer Large Probe observations. The particle size

250 distribution is constrained at the unit optical depth by the frequent observations of glory at four VMC wavelengths, but larger particles may exist in the deeper cloud layer. All VEx occultation experiments used the common atmospheric composition of $96.5 \% \mathrm{CO}_{2}, 3.5 \% \mathrm{~N}_{2}$ below $90 \mathrm{~km}$ when starting this ISSI study. The assumed mean molecular weight dependence on altitude may be different from the actual Venus atmosphere above $90 \mathrm{~km}$.

Radio occultation experiments can experience a multi-path interference dominantly above $75^{\circ}$ latitude at the first inversion layer at about $65 \mathrm{~km}$ altitude defined as the tropopause (Pätzold et al., 2007) implying an even cooler temperature inversion by an additional $15 \mathrm{~K}$ and a shorter thicknessthan previously thought.

One potential source of bias in the SPICAV stellar occultation data retrieval may be caused by the simplification of the radiative transfer complexity beyond the single scattering hypothesis. At present, only the forward scattering direction is considered by the retrieval model and the radiative transfer is approximated by a standard and simple Beer Lambert's law. The line-of-sight of the instrument becomes increasingly sensitive to contributions from scattering processes occurring in a narrow angle around the SPICAV field of view as the line of sight intersects denser and denser atmospheric layers. This has not

265 been quantified yet but may contribute to the lesser reliability in the lowest sounded parts of the atmosphere (below $100 \mathrm{~km}$ ).

267 One still unresolved mystery is the high day-to-day variability seen in the neutral number densities 268 observed by SOIR and SPICAV above $\sim 90 \mathrm{~km}$ altitude and by the drag and torque experiences at much 269 higher altitude; the density variability in each of these datasets is nearly two orders of magnitude. The 270 radio occultation density profiles do not show such a large variation in the region of overlap (75 - $90 \mathrm{~km})$. 271 One of the key assumptions in the data reductions of the occultation experiments is the constant 272 composition or well mixed atmosphere which is well maintained below $100 \mathrm{~km}$. There are evidences, 273 however, that the molecular composition might not be constant above $120 \mathrm{~km}$. SOIR experiment results 274 show a considerably varying homopause altitude between $\sim 120 \mathrm{~km}$ and $150 \mathrm{~km}$. SPICAV results see the 
275 homopause altitude between 119 and $138 \mathrm{~km}$ with temporal and spatial variability. The homopause

276 altitude has a clear dependence on the local solar time. It occurs at a higher altitude on the morning side 277 than on the evening side (Piccialli et al., 2015).

278 The mean molecular weight is needed wherever the hydrostatic equation is used, and changes in its value 279 due to change in composition at higher altitudes may become non-negligible. The assumption of 280 hydrostatic balance may no longer be valid if large horizontal density gradients above $120 \mathrm{~km}$ exist as 281 suggested by the drag experimentsand SPICAV and SOIR observations, and, if those create very turbulent large scale motions .

The Venus Express instrument data as well as the ground-based observations will definitely improve the current empirical models. Comparing VEX temperature profiles with VIRA model, there are small differences below $0.1 \mathrm{mbar}(75 \mathrm{~km})$, but there are large discrepancies above $0.1 \mathrm{mbar}(75 \mathrm{~km})$ at polar latitudes $\left(>65^{\circ}\right)$ (Tellmann et al., 2009). The new observations may allow the improvement of the empirical models (VTS3 and Keating et al. 1985) above $0.1 \mathrm{mbar}(100 \mathrm{~km})$. The spatial coverage is better above $90 \mathrm{~km}$, but still incomplete. Some experiments do provide sufficient global coverage and compare solar thermal tidal components with previous results. The focus of this inter-comparison, however, is on averaged temperature and density profiles. While the night side is very well covered by VEX instrument observations, the day side above 0.03 mbar $(100 \mathrm{~km})$ presents a region of ignorance with almost no observations in particular at high latitudes. GCMs must be used to predict the conditions of these high altitude day side regions where observations are lacking. The large number of experiments and

294 investigations that have contributed to the knowledge of the thermal and density structure of the Venus 295 atmosphere give now a consistent, coherent but still somewhat incomplete picture. Improved spatial coverage is necessary - both in latitude-longitude and at all local solar times - at all altitudes. The vertical

297 and horizontal resolutions are different for the various experiments. Distinguishing uncertainties from 298 variability is constrained because of the limited spatial and temporal coverage for a given 299 instrument/experiment. It is therefore very challenging to identify temporal variability when comparing 300 the results of various experiments.

301 Future missions must address in-situ observations by long lived aerial platforms and descent/ascent 302 probes and landers in order to verify remote sensing observations. 
303 The interpretation of SOIR and VIRTIS data requires the information on spectral line shapes. HITRAN is 304 here the more commonly used database and there has been some improvements recently (Rothman et 305 al., 2013).

306 


\section{Acknowledgements}

308 This work was performed by an International Team supported by the International Space Science Institute

309 (ISSI), Bern, Switzerland. It is a pleasure to acknowledge the support for our meetings and the on-line 310 support. The team members were also supported by the respective national funding agencies. A. Piccialli, 311 F. Montmessin, G. Gilli and S. Lebonnois acknowledge support from CNES, Paris; M.Pätzold and S. 312 Tellmann acknowledge support from the Bundesministerium für Wirtschaft, Berlin, via the Deutsches 313 Zentrum für Luft- und Raumfahrt (DLR), Bonn, from grant 500W1401; C. Wilson, J. Oschlisniok, P. Krause, 314 M. Herrmann and T. Widemann acknowledge support from the FP-7 project EUROVENUS of the European 315 Union; M. Sornig acknowledges support from Deutsche Forschungsgemeinschaft (DFG), Bonn, from grant 316 So1044/1-2. The research program was supported by the Belgian Federal Science Policy Office and the 317 European Space Agency (ESA, PRODEX program, contracts C 90268, 90113, and 17645). A.C. Vandaele, A. 318 Mahieux, V.Wilquet and S. Chamberlain acknowledge the support of the "Interuniversity Attraction 319 Poles" program financed by the Belgian government (Planet TOPERS). A. Mahieux thanks the FNRS for the 320 position of "chargé de recherche". The research leading to these results has received funding from the 321 European Union Seventh Framework Program (FP7/2007-2013) under grant agreement $n^{\circ} 606798$. A. 322 Migliorini and D. Grassi were supported by ASI. A. Piccialli acknowledges funding from the European 323 Union Seventh Framework Programme (FP7/2007-2013) under agreement No. 246556. S.S. Limaye 324 acknowledges support from NASA under grant NNX09AE85G.

325

326 


\section{References}

Ando, H., N. Sugimoto, M. Takagi, H. Kashimura, T. Imamura, Y. Matsuda, The puzzling Venusian polar atmospheric structure reproduced by a general circulation model, Nature Communications 7 , 10398 , doi $=\{10.1038 /$ ncomms10398 $\}, 2016$.

Arnold, G., Haus, R., Kappel, D., Piccioni, G., Drossart, P., 2012. VIRTIS/VEX observations of Venus: Overview of selected scientific results. 6(1), 063580 (Sep 24, 2012). doi:10.1117/1.JRS.6.063580, , 20 pp, http://dx.doi.org/10.1117/1.JRS.6.063580.

Bailey, J., Meadows, V.S., Chamberlain, S., Crisp, D., 2008a. The temperature of the Venus mesosphere from $\mathrm{O}_{2}\left(\mathrm{a} \Delta_{\mathrm{g}}\right)$ airglow observations. Icarus 187, 247-259.

Bailey, J., Chamberlain, S., Crisp, D., Meadows, V.S., 2008b. Near infrared imaging spectroscopy of Venus with the Anglo-Australian Telescope. Planet. Space Sci. 56, 1385-1390, doi:10.1016/j.pss.2008.03.006.

Bertaux, J.-L., et al., SPICAV on Venus Express: Three spectrometers to study the global structure and composition of the Venus atmosphere, Planet. Space Sci., 55 (2007), pp. 1673-1700, 2007.

Betz A. L., Johnson M. A., McLaren R. A., Sutton E. C., Heterodyne detection of $\mathrm{CO}_{2}$ emission lines and wind velocities in the atmosphere of Venus, Astrophysical Journal, 208:L141-L144,1976.

Bougher S. W., Dickinson R. E., Ridley E. C., Roble R. G., Nagy A. F., Cravens T. E., "Venus Mesosphere and Thermosphere. II: Global circulation, temperature, and density variations", Icarus 68, 286-312, 1986.

Brecht and Bougher, Dayside thermal structure of Venus' upper atmosphere characterized by a global model, J. Geophys. Res. Planets 117, E08004, 2012.

Bullock M. A. and Grinspoon D. H., The recent evolution of climate on Venus, Icarus 150, 19-37, 2001.

Carlson, R.W. and Anderson, M.S., 2011, Absorption properties of sulfuric acid in Venus' infrared spectral window region. EPSC Abstracts 6, 1171.

Carlson, R.W., and F.W. Taylor, 1993. The Galileo encounter with Venus: results from the near-infrared mapping spectrometer, Planetary and Space Science, Volume 41, Issue 7, July 1993, Pages 475-476

Clancy, R. T.; Muhleman, D. O., Long-term (1979-1990) changes in the thermal, dynamical, and compositional structure of the Venus mesosphere as inferred from microwave spectral line observations of C-120, C-130, and CO-18, Icarus (ISSN 0019-1035), vol. 89, Jan. 1991, p. 129146, http://dx.doi.org/10.1016/0019-1035(91)90093-9.

Clancy, R.T., Sandor, B.J., Moriarty-Schieven, G.H., 2003. Observational definition of the Venus mesopause: Vertical structure, diurnal variation, and temporal instability. Icarus 161, 1-16.

Clancy, R.T., Sandor, B.J., Moriarty-Schieven, G.H., 2008. Venus upper atmospheric CO, temperature, and winds across the afternoon/evening terminator from June 2007 JCMT sub-millimeter line observations. Planet. Space Sci. 56, 1344-1354.

Clancy, R. T., and B. J. Sandor, Circulation of the Venus upper atmosphere: Day vs. night, VEXAG Workshop, August, Chantilly, VA, 2011.

Clancy, R.T., B. J. Sandor, J., G. Moriarty-Schieven, 2012a. Thermal structure and CO distribution for the Venus mesosphere/lower thermosphere: 2001-2009 inferior conjunction sub-millimeter CO 
absorption line observations, Icarus, Volume 217, Issue 2, p. 779-793. 10.1016/j.icarus.2011.05.032

Connes, P., Noxon, J.F., Traub, W.A., Carleton, N.P., 1979. $\mathrm{O}_{2}{ }^{1} \Delta$ emission in the day and night airglow of Venus. Astrophys. J. 233, L29-L32.

Crisp D., "Radiative forcing of the Venus mesosphere. I - Solar fluxes and heating rates", Icarus 67, 484514, 1986.

Crisp D., "Radiative forcing of the Venus mesosphere. II - Thermal fluxes, cooling rates, and radiative equilibrium temperatures", Icarus 77, 391-413, 1989.

Crisp, D., Meadows, V.S., Bezard, B., de Bergh, C., Maillard, J.P., Mills, F.P., 1996. Ground-based nearinfrared observations of the Venus night side: 1.27- $\mu \mathrm{m} \mathrm{O}_{2}\left(\mathrm{a}^{1} \Delta \mathrm{g}\right)$ airglow from the upper atmosphere. J. Geophys. Res. 101, 4577-4594.

Crisp D., Titov D. V., "The thermal balance of the Venus atmosphere", in "Venus II, geology, geophysics, atmosphere, and solar wind environment", 353-384, S. W. Bougher, D. M. Hunten and R. J. Phillips Eds., Univ. of Arizona Press, 1997.

Croom, C.A., R.H. Tolson, 1994. Venusian atmospheric and Magellan properties from attitude control data M.S. Thesis George Washington Univ., Hampton, VA, NASA-CR-4619, NAS 1.26:4619.

Damiani, S., Lauer, M., Müller, M. (2012), Monitoring of aerodynamic pressures for Venus Express in the upper atmosphere during drag experiments based on telemetry. Paper presented at the 23rd International Symposium on Space Flight Dynamics. http://issfd.org/ISSFD_2012/ISSFD23_GC_4.pdf.

Deming D., Espenak F., Jennings D., Kostiuk T., Mumma M., Zipoy D., Modeling of the 10-micron natural laser emission from the mesospheres of Mars and Venus, Icarus, 55, 347-355, 1983.

Encrenaz, T., T. K. Greathouse, M. J. Richter, J. Lacy, T. Widemann, B. Bézard, T. Fouchet, C. deWitt and S. K. Atreya, HDO and SO2 thermal mapping on Venus, II. The SO2 spatial distribution above and within the clouds, Astron. Astrophys., Vol. 53, 2013.

Eymet V., Fournier R., Dufresne J.-L., Lebonnois S., Hourdin F., Bullock M. A., "Net-exchange parameterization of the thermal infrared radiative transfer in Venus' atmosphere", J. Geophys. Res. Planets 114, E11008, 2009.

Fjeldbo, G., A.J. Kliore, V.R. Eshleman, 1971, The neutral atmosphere of Venus as studied with the Mariner $\mathrm{V}$ radio occultation experiments. Astron. J., 76 (1971), pp. 123-140. http://dx.doi.org/10.1086/111096.

Fritts, D. C., L. Wang, and R. H. Tolson, Mean and gravity wave structures and variability in the Mars upper atmosphere inferred from Mars Global Surveyor and Mars Odyssey aerobraking densities, J. Geophys. Res., 111, A12304, doi:10.1029/2006JA011897, 2006.

Garate-Lopez, I., García Muñoz, A., Hueso, R., Sánchez-Lavega, A., 2015, Instantaneous three-dimensional thermal structure of the South Polar Vortex of Venus, Icarus, 245, 16-31, doi:10.1016/j.icarus.2014.09.030

Gilli G., Lebonnois S., Salmi L., Gonzalez-Galindo F., Lopez-Valverde M. A., Eymet V., Forget F., "Thermal structure of Venus upper atmosphere by a ground-to-thermosphere GCM: a preliminary study", EPSC, 2014. 
Gilli G,. Lopez-Valverde M. A., Peralta J., Bougher S., Brecht S., Drossart P., Piccioni G., « Carbon monoxide and temperature in the upper atmosphere of Venus from VIRTIS/Venus Express non-LTE limb measurements ", Icarus, 248, p. 478-498, 2015

Gilli, G., S. Lebonnois, F. Lott, F. Lefèvre, IMpact of a non-orographic gravity wave parameterization in the Venus atmosphere by the LMD Venus GCM, in Venus Venus International Conference (abstract), Oxford, 2016.

Gonzalez-Galindo F., Forget F., Lopez-Valverde M. A., Angelats i Coll M., Millour E., "A ground-toexosphere Martian general circulation model: 1 . Seasonal, diurnal, and solar cycle variation of thermospheric temperature", J. Geophys. Res. Planets 114, 2009.

Gonzalez-Galindo F., Chaufray J-Y., Lopez-Valverde M. A., Gilli G., Forget F., Leblanc F., Modolo R., Hess S., Yagi M., "Three-dimensional Martian ionosphere model: I. The photochemical ionosphere below 180 km", J. Geophys. Res. Planets 118, 2013.

Grassi, D., P. Drossart, G. Piccioni, N. I. Ignatiev, L. V. Zasova, A. Adriani, M. L. Moriconi, P. G. J. Irwin, A. Negrão, and A. Migliorini, 2008. Retrieval of air temperature profiles in the Venusian mesosphere from VIRTIS-M data: Description and validation of algorithms. J. Geophys. Res. 113, E00B09. doi: 10.1029/2008JE003075.

Grassi, D., R. Politi, N. I. Ignatiev, C. Plainaki, S. Lebonnois, P. Wolkenberg, L. Montabone , A. Migliorini, G. Piccioni, and P. Drossart, 2014. The Venus nighttime atmosphere as observed by the VIRTIS-M instrument. Average fields from the complete infrared data set, J. Geophys. Res. Planets, 119, 837-849, doi:10.1002/2013JE004586.

Gubenko, V. N., V. E. Andreev, and A. G. Pavelyev (2008), Detection of layering in the upper cloud layer of Venus northern polar atmosphere observed from radio occultation data, J. Geophys. Res., 113, E03001, doi:10.1029/2007JE002940.

Haus, R.,D. Kappel, D., G. Arnold, G., 2013, Self-consistent retrieval of temperature profiles and cloud structure in the northern hemisphere of Venus using VIRTIS/VEX and PMV/VENERA-15 radiation measurements, Planetary and Space Science, Volume 89,. 77-101. http://dx.doi.org/10.1016/j.pss.2013.09.020.

Haus, R., Kappel, D., Arnold, G., 2014. 2014, Atmospheric thermal structure and cloud features in the southern hemisphere of Venus as retrieved from VIRTIS/VEX radiation measurements, Icarus, Volume 232, p. 232-248, Icarus, Volume 232, p. 232-248. 10.1016/j.icarus.2014.01.020.

Haus, R.,D. Kappel, D., G. Arnold, G., Radiative heating and cooling in the middle and lower atmosphere of Venus and responses to atmospheric and spectroscopic parameter variations, Plan. Space Sci. 117, 262-294, 2015.

Häusler, B. et al., 2006. Radio Science investigations by VeRa onboard the Venus Express spacecraft. Planet. Space Sci. 54, 1315-1335.

Häusler, B. et al., 2007. Venus Atmospheric, Ionospheric, Surface and Interplanetary Radio-Wave Propagation Studies with the VeRa Radio-Science Experiment. ESA Scientific Publication ESASP SP-1295, pp. 1-30. <http://sci.esa.int/sciencee/www/object/index.cfm?fobjectid=41535>.

Hedin, A. E., H. B. Niemann, W. T. Kasprzak, and A. Seiff (1983), Global empirical model of the Venus thermosphere, J. Geophys. Res.,88, 73-83. 
Hinson, D. P.; Jenkins, J. M, 1995. Magellan radio occultation measurements of atmospheric waves on Venus, Icarus, vol. 114, no. 2, p. 310-327.

Howard, H.T., G.L. Tyler, G. Fjeldbo, A.J. Kliore, G.S. Levy, D.L. Brunn, R. Dickinson, R.E. Edelson, W.L. Martin, R.B. Postal, B. Seidel, T.T. Sesplaukis, D.L. Shirley, C.T. Stelzried, D.N. Sweetnam, A.I. Zygielbaum, P.B. Esposito, J.D. Anderson, I.I. Shapiro, R.D. Reasenberg, Venus: Mass, Gravity Field, Atmosphere, and lonosphere as Measured by the Mariner 10 Dual-Frequency Radio System, Science 183, 1297-1301, 1974.

Ignatiev N. I., Titov D. V., Piccioni G., Drossart P., Markiewicz W. J., Cottini V., Roatsch Th., Almeida M., Manoel N., "Altimetry of the Venus cloud tops from the Venus Express observations", J. Geophys. Res. Planets 114, E00B43, 2009.

Jenkins, J.M., P.G. Steffes, Results from 13-cm absorptivity and $\mathrm{H} 2 \mathrm{SO} 4$ abundance profiles from the Season 10 (1986) Pioneer Venus Orbiter radio occultation experiment, Icarus 90, 129-138, doi = 10.1016/0019-1035(91)90075-5, 1991.

Jenkins, J.M., P. G. Steffes, D. P. Hinson, J. D. Twicken, G.L.Tyler, 1994, Radio Occultation Studies of the Venus Atmosphere with the Magellan Spacecraft: 2. Results from the October 1991 Experiments, Icarus, Volume 110, Issue 1, July 1994, Pages 79-94, doi:10.1006/icar.1994.1108

Kappel, D., Arnold, G., Haus, R., Piccioni, G., Drossart, P., 2012. Refinements in the data analysis of VIRTISM-IR Venus night side spectra. Adv. Space Res. 50(2) 228-255, http://dx.doi.org/10.1016/j.asr.2012.03.029.

Keating, G.M. \& Hsu, C.H. (1993), The Venus atmospheric response to solar cycle variations, Geophys. Res. Lett., vol 20 (23), pp 2751-2754.

Keating GM, Tolson RH, Hinson EW, 1979. Venus thermosphere and exosphere: first satellite drag measurements of an extraterrestrial atmosphere, Science. 1979 Feb 23;203(4382):772-774.

Keating, G.M., J. Y. Nicholson III, L. R. Lake, 1980. Venus upper atmosphere structure, J. Geophys. Res., Vol. 85, Issue A13, 7941-7956. DOI: 10.1029/JA085iA13p07941

Keating, G.W., J.L. Bertaux, S.W. Bougher, R.E. Dickinson, T.E. Cravens, A.F. Nagy, A.E. Hedin, V.A. Krasnopolsky, J.Y. Nicholson III, L.J. Paxton, U. von Zahn, Models of Venus neutral upper atmosphere: Structure and composition, Advances in Space Research, Volume 5, Issue 11, 1985, Pages 117-171

Kilore, A.J., 1985. Recent results on the Venus atmosphere from pioneer Venus radio occultations, Icarus, Volume 5, Issue 9, 1985, Pages 41-49. doi:10.1016/0273-1177(85)90269-8.

Kliore, A.J., I.R. Patel, A.F. Nagy, T.E. Cravens, and T.I. Gombosi, Initial observations of the nightside ionosphere of Venus from Pioneer Venus Orbiter radio occultations, Science 205, 99-102, 1979.

Kliore, A. J., V.I. Moroz, G.M. Keating, The Venus International Reference Atmosphere.. A. J. Kliore, V. I. Moroz, G. M. Keating (Editors), Adv. Space Res., Vol. 5, No. 11, 8+305 pp. (1985). ISBN 0-08034631-6.

Knollenberg R. G., Hunten D. M., "The microphysics of the clouds of Venus: Results of the Pioneer Venus particle size spectrometer experiments", J. Geophys. Res. A 85, 8039-8058, 1980.

Kostiuk, T., and M. J. Mumma (1983). Remote-Sensing by IR-Heterodyne Spectroscopy. Applied Optics 22, 2644-2654. 
Krause, P., M. Sornig, C. Wischnewski, T. Stangier, M. Herrmann, G. Sonnabend, T. Kostiuk, T. Livengood, Long-term Variation in Temperature and Dynamic in Venus Upper Atmosphere from groundbased Infrared Heterodyne Spectroscopy, European Planetary Science Congress 2014, EPSC Abstracts, Vol. 9, id. EPSC2014-287, 2014.

Kostiuk, T., T. A. Livengood, G. Sonnabend, K. E. Fast, T. Hewagama, K. Murakawa, A. T. Tokunaga, J. Annen, D. Buhl, F. Schmülling, D. Luz, O. Witasse (2006). Stratospheric zonal winds on Titan at the time of Huygens decent. J. Geophys. Res., 111, E07S03, doi:10.1029/2005JE002630.

Krasnopolsky, V.A., 2010. Venus night airglow: Ground-based detection of $\mathrm{OH}$, observations of $\mathrm{O}_{2}$ emissions, and photochemical model, Icarus, 207, 17-27, doi:10.1016/j.icarus.2009.10.019.

Lebonnois S., Eymet V., Lee C., Vatant d'Ollone J., "Analysis of the radiative budget of Venus atmosphere based on infrared Net Exchange Rate formalism", J. Geophys. Res. 120, 1186-1200, 2015.

Lebonnois, S., N. Sugimoto, G. Gilli, Wave analysis in the atmosphere of Venus below 100-km altitude, simulated by the LMD Venus GCM, Icarus 278, 38-51, 2016.Lee C., Richardson M. I., "A Discrete Ordinate, Multiple Scattering, Radiative Transfer Model of the Venus Atmosphere from 0.1 to 260 ॠ", J. Atm. Sci. 68, 1323-1339, 2011.

Lee Y. J., Titov D. V., Tellmann S., Piccialli A., Ignatiev N., Pätzold M., Häusler B., Piccioni G., Drossart P., "Vertical structure of the Venus cloud top from the VeRa and VIRTIS observations onboard Venus Express", Icarus 217, 599-609, 2012.

Lellouch, E., Goldstein, J.J., Rosenqvist, J., Bougher, S.W., Paubert, G., 1994. Global circulation, thermal structure, and carbon monoxide distribution in Venus' mesosphere in 1991. Icarus 110, 315339.

Lellouch, E., and Witasse, O., A coordinated campaign of Venus ground-based observations and Venus Express measurements, Planetary and Space Science 56 1317-1319, 2008

Linkin, V.M. et al. (1986), Thermal Structure in the Venus Middle Cloud Layer, Soviet Astronomy Letters, vol. 12, Jan.-Feb. 1986, p. 15-17. Translation Pisma v Astronomicheskii Zhurnal, vol. 12, Jan. 1986, p. 36-40.

Linkin, V.M., J. Blamont, S.I. Devyatkin, S.P. Ignatova, V.V. Kerzhanovich, A.N. Lipatov, K. Malik, B.I. Stadnyk, Ya. V. Sanotskii, P.G. Stolyarchuk, A.V. Terterashivili, 1987. Thermal structure of the atmosphere of Venus from the results of measurements taken by landing vehicle VeGa-2, Kosmicheskie Issledovania, Vol. 25, No. 5, pp. 659-672, September-October, 1987.

Lopez-Valverde M. A., Sonnabend G., Sornig M., Modelling the atmospheric CO2 10micron laser emission in Mars and Venus at high spectral resolution, Planetary and Space Science, 59, 999-1009, 2011.

Mahieux, A., Berkenbosch, S., Clairquin, R., Fussen, D., Mateshvili, N., Neefs, E., Nevejans, D., Ristic, B., Vandaele, A.C., Wilquet, V., Belyaev, D., Fedorova, A., Korablev, O., Villard, E., Montmessin, F., Bertaux, J.L. In-flight performance and calibration of SPICAV/SOIR on-board Venus Express. Applied Optics 47, 2252-2265, 2008

Mahieux, A., Wilquet, V., Drummond, R., Belyaev, D., Fedorova, A., Vandaele, A.C. A New Method for Determining the transfer function of an Acousto Optical Tunable Filter. Optics Express 17, 2005-2014, 2009

Mahieux, A., A.-C. Vandaele, E. Neefs, S. Robert, V. Wilquet, R. Drummond, A. Federova, J.-L. Bertaux, Densities and temperatures in the Venus mesosphere and lower thermosphere retrieved from 
SOIR on board Venus Express: Retrieval technique, JGR 115, Issue E14, E12014,doi=10.1029/2010JE003589, 2010.

Mahieux, A., Vandaele, A.C., Robert, S., Wilquet, V., Drummond, R., Montmessin, F., Bertaux, J.L. Densities and temperatures in the Venus mesosphere and lower thermosphere retrieved from SOIR on board Venus Express: Carbon dioxide measurements at the Venus terminator. J. Geophys. Res. 117, doi:10.1029/2012JE004058, 2012

Mahieux, A., Vandaele, A.C., Bougher, S.W., Yelle, R.V., Drummond, R., Robert, S., Wilquet, V., Piccialli, A., Montmessin, F., Tellmann, S., Pätzold, M., Häusler, B., Bertaux, J.L. Update of the Venus density and temperature profiles at high altitude measured by SOIR on board Venus Express. Planet. Space Sci. 113-114, 309-320, 2015a

Mahieux A., Vandaele A. C., Robert S., Wilquet V., Drummond R., Lopez-Valverde M. A., Lopez-Puertas M., Funke B., Bertaux J.-L., Rotational temperatures of Venus upper atmosphere as measured by SOIR on board Venus Express, Planet. \& Space Sci., Vol 113, 309-320, 2015b.

Mahieux A., Vandaele A. C., Wilquet V., Erwin J. T., Yelle R. V., A 1-D radiative transfer model of the Venus mesosphere and thermosphere: Model description and comparison with SOIR/VEx, Icarus, in preparation, 2016

Mariner Stanford Group, Venus: Ionosphere and Atmosphere as Measured by Dual-Frequency Radio Occultation of Mariner V, Science 158, 1678-1683, 1967.

Mendonca J. M., Read P. L., Wilson C. F., Lee C., "A new fast and flexible radiatif transfer method for Venus general circulation models", Planet. \& Space Sci., Vol. 105, pp. 80-93, 2015.

Migliorini, A. D. Grassi, L. Montabone, S. Lebonnois, P. Drossart, G.Piccioni, Investigation of air temperature on the night side of Venus derived from VIRTIS-H on board Venus-Express, Icarus, Volume 217, Issue 2, p. 640-647. doi:10.1016/j.icarus.2011.07.013, 2012.

Montmessin, F., Quémerais, E., Bertaux, J.L., Korablev, O., Rannou, P., Lebonnois, S., 2006. Stellar occultations at UV wavelengths by the SPICAM instrument: retrieval and analysis of Martian haze profiles. J. Geophys. Res. (Planets) 111, 9, E09S09, doi : 10.1029/2005JE002662.

Montmessin, F.; Bertaux, J.-L.; Lefèvre, F.; Marcq, E.; Belyaev, D.; Gérard, J.-C.; Korablev, O.; Fedorova, A.; Sarago, V.; Vandaele, A. C., 2011, A layer of ozone detected in the night side upper atmosphere of Venus, Icarus, Volume 216, Issue 1, p. 82-85, doi: 10.1016/j.icarus.2011.08.010

Moroz, V.I., 1981, The atmosphere of Venus, Space Science Reviews, 1981, Volume 29, Issue 1, pp 3-127.

Moroz V. I., Spankuch D., Linkin V. M., Dohler W., Matsygorin I. A. et al. Venus spacecraft infrared spectra. Applied Optics, 25, No. 10, 1986

Moroz, V.I., and L.V. Zasova, 1997. VIRA-2: a review of inputs for updating the Venus International Reference Atmosphere, Adv. Space Res., Vol. 19, No. 8, pp. 1191-1201.

Muhleman, D.O., Orton, G.S., Berge, G.L., 1979. A model of the Venus atmosphere from radio, radar, and occultation observations. Astrophys. J. 234, 733-745.

Müller-Wodarg, I. C. F., J. M. Forbes \& G. M. Keating, 2006. The thermosphere of Venus and its exploration by a Venus Express Accelerometer Experiment. Planet. \& Sp. Sci. , 54, 1415-1424.

Müller-Wodarg, I., S. Bruinsma, J.-C. Marty, and H. Svedhem, 2016. In situ observations of waves in Venus' polar lower thermosphere with Venus Express aerobraking, Nature Physics, DOI: 10.1038/nphys3733 
Nevejans, D., Neefs, E., Van Ransbeeck, E., Berkenbosch, S., Clairquin, R., De Vos, L., Moelans, W., Glorieux, S., Baeke, A., Korablev, O., Vinogradov, I., Kalinnikov, Y., Bach, B., Dubois, J.P., Villard, E. Compact high-resolution space-borne echelle grating spectrometer with AOTF based on order sorting for the infrared domain from 2.2 to 4.3 micrometer. Applied Optics 45, 5191-5206, 2006

Oertel, D., D. Spankuch, H. Jahn, H. Becker-Ross, W. Stadthaus, J. Nopirakowski, W. Dohler, K. Schafer, J. Guldner, R. Dubois, V.L. Moroz, V/M/ Linkin, V.V. Kerzhanovich, I.A. Matsygorin, A.N. Lipatov, A.A. Shurupov, L.V. Zasova, E.A. Ustinov, Infrared spectrometry from Venera-15 and Venera16, Adv. Space Res., 5, 1985.

Oertel, D., V.I. Moroz, D. Spankuch, V.M. Linkin, et al., Infrared spectrometry from Venera-15 and Venera16, Adv. Space Res., 5, 1987

Oschlisniok, J., B. Häusler, M. Pätzold, G.L. Tyler, M.K. Bird, S. Tellmann, S. emus, and T. Andert (2012). Microwave absorptivity by sulfuric acid in the Venus atmosphere: First results from the Venus Express Radio Science experiment VeRa, Icarus, 221, 940 - 948.

Ohtsuki, S., Iwagami, N., Sagawa, H., Ueno, M., Kasabac, Y., Imamura, T., Nishihara, E., 2008. Imaging spectroscopy of the Venus 1.27- $\mu \mathrm{m}, \mathrm{O}_{2}$ airglow with ground-based telescopes. Adv. Space Res. 41, 1375-1380, 2008.

Quémerais, E., Bertaux, J.L., Korablev, O., Dimarellis, E., Cot, C., Sandel, B.R., Fussen, D., 2006. Stellar occultations observed by SPICAM on Mars Express. Journal of Geophysical Research (Planets) $111,9$.

Palmer, K.F. and Williams, D., 1975. Optical constants of sulphuric acid: Application to the clouds of Venus. Appl. Opt. 14(1), 208-219, http://dx.doi.org/10.1364/AO.14.000208.Pätzold, M. et al. (2007). The structure of Venus/'middle atmosphere and ionosphere, Nature 450 (7170), 657-660.

Pätzold, M., B. Häusler, M.K. Bird, S. Tellmann, R. Mattei, S.W. Asmar, V. Dehant, W. Eidel, T. Imamura, R.A. Simpson, G.L. Tyler, (2007). The structure of Venus/'middle atmosphere and ionosphere, Nature 450 (7170), 657-660.

Pere, Ch., Tanga, P., Widemann, Th., Bendjoya, Ph., Bendjoya, P., Multilayer modeling of the aureole photometry during the Venus transit: comparison between SDO/HMI and VEx/SOIR data, 2016arXiv160808544P, 2016.

Persson, M., Venus Thermosphere Densities as Revealed by Venus Express Torque and Accelerometer Data, 2015. Master's thesis submitted to Luleå University of Technology, http://pure.Itu.se/portal/files/104159817/LTU-EX-2015-104154994.pdf.

Piccialli A., Montmessin F., Belyaev D., Mahieux A., Fedorova A., Marcq E., Bertaux J.-L., Tellmann S., Vandaele A. C., Korablev O., "Thermal structure of Venus night side upper atmosphere measured by stellar occultations with SPICAV/Venus Express", Planet. \& Space Sci., In press, 2015.

Piccioni, G., et al. (2007). VIRTIS (Visible and Infrared Thermal Imaging Spectrometer) for Venus Express, ESA-SP 1295.

Piccioni, G., Zasova, L., Migliorini, A., Drossart, P., Shakun, A., Garcia Munoz, A., Mills, F.P., CardesinMoinelo, A., 2009. Near-IR oxygen nightglow observed by VIRTIS in the Venus upper atmosphere. J. Geophys. Res. 114. E00B38. 
613

614

615

616

617

618

619

620

621

622

623

624

625

626

627

628

629

630

631

632

633

634

635

636

637

638

639

640

641

642

643

644

645

646

647

648

649

650

651

652

653

Pollack, J.B., Dalton, J.B., Grinspoon, D., Wattson, R.B., Freedman, R. et al., 1993. Near-infrared light from Venus' night side: A spectroscopic analysis. Icarus 103(1), 1-42, http://dx.doi.org/10.1006/icar.1993.1055.

Rengel, M., P. Hartogh, C. Jarchow. Mesospheric vertical thermal structure and winds on Venus rom HHSMT CO spectral-line Observations, Planet. Space Sci 56, 1368-1384, 2008a

Rengel, M., P. Hartogh, and C. Jarchow, HHSMT observations of the Venusian mesospheric temperature, winds, and CO abundance around the MESSENGER flyby, Planet. Space Sci. 56, 1688-1695, 2008b.

Rodgers, C.D. Inverse methods for atmospheric sounding: Theory and practice, University of Oxford, 2000.

Roldan C. , Lopez-Valverde M. A., Lopez-Puertas M., Edwards D. P., "Non-LTE Infrared Emissions of CO2 in the Atmosphere of Venus", Icarus 147, 11-25, 2000.

Roos-Serote, M., P. Drossart,Th. Encrenaz, TH. Encrenaz, E. Lellouch, R.W. Carlson, K.H. Baines, F.W. Taylor, and S.B. Calcutt, 1995, The thermal structure and dynamics of the atmosphere of Venus between 70 and $90 \mathrm{~km}$ from the Gaileo-NIMS spectra, Icarus, 114, 300-309.

Rosenblatt, P., S.L. Bruinsma, I.C.F. Mueller-Wodarg, B. Haeussler, H. Svedhem, J.C. Marty (2011) First ever in situ observations of Venus' polar upper atmosphere density using the tracking data of the Venus Express Atmospheric Drag Experiment (VExADE), Icarus, doi:10.1016/j.icarus2011.06.019

Rosenblatt, P., S.L. Bruinsma, I.C.F. Müller-Wodarg, B. Häusler, H. Svedhem, J.C. Marty, First ever in situ observations of Venus' polar upper atmosphere density using the tracking data of the Venus Express Atmospheric Drag Experiment (VExADE), Icarus, 217, Issue 2, Pages 831-838. doi:10.1016/j.icarus.2011.06.019, 2012.

Rothman L. S., Gordon I. E., Barbe A., Benner D. C., Bernath P. F., Birk M., Boudon V., Brown L. R., Campargue A., Champion J.-P., Chance K., Coudert L. H., Dana V., Devi V. M., Fally S., Flaud J.M., Gamache R. R., Goldman A., Jacquemart D., Kleiner I., Lacome N., Lafferty W. J., Mandin J.-Y., Massie S. T., Mikhailenko S. N., Miller C. E., Moazzen-Ahmadi N., Naumenko O. V., Nikitin A. V., Orphal J., Perevalov V. I., Perrin A., Predoi-Cross A., Rinsland C. P., Rotger M., Šimečková M., Smith M. A. H., Sung K., Tashkun S. A., Tennyson J., Toth R. A., Vandaele A.-C., Vander Auwera J., "The HITRAN 2008 molecular spectroscopic database", J. of Quantit. Spec. and Rad. Transfer 110, 533-572, 2009.

Rothman L. S., Gordon I. E., Barber R. J., Dothe H., Gamache R. R., Goldman A., Perevalov V. I., Tashkun S. A., Tennyson J., "HITEMP, the high-temperature molecular spectroscopic database", J. of Quantit. Spec. and Rad. Transfer 111, 2139-2150, 2010.

Rothman L. S., Gordon I. E., Babikov Y., Barbe A., Benner D. C., Bernath P. F., Birk M., Bizzocchi L., Boudon V., Brown L. R., Campargue A., Chance K., Cohen E. A., Coudert L. H., Devi V. M., Drouin B. J., Fayt A., Flaud J.-M., Gamache R. R., Harrison J. J., Hartmann J.-M., Hill C., Hodges J. T., Jacquemart D., Jolly A., Lamouroux J., Le Roy R. J., Li G., Long D. A., Lyulin O. M., Mackie C. J., Massie S. T., Mikhailenko S., Müller H. S. P., Naumenko O. V., Nikitin A. V., Orphal J., Perevalov V., Perrin A., Polovtseva E. R., Richard C., Smith M. A. H., Starikova E., Sung K., Tashkun S., Tennyson J., Toon G. C., Tyuterev V. G., Wagner G., "The HITRAN2012 molecular spectroscopic database", J. of Quantit. Spec. and Rad. Transfer 130, 4-50, 2013.

Venus Thermal Structure - Intercomparison of Venus Express and Ground Based Results 
654

655

656

657

658

659

660

661

662

663

664

665

666

667

668

669

670

671

672

673

674

675

676

677

678

679

680

681

682

683

684

685

686

687

688

689

690

691

692

693

Sagawa, H., P. Hartogh, M. Rengel, Interferometric measurements of Venus mesospheric wind using millimeter/submillimeter interferometers, in International Venus Conference, Aussois, 20-26 June 2010, 2010.

Sagdeev, R. Z., et al., 1986, The VeGa Venus balloon experiment, Science, 231, No. 4744, 1407, Mar. 1986.

Schafer K., Zasova,L.V., Spankuch,D., et al. Structure of the middle atmosphere of Venus from analyses of Fourier-spectrometer measurements aboard Venera-15. Adv. Space Res., 7, No. 12, 17, 1987

Schaefer, K., R. Dubois, R. Haus, K. Dethloff, H. Goering, et al., 1990. Infrared Fourier Spectrometer Experiment from Venera 15, Adv. Space Res., 10, N5, 57-66.

Schofield, J. T. and Taylor, F. W. 1983. Measurements of the mean, solar-fixed temperature and cloud structure of the middle atmosphere of Venus, Royal Meteorological Society, Quarterly Journal (ISSN 0035-9009), vol. 109, Jan. 1983, p. 57-80. http://dx.doi.org/10.1002/qj.49710945904

Seiff, A., 1983, Thermal structure of the atmosphere of Venus. In Venus (A83-37401 17-91), University of Arizona Press, Tucson, AZ, , p. 215-279.

Seiff, A., Schofield, J.T., Kliore, A.J., Taylor, F.W., Limaye, S.S. et al., 1985. Models of the structure of the middle atmosphere of Venus from the surface to 100 kilometers altitude. In: The Venus International Reference Atmosphere, Kliore, A. J., Moroz, V.I., Keating, G.M. (Eds.), Adv. Space Res. 5(11), 1-305 (1985), http://dx.doi.org/10.1016/0273-1177(85)90197-8.

Spankuch D., L.V. Zasova, K. Schafer, E.A.Ustinov, J.Guldner et al.Infrared experiment aboard the automatic interplanetary stations Venera-15, Venera-16. Preliminary results of temperature retrieval. Veroffenlichungen des Forschungsbereichs Geo- und Kosmoswissenschaften, 18, 2846, 1990

Smith, W.L., 1970. Iterative solution of the radiative transfer equation for the temperature and absorbing gas profile of an atmosphere. Appl. Opt. 9(9), 1993-1999, doi: 10.1364/AO.9.001993.

Snels M., Stefani S., Grassi D., Piccioni G., Adriani A., "Carbon dioxide opacity of the Venus' atmosphere", Planet. \& Space Sci. 103, 347-354, 2014.

Sonnabend, G.M. Sornig, R. Schieder, T. Kostiuk, J. Delgado, Temperatures in Venus upper atmosphere from mid-infrared heterodyne spectroscopy of CO 2 around 10mum wavelength, Planetary and Space Science, Volume 56, Issue 10, p. 1407-1413. http://dx.doi.org/10.1016/j.pss.2008.05.008, 2008.

Sonnabend, P. Kroetz, M. Sornig, D.Stupar, 2010, Direct observations of Venus upper mesospheric temperatures from ground based spectroscopy of $\mathrm{CO} 2$, Geophysical Research Letters, Volume 37, Issue 11, CiteID L11102. http://dx.doi.org/10.1029/2010GL043335.

Sornig M., Investigations of Upper Atmosphere Dynamics on Mars and Venus by High Resolution Infrared Heterodyne Spectroscopy of $\mathrm{CO}_{2}$, Cuvillier Verlag Goettingen, Dissertation, I. Physikalisches Institut, University of Cologne, Germany, 2009.

Stamnes, K., Tsay, S.C., Wiscombe, W. and Jayaweera, K., 1988. Numerically stable algorithm for discreteordinate-method radiative transfer in multiple scattering and emitting layered media. Appl. Opt. 27(12), 2502-2509, http://dx.doi.org/10.1364/AO.27.002502.

Steffes, P.G., V.R. Eshleman, Sulfuric acid vapor and other cloud-related gases in the Venus atmosphere Abundances inferred from observed radio opacity, Icarus 51, 322-333, 1982.

Venus Thermal Structure - Intercomparison of Venus Express and Ground Based Results 
Steffes, P.G., Jenkins, J. M., Austin, R.S., Asmar, S.W., Lyons, D.T., Seale, E.H., and Tyler, G.L., Radio occultation studies of the Venus atmosphere with the Magellan spacecraft, 1. Experimental description and performance, Icarus, 110, 71-78, 1994.

Sugimoto, N., M. Takagi, Y. Matsuda, Baroclinic instability in the Venus atmosphere simulated by GCM, J. Geophys. Res. 119, 1950-1968, 2014b.

Sugimoto, N., M. Takagi, Y. Matsuda, Waves in a Venus general circulation model, Geophys. Res. Lett. 41, 7461-7467, 2014b.

Tanga, P., T. Widemann, B. Sicardy, J.M. Pasachoff, J. Arnaud, L. Comolli, A. Rondi, S. and P. Sütterlin, 2012, Sunlight refraction in the mesosphere of Venus during the transit on June 8th, 2004, Icarus, 218, 207-219. doi:10.1016/j.icarus.2011.12.004

Tanga, P., T. Widemann, B. Sicardy, J.M. Pasachoff, J. Arnaud, L. Comolli, A. Rondi, S. Rondi, P. Sütterlin, Sunlight refraction in the mesosphere of Venus during the transit on June 8th, 2004, Icarus 218, 207-219, 2012.

Tashkun, S.A., Perevalov, V.I., Teffo, J.L., Bykov, A.D., Lavrentieva, N.N., 2003. CDSD-1000, the hightemperature carbon dioxide spectroscopic databank. J. Quant. Spectrosc. Radiat. Transfer 82(1-4), 165-196, http://dx.doi.org/10.1016/S0022-4073(03)00152-3.

Taylor, F. W.; $\quad$ Beer, R.; $\quad$ Chahine, M. T.; $\quad$ Diner, D. J.; $\quad$ Elson, L. S.; $\quad$ Haskins, R. D.; $\quad$ McCleese, D. J.; Martonchik, J. V.; Reichley, P. E.; Bradley, S. P.; Delderfield, J.; Schofield, J. T.; Farmer, C. B.; Froidevaux, L.; Leung, J.; Coffey, M. T.; Gille, J. C, 1980. Structure and meteorology of the middle atmosphere of Venus Infrared remote sensing from the Pioneer orbiter, Journal of Geophysical Research, vol. 85, Dec. 30, 1980, p. 7963-8006. http://dx.doi.org/10.1029/JA085iA13p07963

Tellmann, S., Pätzold, M., Häusler, B., Bird, M.K., Tyler, G.L., 2009. Structure of the Venus neutral atmosphere as observed by the Radio Science experiment VeRa on Venus Express. J. Geophys. Res. 114(E00B36), 354-372, http://dx.doi.org/10.1029/2008JE003204.

Tellmann, S., B. Häusler, D.P. Hinson, G.L. Tyler, T.P. Andert, M.K. Bird, T. Imamura, M. Pätzold, S. Remus, Small-scale temperature fluctuations seen by the VeRa Radio Science Experiment on Venus Express, Icarus 221, 471-480, 2012.

Titov D. V., M.A. Bullock, D. Crisp, N. O. Renno, F.W. Taylor, L.V. Zasova, "Radiation in the atmosphere of Venus", in "Exploring Venus as a terrestrial planet", 121-138, L.W. Esposito, E.R. Stofan, and Th.E. Cravens Eds., Geophysical Monograph Series 176, American Geophysical Union, 2007.

Titov D. V., Piccioni G., Drossart P., Markiewicz W. J., "Radiative energy balance in the Venus atmosphere", in "Towards understanding the climate of Venus: Application of terrestrial models to our sister planet", 23-53, L. Bengtsson, R.-M. Bonnet, D. Grinspoon, S. Koumoutsaris, S. Lebonnois and D. V. Titov Eds., ISSI Scientific Report series 11, Springer Netherlands, 2013.

Tolson, R. H.; Patterson, M. T. and Lyons, D. T., "Magellan windmill and termination experiments", Proceedings of the 10th International Symposium on Flight Dynamics, 1995.

Vandaele, A.C., Mahieux, A., Robert, S., Berkenbosch, S., Clairquin, R., Drummond, R., Letocart, V., Neefs, E., Ristic, B., Wilquet, V., Colomer, F., Belyaev, D., Bertaux, J.L., 2013. Improved calibration of SOIR/Venus Express spectra. Opt. Express 21, 21148.

Venus Thermal Structure - Intercomparison of Venus Express and Ground Based Results 
Vasilev, M.B., A.S. Vyshlov, M.A. Kolosov, A.P. Mesterton, N.A. Savich, V.A. Samovol, L.N. Samoznaev, A.I. Sidorenko, Two-frequency radio occultation measurements with Venera-9 and Venera-10 orbiters, Acta Astronautica 7, 335-340, 1980.

Widemann, T., S. Jaeggli, K. Reardon, P. Tanga, C. Père, J.M. Pasachoff, A.C. Vandaele, V. Wilquet, A. Mahieux, C. Wilson, Venus' thermospheric temperature field using a refraction model at terminator : comparison with 2012 transit observations using SDO/HMI, VEx/SPICAV/SOIR and NSO/DST/FIRS, 2014, American Astronomical Society, DPS meeting \#46, \#302.06.

Wilquet V., Fedorova A., Montmessin F., Drummond R., Mahieux A., Vandaele A. C., Villard E., Korablev O., Bertaux J.-L., Preliminary characterization of the upper haze by SPICAV/SOIR solar occultation in UV to mid-IR onboard Venus Express, J. Geophys. Res., 114(E00B42), doi:10.1029/2008je003186, 2009

Wilson C. F., Guerlet S., Irwin P. G., Tsang C. C., Taylor F. W., Carlson R. W., Drossart P., Piccioni G., "Evidence for anomalous cloud particles at the poles of Venus", J. Geophys. Res. Planets 113, E00B13, 2008.

Wilson, C.F., M. Perez-Ayucar, W.J. Markiewicz, A.C. Vandaele, A. Mahieux, J.L. Bertaux, Venus Express observations during the 2012 Venus transit, EPSC2012-913, 2012.

Wilson, C.F., E. Marcq, N. Ignatiev and the ISSI Venus Clouds Team, Progress towards a Venus reference cloud model (Invited), COSPAR Scientific Assembly, Moscow, August 2014.Wiscombe, W.J., 1980. Improved Mie scattering algorithms. Appl. Opt. 19(9), 1505-1509, http://dx.doi.org/10.1364/AO.19.001505.

Wordsworth R. D., Forget F., Eymet V., "Infrared collision-induced and far-line absorption in dense $\mathrm{CO} 2$ atmospheres", Icarus 210, 992-997, 2010.

Yakovlev, O.I., Matygov, S.S., and Gubenko, V.N., Venera-15 and 16 Middle Atmosphere Profiles from Radar Occultations: Polar and Near-Polar Atmosphere of Venus, Icarus, vol. 94, pp. 493-510, 1991.

Zalucha A. M., Brecht A. S., Rafkin S., Bougher S. W., Alexander M. J., "Incorporation of a gravity wave momentum deposition parameterization into the Venus Thermosphere General Circulation model (VTGCM)", J. Geophys. Res. Planets 118, 2013.

Zasova, L.V. and Moroz, V.I., Latitude Structure of the Upper Clouds of Venus, Adv. Space Res., vol. 12, pp. 79-90, 1992.

Zasova, L.V., Moroz, V.I., Linkin,V.M., Venera-15, 16 and VEGA mission results as sources for improvements of the Venus reference atmosphere, Adv. Space Res. 17, 171-180, 1995.

Zasova L. V., Khatountsev I. A., Moroz V. I., Ignatiev N. I., "Structure of the Venus middle atmosphere: Venera 15 Fourier spectrometry data revisited", Adv. Space Res. 23, 1559-1568, 1999.

Zasova, L.V., V.I. Moroz, V. Formisano, N.I. Ignatiev, I.V. Khatuntsev, 2004, Infrared spectrometry of Venus: IR Fourier spectrometer on Venera 15 as a precursor of PFS for Venus express, Advances in Space Research, Volume 34, Issue 8, 2004, Pages 1655-1667. doi:10.1016/j.asr.2003.09.067.

Zasova, L.V., Moroz, V.I., Linkin, V.M., Khatuntsev, I.V., Maiorov, B.S., 2006. Structure of the Venusian atmosphere from surface up to $100 \mathrm{~km}$. , Cosmic Res. 44(4), 364-383, http://dx.doi.org/10.1134/S0010952506040095.

Zasova L. V., Ignatiev N. I., Khatountsev I. A., Linkin V., "Structure of the Venus atmosphere", Planet. \& Space Sci. 55, 1712-1728, 2007.

Venus Thermal Structure - Intercomparison of Venus Express and Ground Based Results 